\author{
UNIVERSIDADE DE SÃO PAULO \\ INSTITUTO DE FISICA E QUIMICA DE SÃO CARLOS \\ DEPARTAMENTO DE FISICA E CIÊNCIA DOS MATERIAIS
}

\title{
ESTRUTURA ELETRÔNICA DE POÇOS \\ QUÂNTICOS COM DOPAGEM SELETIVA
}

Sebastião Rocha Aladim Neto

ot.

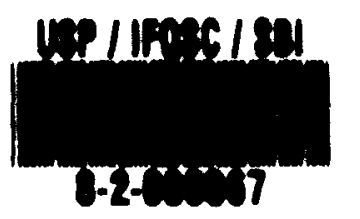

Dissertação apresentada ao Instituto de

Física e Química de São Carlos, para a obtenção do título de Mestre em Física Básica.

Orientador : Dr. Gilmar E. Marques

São Carlos - São Paulo

$-1990-$ 


\section{UNIVERSIDADE DE SĀO PAULO}

INSTITUTO DE FISICA E OUIMICA DE SAOO CARLOS

MEMBRDS DR COMISSRD JULGRDORA DR DISSERTACAD DE MESTRADD DE SEBASTIAD RDCHA RLADIM NETO APRESENTADA RD INSTITUTO DE FISICA E DUIMILA DE SAD CARLDS, DA UNIVERSIDADE DE SRD PAULD, EM 29 DE MAID DE 1990.

COMISSAD JULGADORA:

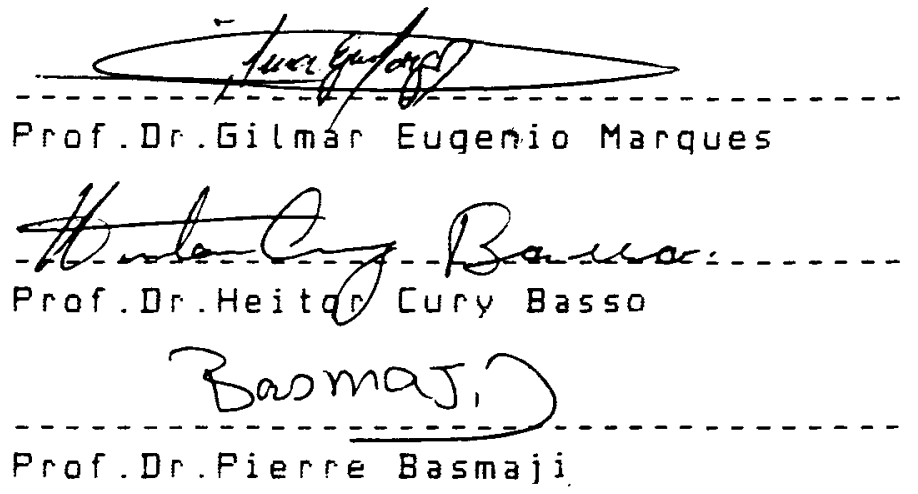


Aas meus Pais. Em retribuiçãa à educação e as oportunidades que me deram. 


\section{AGRADBCNENTOS}

Ao Prof. Gilmar pela orientação e paciência.

Ao Abraham pela amizade, incentivo, e por ter me mostrado como abordar um problema difficil... um pé depois do outro.

A torma do "corredor", Nagib, Miled, Santoro, Wilson, Beto, Zé Carlos, Liliane, por terem ajudado a manter o moral sempre alto.

Aos sócios do "corredor", Bras e Reginaldo

A Du, minha amiga, pelas sugestzes, datilografia e correçžes de português.

A Du, minha mulher, pelo carinho, amor, dedicação e incentivo que tornaram estes dois anos de trabalho menos árduos.

A todos, que tenham contríbuido de alguma forma para a realização deata tese, meu agradecimento em particular. 


\section{R E S U M O}

Neste trabalho realizamos a cálculo da estrutura eletrônica de poços quânticos com dopagem seletiva, usando um método $\mathbf{k} \cdot \mathbf{p}$ com 8 bandas. Utilizamos um processo de bloco-diagonalizaçăo para reduzir o Hamiltoniano $8 \times 8$ a dois blocos $4 \times 4$ a fim de diminuir o esforço computacional. Calculamos o efeito do potencial autoronsiatente sobre a mass dos portadores e sobre as densidades de estado.

Os resultados abtidos para as energiss de excitaçäo de uma particula estấa em pleno acordo com os dados obtidos em experimentos de abrorsân btica intra-banda (espalhamento Raman ressonante). 


\section{A B S T R A C T}

In this work we developed a calculation of the electronic structure of modulation doped quantum welle using a $\mathbf{k} \cdot \mathbf{p}$ method with 8 bands. We have used a procedure which block-diagonalizes this $8 \times 8$ Hamiltonian into two $4 \times 4$ blocks to reduce the computacional effort. We have calculated the effect of the self-consistent potential on the effetive mass of carriers and on the densities of states.

The realts obtained for one-particle excitations are in complete agrement with intra-band optic absorption experiments (ressonant Raman scattering). 
Indice

Resumic

Abstract

Capitulo I - Introdução

I.1 Pó̧os Quânticos 1

I.2 Poços Quânticos com Dopagem Seletiva 1

Capitalo II - Estrutura de Bandas de Semicondutores do Grupo III-V

II.1 Estrutura Cristalina 6

II.2 Estrutura de Bandas 6

II.3 Estrutura Eletrönica de Soluçbes Sólidas 11

Capitulo III - $\mathbf{O}$ Método $\mathbf{k} \cdot \mathbf{p}$

III.1 Introdução 12

III.2 A Representação k-p 12

III.3 Teoria de Perturbação de Lowdin-Feenberger 15

III.4 Hamiltoniano para Semicondutores do Grupo II-VI $\&$ III-VI 18

III.5 Interaçăo Spin-Orbita

III.6 Bloco-Diagonalizaçăo do Hamiltoniano $8 \times 8$

III.7 Determinaçấo dos Parâmetros do Hamiltoniano 27

Capitulo IV - A Aproximaçầi de Funçáo Ervelope

IV.1 Introduçäo 32

IV.2 Banda Năo-Degenerada 32

IV.3 Banda Degenerads 42

V.4 Condiçấo de Contomo da Funçăo Envelope 44

Oapitulo V - Método Autoconsistente para o Cálculo de Bandas de Energia

$\begin{array}{lll}\text { V.1 Introduçăo } & 48\end{array}$

V.2 Expansäo em funçöes Ortogonais 48

Yo Cálolo Autoconsistente 55 
Capitulo VI - Resultados e Concluades

VI.1 Resultados e Discugsöes 61

$\begin{array}{lll}\text { VI.2 Conclusbes } & 67\end{array}$

Apêndice A 81

Apêndice B 84

Bibliografia 


\section{CAPITULO I}

\section{INTRODUÇÃO}

I.1 - Objetivos

Elétrons confinados em camadas bidimensionais de semicondutores, como em heterojunç̧es e poços quânticos, sầ de grande importância nä́o ố para a Física como para a tecnologia. Isto deve-se ao fato de que, nestes istemas, parametros fundamentajs que governam o comportemento dos elétrons podem ser modificados experimentalmente. Por exemplo, a massa, os niveis eletrónicos e a concentraçán de elétrons podem ser modificados para qualquer situą̧âo de interese. Desta forma tais sistemas podem ser usados para investigar questós básicas como, por exmplo, em teoria de muitos corpos, ou para a aplicação em dispositivos eletrônicos e/on eletrob́ticos. Em qualquer destes casos o conhecimento da estrutura eletrónica torna-se essencial para se determinar as propriedades desses sistemas.

$O$ objetivo de nosso trabalho foi o desenvolvimento de um método sofieticado para es calcular a estrutura eletrónica de poço quânticos com dopagem eleletiva (1) onde consideramos todos os posiveis acoplamentos de un elétron neste sistema.

Os cálculos realizados até hoje ${ }^{(2,3)}$ näo consideram o acoplamento entre as bandas de valência e a banda de conduçăo. No nosso caso, utiliamos um método multibandar $\mathbf{k} \cdot \mathbf{p}$ de dimensín $8 \times 8$, onde este acoplamento é levado em coneideracano explicitamente.

I.2 - Pogos Quânticos com Dopagem Seletiva

Foģos quânticos de semicondutores são formados quando uma camada estreita (da ordem de $30 \&$ a $500 \&$ ) de um semicondutor é limitada dos dois lados por un outro semicondutor de "gañ" maior" (4). Para o uso de poços quânticos como dispositivos eletrónicos devem existin, dentro do poşo, portadores em quantidade muficiente para o início dos procesos de condugâ. Em outros dispositivon tais como dodos a transetores, estes portadores devem ser introduados através de dopagen, de 
forma que, através de algum processo de ionização, os dopantes forneçam as cargas necessárias. Nos diodos, essa jonização é obtida através da energia térmica. Em poços quânticos dopados existe uma ionizaçă considerável mesmo a temperaturas próximas do zero absoluto. Neste caso a ionzaçäo ocorre para manter o potencial químico igual entre as interfaces, năo dependendo, portanto, da temperatura. A ionização térmica também ocorre em poços quânticos, devido a impurezas residuais como o carbono, mas seu efeito é importante apenas em heterojunçäes (4).

Umi poço quântico dopado é construido da mema foma que um poşo quâtico comum. A diferença é que, quando se está crescendo a barreira, usa-qe uma mistura que contenha o dopante na concentraçäo desejadi. Desta forma em cada barreira existirá uma região onde o dopante estará localizado. O esquema de uri poco dopado pode eer resumido na fig. 1.1a. Nenta figura th é o potencial químico, $\mathrm{L}_{w}$ a largura do poşo e $\mathrm{L}_{\varepsilon}$ o comprimento da regiäo de eeparação entre as

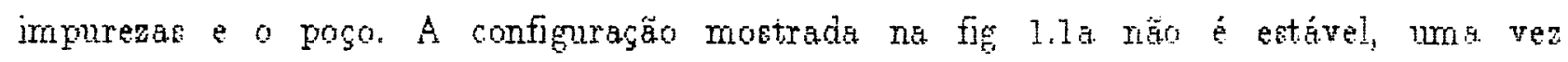
que, on elétrons ligados às impurezse têm agora hiveis de energia resconantes com os estados eletronicos na regia do poco. Asim, atraves de turelamento, estes elétrons transferem-se para o pogo ocupando os niveis disponiveis e elevando o potencial quimico na regáa. Esta transerência continua até que o potencial químico do poso iguale ao da barreira. Neste momento cessa a traneferencia de carga e a sistema atinge uma configuragăo estável. A configuragăo final estés enquematizada na fige 1.1 b, onde vemos a aparecimento de um novo comprimento, Ld relevante ao problema, e que chamaremos comprimento da regiấo de depleçấo Esta é a largura da regiăo onde os doadores estâo jonizados, e deve depender, portanto, da concentracto de doadores e da estrutura eletrónica do poco.

A localizaço do potencial químico é determinada pelo tipo de impurea ueada, e pela distância desta ao poso. A dependência com a distância ao poço deve-se à perturbagáo causada por este nos estados eletrônicos do impureza. Connderando pocos com a largura da camada de separacăo suficientemente larga, $I_{s}$ $>100$ A, pode-se usar os niveje conhecidos do dopante no volume do cristal.

Devido a conervaga de enerén no process de turelamento, o estado final do eletron no poso nem sempre o de menor energia. Ocorre entäo un processo de relaxaço, mediado por fônons, que leva o elétron para o estado desocupado de menor energia. 

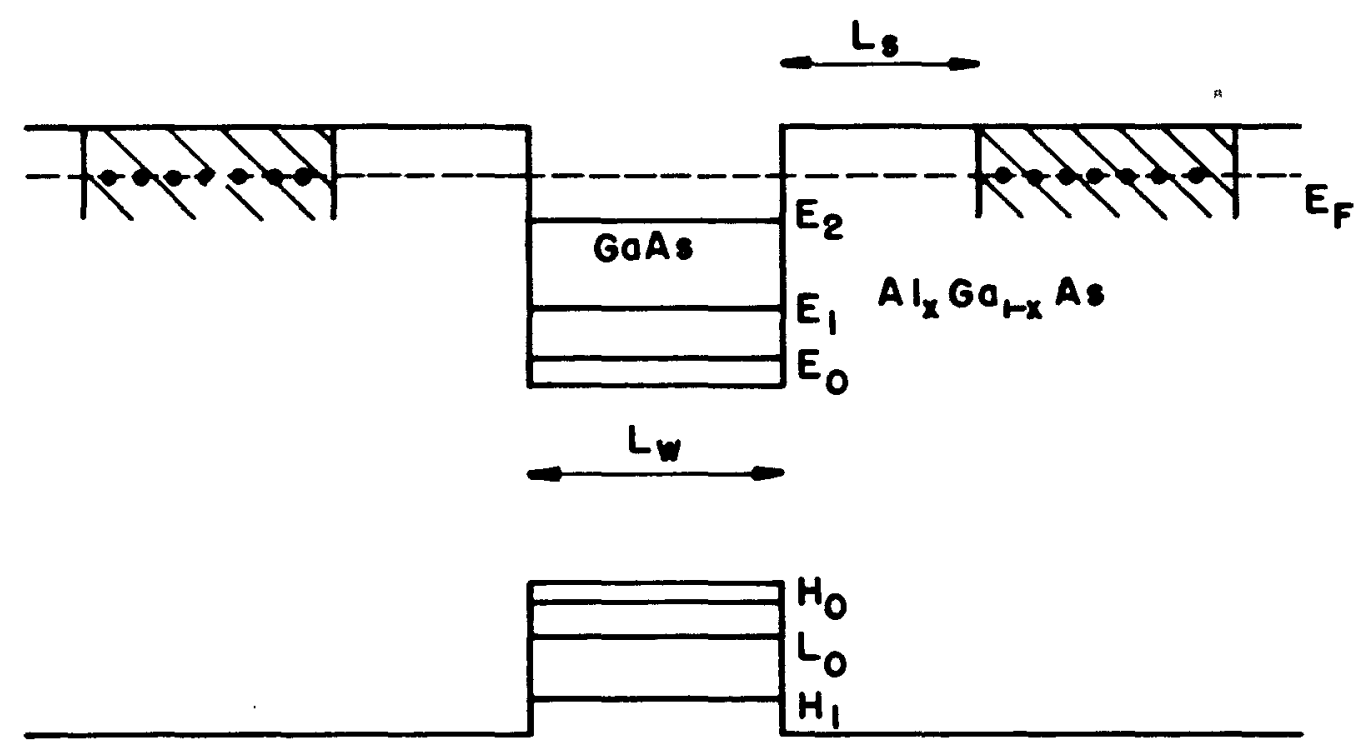

Fig. 1.1b: Poço quântivo semicondutor com dopagem seletiva (Configuração Estável). $\mathrm{L}_{w}$ é a largura do poço, $\mathrm{L}_{\delta}$ é a largura de região que separa os daadores dos elétrons no poşo. $\mathrm{L}_{d}$ é a largura da região onde os doadores estão jonizados. 

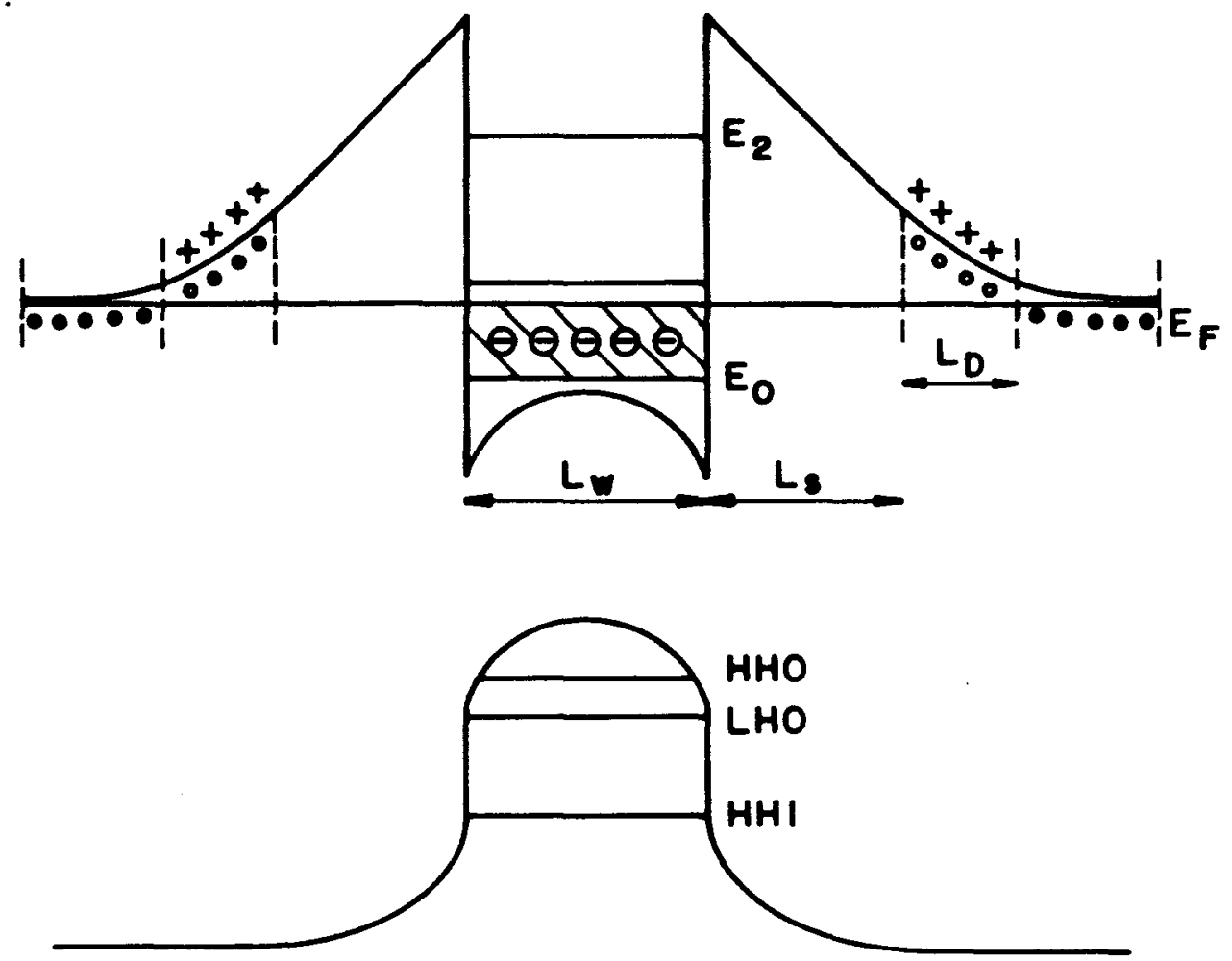

Fig 1.1a: Poģo quântivo semicondutor com dopagem seletiva

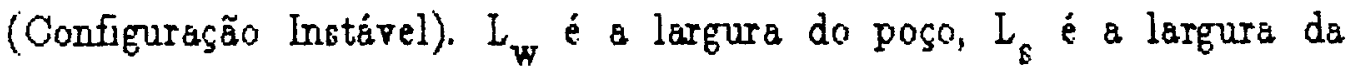
região que separa os doadores dos elétrons no poço. $E_{f}$ é o nível de Fermi, fixa pelo nivel das impurezas. 
Existe ainda, mesmo no cristal perfeito, uma dependência destes niveis de impureza com a concentração da liga. No caso do silicio em arceneto de gálio e aluminio, este nivel de impureza depende, de maneira năo-trivial, da concentraçáo de aluminio. Contudo, a origem de tais niveis ainda năo é bem compreendida. 


\section{CAPÍTULO II}

\section{ESTRUTURA DE BANDAS DE SEMICONDUTORES DO GRUPO III - V}

II.1 - Estrutura Oristalina

Semicondutores do grupo III-V cristaliam-se em uma estrutura do tipo Zinc-Blend (1). Esta estutura cristalina é formada por duas redes FCO deslocadas, uma em relą̧ão a outra, de $1 / 4$ do parâmetro de rede na direçăo diagonal (fig. 2.1) como na estrutura cristalina do tipo Diamante, porém com átomas diferentes em cada rede. A principal diferença entre as estruturas Zinc-Blend e a do Diamante é a falta de simetria de inversão espacial da primeira. Sem simetria de inveráa expacial o Teorema de $\operatorname{Kramer}^{(2,3)}$ ainda é válido, ou eja, as energias nos pontos $\mathbf{k}$ e -k, onde $\mathbf{k}$ é um vetor da primeira zona de Brillouin, sấo degeneradas. Contudo, a degenerescencia de apin é perdida, já que inverter o spin em uma funçäo de onda $\Psi_{\mathbf{k}}(\mathbf{r})$ é o mesmo que olhar para a função $\Psi_{\mathbf{k}}(-\mathbf{r})$, resultando em energias diferentes se năo existe simetria de inversăo espacial $(2,3)$.

A zona de Brillowin da estrutura do tipo Zinc-Blend é urn octaedro truncado. Seue principais pontos e linhas de simetria estäo indicados na fig. 2.2 uando-se 5 notaçá de Bouckert ef al ${ }^{(4)}$. Esta estruture pertence ao grupo de simetria espacial $T_{d}$ o grupo de simetria do tetraedro $(5)$. Uma vez que iremoa considerar o spin do elétron, nós extendemos este grupo para o grupo duplo $\mathrm{T}_{\mathrm{d}}^{2}$ incluindo a representação $\mathrm{E}$ para a rotaça $360^{\circ}$, que troca o sinal da funçăo de ond $a^{(5)}$

Na tabela II.I encontram-se os caracteres ds representaça do grupo $\mathrm{T}_{\mathrm{d}}^{2}$ para o ponto $\Gamma$, que sera dicutido neste trabaho.

\section{II.2 - Estruture de Bandas}

Estamon interesados principalmente no ponto $\Gamma(\mathbf{k}=0)$, ande ocorrem os extremos das bandas de conduço e valencia em semiondutores do gupo III-V. 


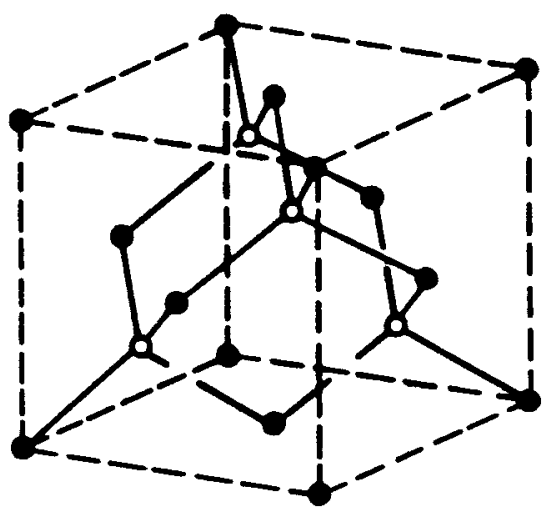

Fig. 2.1 : Estrutura cristalina do tipo Zinc-Blend.

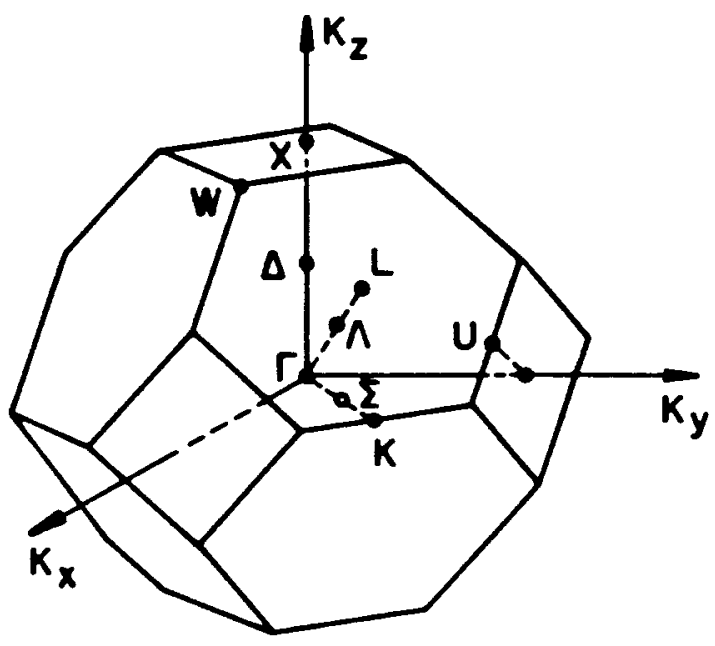

Fig. 2.2 : 1 a Zona de Brillouin para a estrutura Zinc-Blend, usando-se a notação de Bouckert et al. (4). 
Este interesse deve-se an fato de que os vetores de onda em poços quânticos são, geralmente, da ordern de $1 / 100 \mathrm{E}$, ou seja, muito menores que os vetores $\mathrm{d} a$

Tabela II.1 - Caracteres para o grupo de simetria no ponto $\Gamma^{(6)}$.

\begin{tabular}{lcrrrrrrr}
\hline & $\mathrm{E}$ & $\mathrm{E}$ & $6 \mathrm{O}_{4}^{2}$ & $8 \mathrm{C}_{3}$ & $8 \mathrm{C}_{3}$ & $6 \mathrm{IxO}_{4}$ & $6 \mathrm{IxO}_{4}$ & $12 \mathrm{IxO}_{2}$ \\
\hline$\Gamma_{1}$ & 1 & 1 & 1 & 1 & 1 & 1 & 1 & 1 \\
$\Gamma_{2}$ & 1 & 1 & 1 & 1 & 1 & -1 & -1 & -1 \\
$\Gamma_{3}$ & 2 & 2 & 2 & -1 & -1 & 0 & 0 & 0 \\
$\Gamma_{4}(\mathrm{x}, \mathrm{y}, \mathrm{z})$ & 3 & 3 & -1 & 0 & 0 & -1 & -1 & 1 \\
$\Gamma_{5}$ & 3 & 3 & -1 & 0 & 0 & 1 & 1 & -1 \\
$\Gamma_{6}$ & 2 & -2 & 0 & 1 & -1 & $\sqrt{2}$ & $-\sqrt{2}$ & 0 \\
$\Gamma_{7}$ & 2 & -2 & 0 & 1 & -1 & $-\sqrt{2}$ & $\sqrt{2}$ & 0 \\
$\Gamma_{8}$ & 4 & -4 & 0 & -1 & 1 & 0 & 0 & 0 \\
\hline
\end{tabular}

rede reciprocs $(\because 1 / \mathrm{A})$.

Nos compostas binários do grupo III-V, como o GaAs, existem aito elétrons de valêricia por cela unitária, onde trếs stăo do elemerito da coluna III e cinco do elemento da coluna $\mathrm{V}$. Os outros elétrone, que ocupam os orbitais mais profundos, näo tomam parte nos processos em que estamos normalmente interessados, como conduçăo e absorģăo stica. Săo os oito elétrons externos que formam as ligaçôes tetraédricas entre os átomos da rede.

Se consideramos un átomo da coluna III ou da coluna V ho vácuo e despresarmos os efeitos de spin-brbita, os estados a e p seră degenerados. No interior do cristal esta degenerescencia é quebrada pela menor simetria de estrutura. cristaina, dando origem a um estado s com energa diferente da do estado p. Os orbitais s e $p$ de atomos vizinhos podem agora combinar-se fonmando estados s-s e p-p ligantes a nâ-ligantes. Os quatro estados ligantes, ocupados pelos oito elétrons disponiven por cela, possuern energias menores que os estados näo-ligantes, dendo 
origem $\dot{a}$ banda de valência. Os estados não-ligantes permanecem vazios, dando origem a banda de condução. A primeira banda de condução é do tipo a năo-ligante, enquanto que a banda de valência é do tipo p ligante (fig. 2,3).

A função de onda total para a banda de condução deve transformar-se de acordo com a representaçáo $\Gamma_{1}$ da tabela $I_{1}$ já que ce origina de orbitais do tipo a (escalar). Enquanto que a banda de valência transforma-se de acordo com a representação $\Gamma_{4}$, pois é formads por orbitais do tipo $p$ (fig. 2.3). Eater orbitais transtoman-se como vetures, dá a notaģa $(x, y, z)$ para a representaça $\Gamma_{4}$ na tabela 1 .

Até aqui não diecutimos o efeito do spin do elétron, nem do acoplamento spin-brbita ${ }^{(7)}$ na estrutura de bandas. 0 efeito de incluir-se o spin é de se formar funçbes de onda que $\varepsilon$ ăo o produto de uma parte puramente espacial, com uma parte purarmente de spin. A funçäo de onda total transformar-se-á, entấo, cono o produto direto da representaçăo da parte eqpacial e a representação $D^{1 / 2}$, que é a representação para o grupo $\mathrm{SU}(2)$ ou min $1 / 2^{(5)}$. A decomposiçấo deste produto direto, em termos da representaçáo do grupo $\mathrm{T}_{d}^{2}$ no ponto $\Gamma$, é dada na tabela II.2. $O$ efeito do termo de acoplamento spin-orbita levanta a degenerescencia criada pela decomposiçắ do produto direto, i.e., quando a decomposição dá origern a mais de um termo, eles săo separados pelo acoplamento spin-trbita, como indicado ra tabela II.2 e ng fig. 2.4 .

Referiremo-nos várias vezes às funçóe de base $|x\rangle,|y\rangle,|z\rangle \in|0\rangle$, ou a combinaçóe lineares destas, como as funç̧es de Bloch em uma dada banda. Isto será feito apenas para enfatizar o caráter da representaço do grupo de simetria das furçôes de Bloch destas bandas.

Tabela II.2 - Decomposiçăo do produto direto $\mathrm{T}_{\mathrm{d}}^{2} \otimes \mathrm{D}^{1 / 2}(6)$.

\begin{tabular}{cccccc}
\hline$\Gamma_{\mathrm{j}}$ & $\Gamma_{1}$ & $\Gamma_{2}$ & $\Gamma_{3}$ & $\Gamma_{4}$ & $\Gamma_{5}$ \\
$\Gamma^{6} \mathrm{D}^{1 / 2}$ & $\Gamma_{6}$ & $\Gamma_{7}$ & $\Gamma_{8}$ & $\Gamma_{7}+\Gamma_{8}$ & $\Gamma_{6}+\Gamma_{8}$ \\
\hline
\end{tabular}




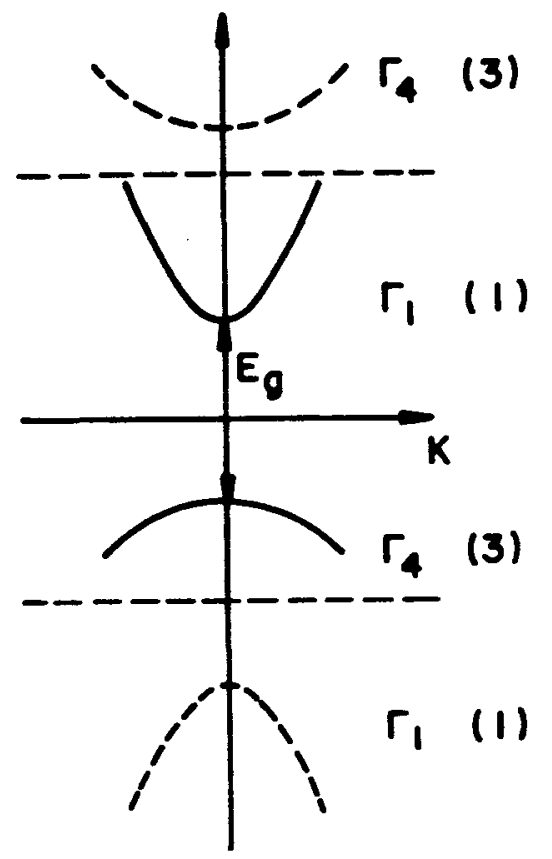

Fig. 2.3 : Estrutura de bandas em um semicondutor com spin-orbita igual a zera. Em parênteses estão indicadas as degenerescências das bandas.

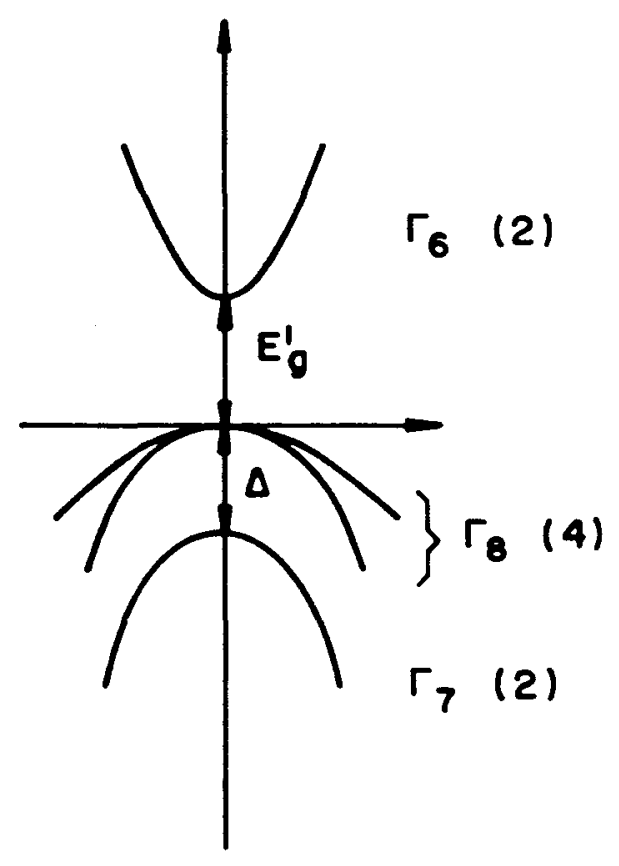

Fig. 2.4 : Estrutura de bandar para materiais do grupo III-V. Em parênteses estão indicadas as degenerecências das bandas. 


\section{II.3 - Estrutura Eletrônica de Soluçōes Sólidas}

E possivel formar soluçóes sólidas, ternárias ou quatemárias, com os elementos do grupo III-V ou do grupo II-VI. Nestas soluçzes dois átomas do grupo III (II) ocuparn aleatorianente os sitios de uma das redes f.c.c., enquanto a outra ocupada pelos átomos do grupo V (VI).

Do ponto de vista da estrutura eletrónica estes materiais näo săo cristalinos. Devido a distribuição aleatória dos átomos na rede Zinc-Blend, o potencial sentido pelos elétrons não posøuj simetria de translação. E poseivel recuperar esta simetria fazendo-se uso de uma aproximação. Para isto substituímos o potencial real por uri potencial médio. Considere a solução soblida $A B_{1-x} C_{x}$ onde $B$ e $C$ são átomos do grupo III, por exemplo. No lugar do potencial V(r) não periódico, criado pelos átomos $\mathrm{B}\left(\mathrm{V}_{\mathrm{B}}\right)$ e $\mathrm{O}\left(\mathrm{V}_{\mathrm{C}}\right)$ usa-se o potencial $\langle\mathrm{V}\rangle=\mathrm{x} \mathrm{V}_{\mathrm{O}}+(1-\mathrm{x}) \mathrm{V}_{\mathrm{B}}$. Com isto recupera-ge a invariancia de translação e, com elá, pademos definir estados de Bloch além de bandas de energia, massas efetivas, etc. ,

Uma vez que o potencial médio depende da concentração, parâmetros como gap de energia e massas efetivas tornam-se dependentes desta concentração.

Se dois compostos binários possuem estrutura de bandas semelhantes e parâmetros de rede de mesma ordem, o gap fundamental varia quase linearmente do valor de un ao valor do outro com a concentraçấ da lige. Um exemplo bem conhecido, que pertence ao grupo II-VI, é a liga $\mathrm{H}_{\mathrm{E}_{1-\mathrm{x}} \mathrm{Cd}} \mathrm{Te} . \mathrm{O}$ gap desta liga varia quase linearmente entre os do $\mathrm{Hg}_{\mathrm{T}} \mathrm{e}$ do CdTe. Esta linearidade nẵo se mantén se a estrutura de bandas for diferente ou se os parâmetros de rede forem

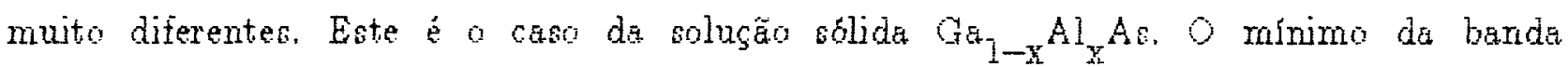
de conduça no GaAs ocorre no ponto $\Gamma$, enquanto que para a AlAs o minimo ocorre próxino ao ponto $X$. Apesar dos parâmetros de rede serem de meana ordem, a dependência do gap fundamental com a concentraçăo é fortemente náa-linear. 


\section{CAPÍTULO III \\ O Método $\mathbf{k} \cdot \mathbf{p}$}

III.1 - Introduçăn.

método $\mathbf{k} \cdot \mathbf{p}^{(1)}$ foi desenvolvido, inicialmente, para explorar as propriedades das bandas de energia e funçós de onda perto de algum ponto inourtante ná zona de Brillouin, através do uso de teoria de perturbaçäo. O método é uma conequência direta da equação para as funçóes de Bloch. Ele foi usado em alguns casos, nos primórdios do desenvolvimento da teoria de bandas, sem ter sido dignifjcado como un método. Goube a Dreselhause at al. ${ }^{(2)}$ estabelecerem a importância do método como uma base rigorasa para a determinaçăo da estrutura de bandas.

Ométodo, junto com o uso do grupo de simetria do cristal, mostra que a estrutura de bandas em torno de um ponto $\mathbf{k}$, um extremo na primeira aona de Briliouin, depende de urn pequeno número de parâmetros como massa eletrónicas e gaps, que podem ser determinados experimentalmente.

As funģ̧es de Bloch para um dado $\mathrm{k}$ formam uma base completá de funç̧es peribdicas na cela unitária, portanto, conhecendo-se os elemertos de matriz do monento e as energias para todas as bandas nesta base, so energia para outros vetores $\mathrm{k}$ etarăo completamente determinadas.

As limitaços do método năo provém das limitaģes da teoria de perturbacán, mas do quanto podenos conhecer, ou deteminar empiricamente, da matris $k$-p.

III.2 - A Representagá $\mathbf{k} \cdot \mathbf{p}$

Como foj dito na seçá anterior, confecendo-se os elementos de matria k-p, para un ponto $\mathbf{k}$ da zona de Brillouir, podemos determinar a estrutura de bandas en tomo deste ponto. Isto e o que chamamos de representacáa $\mathbf{k} \cdot \mathbf{p}$. Esta representage pode sen obtide resolvendo a equaga de Schroedinger para un elétron movendo-se em um potencial, $V(\mathbf{r})$, cora a periodicidade da rede. A funço de 
onda para um elétron movendo-se neste potencial pode ser escrita como:

$$
\Psi_{n}(\mathbf{r}, \mathbf{k})=e^{i \mathbf{k}-\mathbf{r}} u_{k}(\mathbf{r})
$$

onde $u_{k}(\mathbf{r})$ é uma função com periodicidade da rede, e que obedece t̀ anguirite

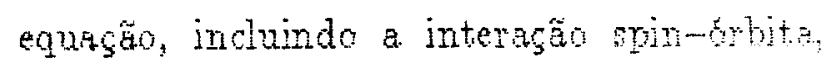

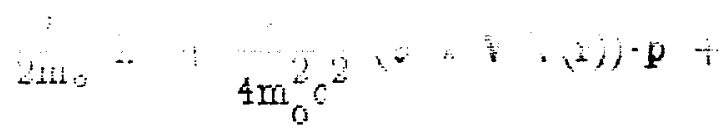

$$
\begin{aligned}
& \left.\frac{\hbar_{0}}{m_{0}} \mathbf{k} \cdot \mathbf{p}+\mathbf{k} \cdot\left(\frac{\hbar_{k}^{2}}{4 m_{0}^{2} c^{2}} \sigma \times \nabla V(r)\right)\right] u_{k, n}(r)=E_{n}^{\prime}(\mathbf{k}) u_{k, n}(\mathbf{r})
\end{aligned}
$$

onde $\sigma=\left(\sigma_{\mathrm{x}}, \sigma_{\mathrm{y}}, \sigma_{\mathrm{z}}\right)$ a áa as matrizes de Pauli para a spin do elétron, $p$ momento orbital do elétron, $k k$ o momento cristaling, e $n$ o indice de banda. $O$ quinto termo do lado esquerdo da eq. 3.2 é o mais importante, é é que dá o nome ao método. O quarto termo, independente de $\mathbf{k}$ é responsável pela quebra da degenerescencia da banda de valencia como veremos adiante. 0 fltimo termo, aperar de depender de $\mathbf{k}$, nấo será considerado poje, quando comparado com o momento orbital p nas regioes onde a interąăo spin-órbita é importante, ou seja, no interior dos átomos do cristal, o momento do cristal, hk, é desprezivel.

Por simplicidade de exposjçăo näo consideraremos, por enquarto, à interaçă apin-orbita. Oom esta simplificaço a eq. 3.2 torna-se:

$$
\left[\frac{p^{2}}{2 m_{0}}+V(\mathbf{r})+\frac{\hbar}{m_{0}} \mathbf{k} \cdot \mathbf{p}\right] u_{k, n}(\mathbf{r})=E_{n}(\mathbf{k}) u_{k, n}(\mathbf{r})
$$

onde

$$
E_{n}(k)=E_{n}^{1}(k)-\frac{k^{2}}{2 m_{0}} k^{2}
$$

Como foi dito na eeço IIIn, devemos procurar as soluçes da eq. 3.3 em 
tormo de um dado $\mathbf{k}_{\alpha^{\prime}}$ para o qual a colução $\dot{e}$ conhecida. Escrevendo $\mathbf{u}_{\mathbf{k}}, \mathbf{n}(\mathbf{r})$ coma sendo esta soluçãa canhecida, pademos usar estas funçz̃es como uma base para resalver a eq. 3.3 para qualquer outro $\mathbf{k}$ em torno de $\mathbf{k}_{0}$, ou seja,

$$
u_{\mathbf{k}, n}(\mathbf{r})=\sum_{\mathbf{n}^{\prime}} \mathrm{C}_{\mathrm{n}, \mathrm{n}^{\prime}}\left(\mathbf{k}-\mathbf{k}_{0}\right) u_{\mathbf{k}_{0}, \mathrm{n}^{\prime}}(\mathbf{r})
$$

Somando e subtraindo o termo $-\frac{\hbar^{2}}{2 m_{0}} \mathbf{k}_{0}^{2}+\frac{\hbar}{m_{0}} \mathbf{k}_{0} \cdot \mathbf{p}$ so Hamiltoniano da eq. 3.3, podemos reescrevê-lo como:

$$
\left[\frac{\mathbf{p}^{2}}{2 m_{0}}+V(\mathbf{r})+\frac{\hbar}{m_{0}}\left(\mathbf{k}-\mathbf{k}_{0}\right) \cdot \mathbf{p}+\frac{\hbar^{2}}{2 m_{0}}\left(\mathbf{k}^{2}-\mathbf{k}_{0}^{2}\right)\right] u_{\mathbf{k}, n}(\mathbf{r})=E_{n}(\mathbf{k}) u_{k, n}(\mathbf{r})
$$

e, substituindo a expansão da eq. 3.5 na eq. 3.6, obtém-se a equação de autovalor matricial para os caeficientes $\mathrm{C}_{\mathbf{n}, \mathrm{n}^{\prime}}\left(\mathbf{k}-\mathbf{k}_{0}\right)$ :

$$
\sum_{1}\left[\left[E_{n}(\mathbf{k})+\frac{\hbar^{2}}{2 m_{0}}\left(\mathbf{k}^{2}-\mathbf{k}_{0}^{2}\right)\right] \delta_{n^{\prime} n}+\frac{\hbar_{1}}{m_{0}}\left(\mathbf{k}-\mathbf{k}_{0}\right) \cdot \mathbf{p}_{n^{\prime} n}\right] C_{n^{\prime} n}=E_{n} C_{n^{\prime} n}
$$

onde

$$
p_{n^{\prime} n}=\int d^{3} \mathbf{r} u_{k_{0}, n}^{*}(r) p u_{k_{0}, n^{\prime}}(\mathbf{r})
$$

A eq. 3.7 é a equação para a funçãa de Bloch $u_{\mathbf{k}, \mathbf{n}}(\mathbf{r})$ no ponto $\mathbf{k}$, escrita na representação $\mathbf{k}_{0}$. Ela é válida para qualquer ponto $\mathbf{k}_{\sigma^{\prime}}$ mas usualmente é escrita para um $\mathbf{k}_{0}$ com alguma caracteríatica especial que possa ser usada na simplificação do cálculo, tal como possuir alta simetria e/ou ser um extremo de banda. Restringindo $\mathbf{k}$ a valores próximos de $\mathbf{k}_{\alpha}$, podemas tratar a termo:

$$
\mathrm{H}_{0}=\frac{\hbar_{k}}{m_{0}}\left(\mathbf{k}-\mathbf{k}_{0}\right) \cdot \mathrm{p}_{n^{\prime} n}
$$


como ưna perturbaçä́o.

A matriz do Hamiltoniano obtida com o ueo da base $u_{\mathbf{k}_{0}, n}(\mathbf{r})$ tem dimensão igual ao número de bandas do cristal, e todas estas estão acopladas entre si pelo termo $\mathbf{p}_{n}{ }^{\prime}$. Desta forma parece que estamos tornando o problema maja difícil ao invés de resolvê-lo. Pade-se dar um passo importante na direção da solução se analisarmos a matriz obtida de um outro ponto de vista. Se resolvessemos a eq. 3.7 por teoria de perturbação, poderiamas afirmar o seguinte: a energia $E_{n}(\mathbf{k})$ de um banda $n$ é igual a energia $E_{n}\left(\mathbf{k}_{0}\right)$ mais termos proporcionais $\grave{a}$ razão

$$
\frac{\mathbf{p}_{n_{n} n^{\prime}}}{E_{n}\left(k_{0}\right)-E_{n^{\prime}}\left(\mathbf{k}_{0}\right)}
$$

de modo que bandas de energia muito separadas energeticamente da banda em que estamos interessados darão uma contribuição muito pequena à banda $n$, enquanto que as mais próximas darão uma contribuição muito maior. Isto significa que, se pudermos isolar as contribuiç̧es das bandas que estäo muito separadas da banda $n$ das que estão muito próximas, a dimensão da matriz original pode ser fortemente reduzida, e o problema estará bem majs próximo de uma soluçăo. Um problema análogo a este foj encontrado por Lœwdin $(3)$ ern teoria quantica molecular, e por Feenberger ${ }^{(4)}$ em teoria de eppalhamento.

\section{III.a - Teoria de Perturbaşáo de Lcewdin-Feenberger}

Nesta seçăo analisaremos a teoria de perturbaçăo de Lowdin-Feenberger. Nó estamos intereseados na solução da equaç̃̃o de Schroedinger,

$$
\mathrm{H} \Psi(\mathbf{r})=\mathrm{E} \Psi(\mathbf{r})
$$

Escolhendo uma base qualquer de funçzes ortonormais $\varphi_{n}(\mathrm{r})$, podemos escrever a fungto $\Psi(\mathrm{r})$ como 


$$
\Psi(\mathbf{r})=\sum_{\mathrm{n}} \mathrm{C}_{\mathrm{n}} \varphi_{\mathrm{n}}(\mathbf{r})
$$

e traneformar a eq. 3.10 na equação secular:

$$
\sum_{n}\left(H_{m n}-E \delta_{m n}\right] C_{n}=0
$$

onde

$$
\mathrm{H}_{\mathrm{mn}}=\int \mathrm{d}^{3} \mathbf{r} \varphi_{m}^{*}(\mathrm{r}) \mathrm{H} \varphi_{\mathrm{n}}(\mathrm{r})
$$

Assumimos que nosso espaço de estados, descrito pelas funç̧es $\varphi_{n}$, pode ser diridido em dois grupos. Um grupo de estados que interage fortemente entre si, e um outro grupo que interage fracamente com o primeiro. Podemos, então, separar as contribuiçžes devidas a.o6 dois grupos, que chamaremas de A e B respectivamente. Escolhendo um nível $n$ (ou banda), en particular, podernos encrever a eq. 3.12

$$
\mathrm{C}_{\mathrm{m}}\left(\mathrm{H}_{\mathrm{mm}}-\mathrm{E}\right)+\sum_{\mathrm{n} m \mathrm{~m}}^{\mathrm{A}} \mathrm{H}_{\mathrm{mn}} \mathrm{C}_{\mathrm{n}}+\sum_{\mathrm{n} m \mathrm{~m}}^{\mathrm{B}} \mathrm{H}_{\mathrm{mn}} \mathrm{C}_{\mathrm{n}}=0 \quad 3.14 \mathrm{a}
$$

ou

$$
\mathrm{C}_{m}\left(E-H_{m m}\right)=\sum_{n}^{A} H_{m n}^{\prime} C_{n}+\sum_{n}^{B} H_{m n}^{\prime} C_{n}
$$

onde definimos $\mathrm{H}_{\mathrm{mn}}^{\prime} \equiv \mathrm{H}_{\mathrm{mn}}\left(1-\delta_{\mathrm{mn}}\right)$. Da eq. $3.14 \mathrm{~b}$ podemas escrever, para os coeficientes da expansão, a equação:

$$
C_{m}=\sum_{n}^{A} \frac{H_{m n}^{\prime}}{E-H_{m m}} C_{n}+\sum_{n}^{B} \frac{H_{m n}^{\prime}}{E-H_{m i i}} C_{n}
$$

$O$ coeficiente $C_{m}$ fornece a componente da função de onda $\Psi(r)$ na banda m. Contudo, precisamos eliminar do cálculo desta função tatal qualquer referência ao 
grupo de estados B. Isto pode ser feito através de um processo de iteração, aubstituindo para $C_{n}$, em todas as somas de estados exclusivos de $B$, a propria expressão da eq 3.15. Assim, obtemos a expressăo formal:

$$
\begin{aligned}
& \mathrm{C}_{\mathrm{m}}=\sum_{\mathrm{A}}^{\mathrm{A}}\left[\frac{\mathrm{H}_{\mathrm{mn}}^{\prime}}{\left(\mathrm{E}-\mathrm{H}_{\mathrm{mm}}\right)}+\sum_{\alpha}^{\mathrm{B}} \frac{\mathrm{H}_{\mathrm{m} \alpha}^{\prime}}{\left(\mathrm{E}-\mathrm{H}_{\mathrm{mm}}\right)\left(\mathrm{E}-\mathrm{H}_{\alpha \alpha}^{\prime}\right)}+\right. \\
& \left.\sum_{\alpha, \beta}^{\mathrm{B}} \frac{\mathrm{H}_{\mathrm{m} \alpha}^{\prime} \mathrm{H}_{\alpha \beta}^{\prime} \mathrm{H}_{\beta \mathrm{m}}^{\prime}}{\left(\mathrm{E}-\mathrm{H}_{\mathrm{mm}}\right)\left(\mathrm{E}-\mathrm{H}_{\alpha \alpha}\right)\left(\mathrm{E}-\mathrm{H}_{\beta \beta}\right)}+\cdots\right] \mathrm{O}_{\mathrm{n}^{\prime}}
\end{aligned}
$$

Introduzindo a notação:

$$
\mathrm{U}_{\mathrm{mn}}^{\mathrm{A}}=\mathrm{H}_{\mathrm{mn}}^{\prime}+\sum_{\alpha}^{\mathrm{B}} \frac{\mathrm{H}_{\mathrm{m} \alpha}^{\prime} \mathrm{H}_{\alpha \mathrm{n}}^{\prime}}{\left(\mathrm{E}-\mathrm{H}_{\alpha \alpha}\right)}+\sum_{\alpha, \beta}^{\mathrm{B}} \frac{\mathrm{H}_{\mathrm{m} \alpha}^{\prime} \mathrm{H}_{\alpha \beta}^{\prime} \mathrm{H}_{\beta n}^{\prime}}{\left(\mathrm{E}-\mathrm{H}_{\alpha \alpha}\right)\left(\mathrm{E}-\mathrm{H}_{\beta \beta}\right)}, 3.17
$$

abtemos, caso m seja um estado do grupo B, que:

$$
\mathrm{\sigma}_{\mathrm{m}}=\sum_{\Omega}^{A} \frac{\mathrm{U}_{\mathrm{mn}}^{\mathrm{A}}-\mathrm{H}_{\mathrm{mn}}{ }^{\delta} \mathrm{mn}}{\left(\mathrm{E}-\mathrm{H}_{\mathrm{mm}}\right)} \mathrm{\sigma}_{\mathrm{n}}
$$

- que elimina, na expanaño da função de onda total, a referência aos estados do grupo B. Caso m seja um estado do grupo A, obtemas:

$$
\sigma_{\mathrm{m}}^{A}=\sum_{\mathbb{1}}^{A} \frac{\mathrm{U}_{\mathrm{mn}}^{A}}{\left(\mathrm{E}-\mathrm{H}_{\mathrm{mm}}\right)} \mathrm{O}_{\mathrm{n}}
$$

ou

$$
\left(\mathrm{E}-\mathrm{H}_{\mathrm{mm}}\right) \mathrm{O}_{\mathrm{m}}=\sum_{\mathrm{L}}^{A} \mathrm{U}_{\mathrm{mi}}^{A} \sigma_{\mathrm{r}}
$$


Como $\mathrm{U}_{\mathrm{mm}}^{\mathrm{A}}=\mathrm{H}_{\mathrm{mm}}$, podemos escrever, finalmente:

$$
\sum_{1}^{A}\left[U_{m n}^{A}-E \delta_{m n}\right] C_{n}=0 .
$$

Isto termina a transformação para o sub-espaço de funçzen A. Obtivemas um novo Hamiltoniano dado pela matriz $\mathrm{U}_{\mathrm{mn}}^{\mathrm{A}}$, da eq. 3.17 , que é o Hamiltoniano inicial "renormalizado" incluindo somente os estados do grupo A. A dimeneño deste Hamiltoniano é, portanto, a dimeneão do sub-espaço A. A funçấo de onda $\Psi(\mathbf{r})$ pode ser escrita, usando-se a eq. 3.15 para os coeficientes $C_{n}$, apenas com as funças $\varphi_{n}$ pertencentes à A. O próximo passo cerá a aplicą̧ăo desta teoria para o caso especifico de um cemicondutor do grupo III-V ou II-VI com estrutura Zinc-Blend, para a obtençăo da estrutura de bandas..

\section{III.4 - Hamiltoniano para Semicondutores do Grupo II-VI e III-VI}

Consideraremos como estados de Bloch do grupo A as funçęes discutidas no Cap. II, isto é, $|x\rangle,|y\rangle,|a\rangle$ para os estados da banda de valência e $\mid$ b $\rangle$ para a banda de conduçăo e, como estados $B$ os estados da banda ligante $\Gamma_{1}$, que chamaremos de $\Gamma_{1}^{V}$, e os estados da banda näo-ligante $\Gamma_{4}$, que charaaremos de $\Gamma_{4}^{C}$. Como exemplo, podemos calcular alguns elementos da matria Hamiltoniana da perturbaça $\mathbf{k} \cdot \mathbf{p}$ entre os estados A, desconsiderando a interaçấ spin-orbita. 0 elemento de matriz entre estados $\mid$ s é:

$$
\mathrm{H}_{\mathrm{B} B}=\frac{f_{\mathrm{b}}}{\mathrm{m}_{0}}\langle\mathrm{e}|\mathbf{k} \cdot \mathbf{p}| \mathrm{s}\rangle
$$

Após a renormalizaçăo, obtemos:

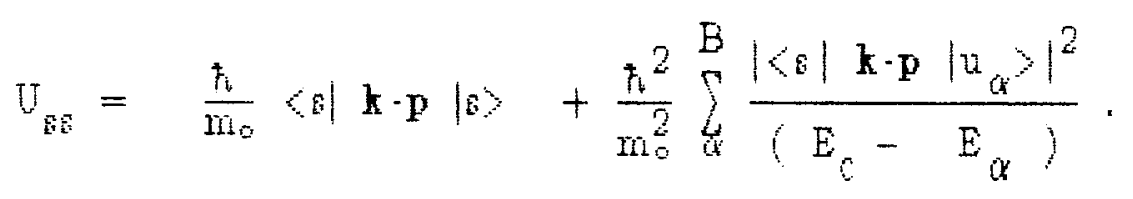


Podemos usar a simetria das bandas para analisar a eq. 3.22, uma vez que o estado inicial $|j\rangle$ e final $|f\rangle$ transformam-se como alguma representação $\Gamma_{i, f}$ e o operador $\mathbf{p}$ como $\Gamma_{4}$. Termos do tipo $\langle f|\mathbf{k} \cdot \mathbf{p}| i\rangle$ serão zero a menos que a decompasição do produto $\Gamma_{4} \otimes \Gamma_{j}$ contenha a representação do estado final $|f\rangle . \mathrm{Na}$ Tabela III.1 damos as regras de seleção nescessárias para a construção do Hamiltoniano.

Tabela III.1 - Regras de Seleção para os elementos de matriz .

\begin{tabular}{llr}
\hline$\Gamma_{i}$ & $\Gamma_{1}$ & $\Gamma_{4}$ \\
$\Gamma_{i} \otimes \Gamma_{4}$ & $\Gamma_{4}$ & $\Gamma_{1}+\Gamma_{3}+\Gamma_{4}+\Gamma_{6}$ \\
\hline
\end{tabular}

Desta tabela vemos que o termo $\langle s|\mathbf{k} \cdot \mathbf{p}| s\rangle$ é zera. Termos do tipo $\left\langle s\left|p_{\mathbf{y}}\right| \mathbf{x}\right\rangle$ e $\left\langle\varepsilon\left|p_{z}\right| x\right\rangle$, epesar da regra de seleção permitir, também são zero já que as reflex̧es nos planos (010) e (001), respectivamente, mudam o sinal destes elementos de matriz. Partanta, podemos escrever a eq. 3.22 como:

$$
\mathrm{U}_{\mathrm{s} G}=\left[\frac{\hbar^{2}}{\mathrm{~m}_{\mathrm{o}}^{2}} \sum_{\alpha}^{\Gamma_{4}^{\mathrm{v}}} \frac{\left|\left\langle\mathrm{s}\left|\mathrm{p}_{\mathrm{y}}\right| \mathrm{u}_{\alpha}\right\rangle\right|^{2}}{\left(\mathrm{E}_{\mathrm{c}}-\mathrm{E}_{\alpha}\right)}\right]\left(\mathrm{k}_{\mathrm{x}}^{2}+\mathrm{k}_{\mathrm{y}}^{2}+\mathrm{k}_{\mathrm{z}}^{2}\right)
$$

ou

$$
\mathrm{U}_{\mathrm{BG}}=\mathrm{A}^{1} \mathrm{k}^{2}
$$

onde $k^{2}=k_{x}^{2}+k_{y}^{2}+k_{z}^{2}$

$$
A^{\prime}=\frac{n^{2}}{m_{0}^{2}} \sum_{\alpha}^{v} \frac{\left.\left\langle s\left|p_{x}\right| u_{\alpha}\right\rangle\right|^{2}}{\left(E_{c}-E_{\alpha}\right)}
$$


0 elemento de matria da perturbação $\mathbf{k}-\mathbf{p}$ entre o estado $|\sigma\rangle$ e $|\mathbf{x}\rangle$ é dado por:

$$
U_{g X}=\frac{p_{6}}{m_{0}}\langle s|\mathbf{k}-\mathbf{p}| x\rangle
$$

e, após a transformação, obtemos,

$$
\mathrm{U}_{\mathrm{sx}}=\frac{\hbar}{\mathrm{m}_{0}}\langle\boldsymbol{s}|\mathbf{k} \cdot \mathbf{p}| \mathbf{x}\rangle+\frac{\hbar^{2}}{\mathrm{~m}_{0}^{2}} \sum_{\left.\alpha\left(E_{c}+E_{v}\right) / 2-E_{\alpha}\right)}^{\left\langle s|\mathbf{k} \cdot \mathbf{p}| \mathrm{u}_{\alpha}\right\rangle\left\langle\mathrm{u}_{\alpha}|\mathbf{k} \cdot \mathbf{p}| \mathbf{x}\right\rangle}
$$

ou

$$
\mathrm{U}_{\mathrm{sx}}=\frac{\hbar_{\mathrm{f}}}{\mathrm{m}_{\mathrm{o}}}\left\langle s\left|\mathrm{p}_{\mathrm{x}}\right| \mathrm{x}\right\rangle \mathrm{k}_{\mathrm{x}}+\left(\frac{\hbar^{2}}{\mathrm{~m}_{0}^{2}} \sum_{\alpha}^{\Gamma_{4}} \frac{\left\langle s\left|\mathrm{p}_{\mathrm{y}}\right| \mathrm{u}_{\alpha}\right\rangle\left\langle\mathrm{u}_{\alpha}\left|\mathrm{p}_{\mathrm{z}}\right| \mathrm{x}\right\rangle}{\left.\left(\mathrm{E}_{\mathrm{c}}+\mathrm{E}_{\mathrm{v}}\right) / 2-\mathrm{E}_{\alpha}\right)}\right) \mathrm{k}_{\mathrm{y}} \mathrm{k}_{\mathrm{z}}
$$

Definindo as constantes:

$$
P=-\mathrm{i} \frac{p_{k}}{\mathrm{~m}_{0}}\left\langle\mathrm{~g}\left|\mathrm{p}_{\mathrm{x}}\right| \mathrm{x}\right\rangle
$$

conhecida como parâmetro de $\mathrm{Kane}^{4}$, e

$$
\mathrm{B}=\frac{\hbar_{4}^{2}}{\mathrm{~m}_{\sigma}^{2}} \sum_{\alpha}^{\mathrm{v}} \frac{\left\langle\mathrm{s}\left|\mathrm{p}_{\mathrm{y}}\right| \mathrm{u}_{\alpha}\right\rangle\left\langle\mathrm{u}_{\alpha}\left|\mathrm{p}_{\mathrm{z}}\right| \mathrm{x}\right\rangle}{\left.\left(\mathrm{E}_{\mathrm{c}}+\mathrm{E}_{\mathrm{v}}\right) / 2-\mathrm{E}_{\alpha}\right)}
$$

podemos escrever a eq. $3.26 \mathrm{~b}$ como:

$$
U_{\mathrm{B} X}=\mathrm{i} P \mathrm{k}_{\mathrm{x}}+\mathrm{B} \mathrm{k}_{\mathrm{y}} \mathrm{k}_{\mathrm{z}}
$$

Fepetindo o mesmo procedimento para todos os elementos de matriz, obternos o 
Hamiltoniano final:

$$
\begin{aligned}
& \mathrm{H}=\ldots
\end{aligned}
$$

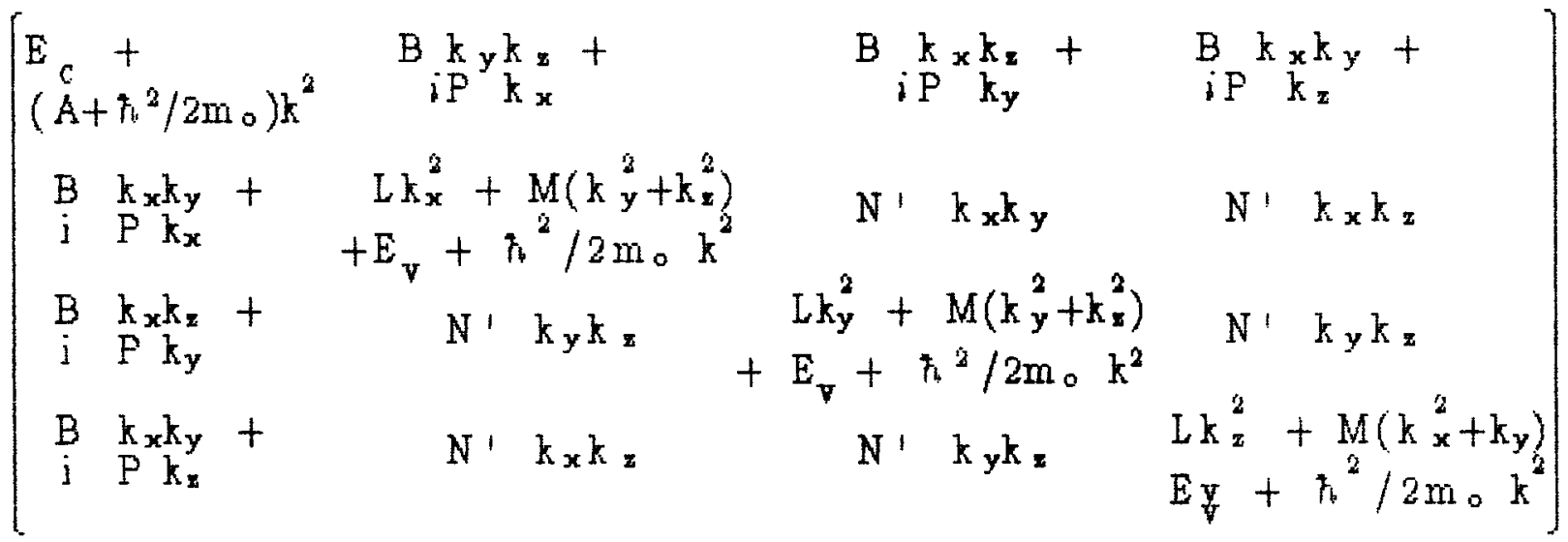

onde $A, F$ e $B$ são dadas pelas expressóes obtidas acima, e as outras constantes, $L$, $\mathrm{M}$ e $\mathrm{N}$, de origem análoga, seguem a notação da ref. (1). Este cálculo fornece um Hamiltoniano correto até primeira ordem na perturbaçắ $\mathbf{k} \cdot \mathbf{p}$ e inclue os efeitos de bandas extemas ao problema. Como mencionado no Capitulo II, este ainda não á o Hamiltoniano correto para materiais III-V, devido a ausência da interaçäo spin-orbita, importante nestes materiais. O próximo passo, partanto, é a inclusăo do termo de acoplamento spin-brbita, que será analisada na seçấo seguinte.

III.5 - Interaçäo Spin-Orbita

Incluindo o spin do elétron nosso espaço de estados quadridimensional torna-se 8-dimensional. Devido à interaçá spin-órbita os estados da banda de valência separam-Ge em um estado singleto, $J=1 / 2$, e em um estado dubleto, $J=3 / 2$. A separaçăo em energia destes estados é dada pelo elemento de matriz:

$$
\Delta=-3 i \frac{\eta_{L}}{4 \mathrm{~m}^{2} c^{2}}\left\langle\mathrm{~B}\left|[\nabla V(\mathbf{r}) \times \mathbf{p}]_{\mathbf{y}}\right| z\right\rangle
$$

Os termos, que surgem no Hamiltoniano final devido a "renomalizagan" $d a$ interaçăo spin-orbita com as outras bandas, däo origem a elementos de matria 
proporcionais a $k$, mas de pequena magnitude(l), e não serão inclusdos.

O Hamiltoniano da interação spin-órbita é diagonal na base do momento angular $\left|J, m_{j}\right\rangle$ de modo que, transformando o Hamiltoniano k.p para esta base, a perturbação de spin-orbita é acrescentada comente aos termos da diagonal. Esta tranoformação pode ser feita usando-se a expressão para $\left|j, m_{j}\right\rangle$ em termos de harmónicos cúbicas:

$$
\begin{aligned}
& \left|u_{1}\right\rangle=|1 / 2,1 / 2\rangle=|\varepsilon\rangle \uparrow \\
& \left|u_{2}\right\rangle=|2 / 2,2 / 2\rangle=\frac{i}{\sqrt{2}}(|x\rangle \uparrow+i|y\rangle \uparrow) \\
& \left|u_{2}\right\rangle=|a / 2,1 / 2\rangle=\frac{i}{\sqrt{6}}(|x\rangle \downarrow+i|y\rangle \downarrow-2|z\rangle \uparrow) \\
& \left|u_{1}\right\rangle=|1 / 2,1 / 2\rangle=\frac{i}{\sqrt{3}}(|x\rangle \downarrow+i|y\rangle \downarrow+|z\rangle \uparrow)
\end{aligned}
$$

e

$$
\begin{aligned}
& \left|u_{5}\right\rangle=|1 / 2,-1 / 2\rangle=|8\rangle \downarrow \\
& \left|u_{8}\right\rangle=|2 / 2,-3 / 2\rangle=\frac{i}{\sqrt{2}}(|x\rangle \downarrow-i|y\rangle \downarrow) \\
& \left|u_{9}\right\rangle=|3 / 2,-1 / 2\rangle=\frac{i}{\sqrt{6}}(|x\rangle \uparrow-i|y\rangle \uparrow+2|z\rangle \downarrow) \\
& \left|u_{8}\right\rangle=|1 / 2,-1 / 2\rangle=\frac{i}{\sqrt{3}}(|x\rangle \uparrow-i|y\rangle \uparrow-|z\rangle \downarrow)
\end{aligned}
$$

onde o segundo grupo de estados pode ser obtido do primeiro através da aplicação do operador de invereão temporal $\dot{\mathrm{K}}=-i \sigma_{y} \cdot \hat{\mathrm{C}} \cdot \hat{\mathrm{J}}$. onde $\sigma_{y}$ e a matria de $\mathrm{Fan}$ cue inverte a componente de spin, $\hat{O}$ o operador de conjugaça complexa e $j$ o operador de inversão espacial. No nosso caso, foram escolhidos a direçăo z para a quantizaçấo do momento angular e o ordenamento dos estados igual ao de Cohen e Marques (5). Esta escolha será útil mais a frente, mas ela difere da utilizada por autros autores como, por exempla, Okhawa e Uemura ${ }^{(6)}$, Altarelli, Kemberg e Fasolino ${ }^{(7)}$, Broido e Sham ${ }^{(8)}$ e Eppenga, Schuurmans e Colak ${ }^{(9)}$. Contudo, o ordenamento escolhido por nós é quase sempre o ordenamento energético das bandas e, partanto, mais conveniente. 
Hamiltoniano k-p final pode ser agora obtido facilmente. Tomando U como a matria que transforma a base de harmônicos cúbicos para a base de momento angular $\left|j, m_{j}\right\rangle$, cujos elementos podem ser obtidos por inspeção do grupo de estados acima, e escrevendo o Hamiltoniano inicial como:

$$
H_{o}=\left[\begin{array}{cc}
H_{s} & 0 \\
0 & H_{u}
\end{array}\right]
$$

onde cada $\mathrm{H}_{\mathrm{s}, \mathrm{u}}$ é uma matriz $4 \times 4$ idêntica a matriz da eq. 3.30 obtemos, através da transformação unitária o Hamiltoniano com interação spin-orbita para qualquer semicondutor do tipo Zinc-Blend, no porto $\Gamma$ :

$$
\mathrm{H}_{30}=\mathrm{U}^{\dagger} \cdot \mathrm{H}_{0} \cdot \mathrm{U}
$$

ou

$$
\mathrm{H}_{\mathrm{so}}=\ldots
$$

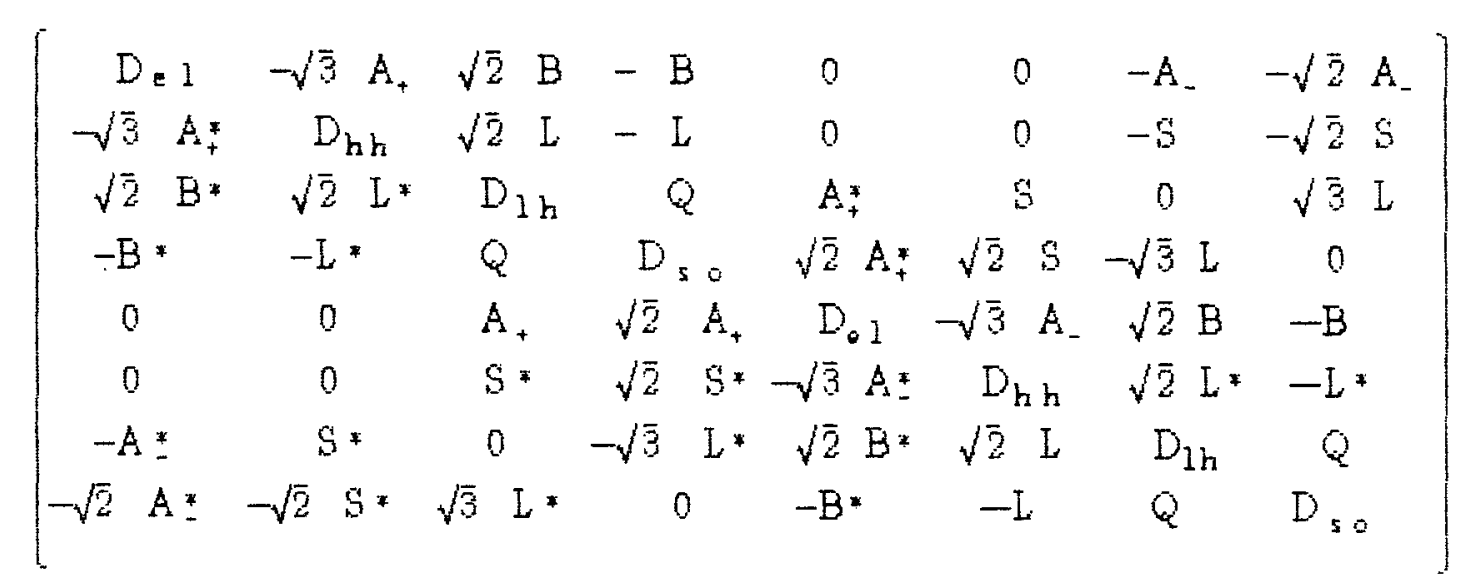

onde

$$
D_{\mathrm{g} 1}=\mathrm{E}_{\mathrm{g}}+(\mathrm{F}+1 / 2)\left(\mathrm{k}^{2}+\mathrm{k}_{\mathrm{z}}^{2}\right) ; \mathrm{k}^{2}=\mathrm{k}_{\mathrm{x}}^{2}+\mathrm{k}_{\mathrm{y}}^{2} .
$$




$$
\begin{aligned}
& D_{\text {hh }}=D_{+} ; D_{\text {lh }}=D_{-} \text {, } \\
& \mathrm{D} \pm=-\left(\gamma_{1} \pm \gamma_{2}\right) \mathrm{k}^{2}-\left(\gamma_{1} \pm 2 \gamma_{2}\right) \mathrm{k}_{2}^{2} \text {, } \\
& D_{\mathrm{so}}=-\Delta-\frac{z_{1}}{2}\left(\mathrm{k}^{2}+\mathrm{k}_{\mathrm{z}}^{2}\right) \text {, } \\
& A \pm=\frac{1}{\sqrt{6}} P k_{ \pm} \pm \sqrt{\frac{2}{3}} G k_{z} k_{\bar{F}} \\
& \mathrm{~B}=\frac{2}{\sqrt{3}} \mathrm{P} \mathrm{k}_{\mathrm{z}}-i \sqrt{\frac{4}{3}} \mathrm{G} k_{x} k_{y} \text {, } \\
& \mathrm{L}=2 i \sqrt{\frac{3}{2}} 7, \mathrm{k}_{\mathrm{z}} \mathrm{k} \text {, } \\
& S=\sqrt{3}\left(\bar{y} k_{-}^{2}-\mu k_{+}^{2}\right) / 2 \text {, } \\
& Q=\sqrt{2} \gamma_{2}\left(k_{z}^{2}-k^{2}\right) \text {, } \\
& \mathrm{k} \pm=\mathrm{k}_{\mathrm{x}} \pm \mathrm{k}_{\mathrm{y}}=\mathrm{k} \mathrm{e}^{i \theta} \text {; }
\end{aligned}
$$

Por caerência com a literatura, algumas canstantes foram redefinidas, de mado que $A, B$ e $L$ desta seção não são as mesmas que as da seção anterior. EL, HH, LH e SO são abreviaçđes para elétron, 'heavy-hole', 'light-hole' e spin-b́rbita. $O$ termo 'heavy' e 'light' são usados para diferenciar os estados degenerados em $\mathbf{k}=0$ que são diferentes em massa. Nas expresszes $3.35, E_{g}=\left(E_{c}-E_{v}\right)$ é o gap fundamental do material; $\mathrm{P}$ é o parâmetro de Kane; $\mathrm{F}$ a parâmetro de segunda ordem (idêntico a $A$ da seção anterior); $\gamma_{1}, \gamma_{2}$ e $\gamma_{a}$ eão equivalentes aos parâmetros de Luttinger $(10)$ para a banda $\Gamma_{8}$, que padem ser escritas em termos dos parâmetros antigos $\mathrm{M}, \mathrm{L}$ e $\mathrm{N}$ coma:

$$
\begin{aligned}
& \gamma_{1}=-1 / 3(L-2 M)-1 \\
& \gamma_{3}=-1 / 3(L+M) \\
& \gamma_{3}=-N / 3
\end{aligned}
$$

$\Delta$ é a energia de separação spin-brbita entre as bandas $\Gamma_{8}$ e $\Gamma_{7}$ (fig.2.4); $\theta$ é 0 ângulo entre $k_{x}$ e $k_{y} ; \mathbf{k}=\left(k_{x}, k_{y}, 0\right)$ é o vetor no plano, e redefinimas o zero de energia que passa a ser no topo da banda de valência. $O$ parâmetro $\mu$, na definição de $S$, é o termo de 'warping' da banda de valência (condução) em semicandutores normais (invertidos), e $G$ é o termo de assimetria de inversão para a banda de valência, análogo à constante $B$ da seção anterior. Este último parâmetro é o 
responsável pela separação do dubleto de Kramer em materiais Zinc-Blend e é zero para materiajs do tipo Diamante. Mesmo para materiais com estrutura Zinc-Blend, $G$ é pequeno $(11,12)$ e portanto será considerado apenas como uma perturbação.

O Hamiltoniano 3.34 é suficiente para o tratamento das bandas de energia de um semicondutor Zinc-Blend. Porém, para heteroestruturas e poços quânticos, $\mathrm{k}_{\mathbf{z}}$ torna-ae o operador $-\mathrm{i} \frac{\mathrm{d}}{\mathrm{dz}}$ e 0 Hamiltoniano $8 \times 8$ passa a representar um sistema de oito equaçbes diferenciais de $2^{\circ}$ grau acopladas. Assim, devemos procurar decompor o Hamiltoniano da eq. 3.29 em blocos menores, tratáveis, ao menos, numericamente.

III.6 - Bloco-Diagonalização do Hamiltoniano $8 \times 8$

Existem várias maneiras de se simplificar o Hamiltoniano da eq. 3.34. Podemos, por exemplo, supor que o acoplamento spin-orbita $\Delta$ é muito grande, excluindo os materiais de $\triangle$ pequeno, e desacoplamos estas banda das outras seis, duas de condução e quatro de valência, ficando corn um Hamiltoniano menor, de dimensäo 6x6. Podemos tomar este Hamiltoniano $6 \times 6$ e desacoplar a banda de condução das bandas de valência, ficando com um Hamiltoniano $4 \times 4$ para a banda de valência, excluindo materiais de gap estreito, semelhante ao Hamiltoniano de Luttinger.

Usaremos um método diferente ${ }^{(5,13)}$. Usaremos novamente uma transformação unitária para diagonalizar o Hamiltoniano $8 \times 8 \mathrm{em}$ dois blocos $4 \times 4$, que separa 0 espaço em dois grupos de estados que säo, relacionados entre si pela cimetris de inversão temporal, de mareira semelhante a que foi feito por Marques, White e

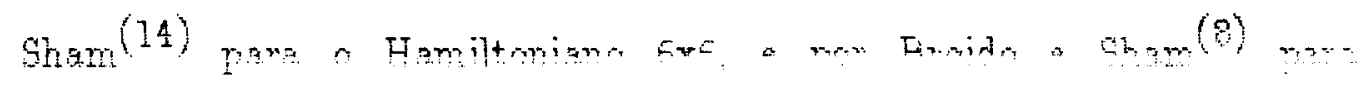

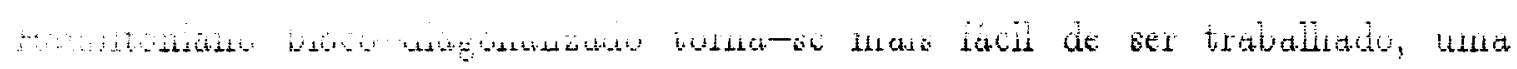
yez que os estados de spin degenerados podem ser tratados separadamente. Desta forma, näo há necessidade de nenhuma aproximação drástica que possa diminuir a aphcabilidade do método a um certo numero de materiais a serem estudados.

Para realizar a transformaçấo descrita acima noe escrevemos o Hamiltoniano, eq. 3.34 , cono a soma de matrizes $8 \times 8$, 


$$
\mathbf{H}=\mathrm{H}_{s}(\overline{7})+\mathbf{H}_{\mathbf{w}}(\mu)
$$

ande $H_{s}(\overline{7})$ é a parte simétrica do Hamiltoniano $3.34 b$, e $H_{w}(\mu)$ a parte de 'warping'. E sempre passivel achar quatro ângulos $\zeta, \phi, \eta$ e $\xi$ de modo que a parte simétrica de $\mathrm{H}, \mathrm{H}_{\mathrm{s}}$, ascuma a forma de dois blocos $4 \times 4$ após a aplicação da transformação unitária U,

$$
\mathrm{J}=\left[\begin{array}{cc}
\mathrm{T} & \mathrm{S} \\
-\mathrm{S}^{*} & \mathrm{~T}^{*}
\end{array}\right]
$$

ande

$$
T=\left[\begin{array}{cccc}
\frac{1}{\sqrt{2}}-\mathrm{e}^{-\mathrm{i} \zeta} & 0 & 0 & 0 \\
0 & \frac{1}{\sqrt{2}}-\mathrm{e}^{-\mathrm{i} \phi} & 0 & 0 \\
0 & 0 & \frac{1}{\sqrt{2}}-\mathrm{e}^{-\mathrm{i} \eta} & 0 \\
0 & 0 & 0 & \frac{1}{\sqrt{2}}-\mathrm{e}^{-\mathrm{i} \xi}
\end{array}\right]
$$

e $S$ é uma matriz $4 x 4$ cuja diagonal é dada por $S=-T^{*}$. A aplicação desta transformação à parte de 'warping', ou seja,

$$
\mathrm{U}^{\dagger} \cdot \mathrm{H}_{\mathbf{w}} \cdot \mathrm{U}=\mathrm{H}_{\mathbf{m}_{1}}+\mathrm{H}_{\mathrm{w}^{2}}
$$

leva a matriz $\mathrm{H}_{w 1}$ a uma forma bloco-diagonal. A matriz $\mathrm{H}_{w 2}$ não é bloco-diaganal, mas a contribução do blaco fora da diagonal na dispersão dos níveje de energia é pequena e só pode ser observada para valores de $\mathbf{k}$ muito grandes. Portanto, nós desprezaremos este termo. De qualquer maneira, conferimos esta aproximação comparando as energjas do Hamiltoniano $8 \times 8$ com 20 do Hamiltaniano $4 \times 4$ para vários valores de $\mathbf{k}$. Para $\mathbf{k}$ da ordem de $10^{5} \mathrm{~cm}^{-1}$, que é muito maior do que os vetares da zona de Brillowin em que estamos interessados, o erro encontrado foj de aproximadamente $0.1 \%$. Portanto, coneideramos esta aproximação bastante seģra. 
Somando as partes do Hamiltoniano 4x4 final, obtemos para o blaco superior, que chamaremas estados-U,

$$
H_{u}=\left[\begin{array}{cccc}
D_{01} & P_{1} & P_{2} & P_{3} \\
P_{1} & D_{h h} & L_{1} & L_{2} \\
P_{2} & L_{1}^{*} & D_{1 h} & Q_{1} \\
P_{a} & L_{2}^{*} & Q_{1}^{*} & D_{s 0}
\end{array}\right]
$$

onde

$$
\begin{aligned}
& P_{1}=-\frac{1}{\sqrt{2}}-P_{k} \\
& P_{2}=\sqrt{\frac{2}{3}} P k_{z}-i \frac{1}{\sqrt{6}} P k \\
& P_{3}=-\frac{1}{\sqrt{3}}-P k_{2}-i \frac{1}{\sqrt{3}}-P k \\
& \mathrm{~L}_{1}=\sqrt{3} 7_{3} \mathrm{k} \mathrm{k}_{\mathrm{z}}-i \frac{\sqrt{3}}{2} \mathrm{k}^{2} 7(\theta) \\
& \mathrm{L}_{2}=-\sqrt{\frac{3}{2}} 7 \mathrm{a}_{\mathrm{a}} \mathrm{k} \mathrm{k}_{\mathrm{z}}-i \sqrt{\frac{3}{2}} \mathrm{k}^{2} \gamma(\theta) \\
& Q_{1}=\sqrt{2} \gamma_{2}\left(k_{z}^{2}-2 k^{2}\right)+i \frac{3}{\sqrt{2}}-y_{1} k k_{x}
\end{aligned}
$$

$D_{e 1}, D_{h h}, D_{1 h}$ e $D_{\text {so }}$ săo idênticos aos definidos na eq. 3.35 , e $7(\theta)=\gamma_{3}+$ $\left(\gamma_{2}-\gamma_{3}\right) \cos ^{2}(2 \theta)$ é a major contribuiçăo do termo de 'warping' ao Hamiltoniano. 0 bloco inferior é igual ao complexo conjugado do bloco superior, como requer a traneformaçăo de inversáo temporal, que liga os dojs subespaços de estados do Hamiltoniano total.

III.7 - Determinaçáo dos Parâmetros do Hamiltoniano

Nesta teoria $\mathbf{k} \cdot \mathbf{p}$ existem sete parâmetros que determinam a estrutura de banda (Eg, P, F, $\Delta, \gamma_{1}, \gamma_{2}$ e $\gamma_{a}$ ) e que säo obtidos do espectro de absorsä́ magnetootica. Na literatura existe um grande número destes parâmetros tabelados, of 
quais dependem da aproximação utilizada para fitar os resultados do espectro. Por exemplo, pode-se fitar os resultados usando um Hamiltoniano $6 x \in$. E em várias destas tabelas a contribuiçăo de segunda ordem, $F$, para a masea da banda $\Gamma_{6}$ é ignorada.

Desde que o gap fundarnental, $E_{g}$, e a separaçăo de spin-órbita, $\Delta$, podem ser obtidos independentemente, como função da concentraçăo da liga e da temperatura, pode-se usá-los junto com as massas efetivas $m_{c}, m_{h h}, m_{1 h}, m_{s o} n a$ direçăo [100], e a masa do buraco pesado na direçấo [111] para o cálculo dos cinco parâmetros restantes, $P, F, 7_{1}, \gamma_{2}$, e $7_{3}$.

O Hamiltoniano $4 \times 4$ pode ser diagonalizado $e$, considerando termos até a ordem de $k^{2}$ nas energias, obtém-ge as massas da relação:

$$
\frac{1}{m_{1}^{*}}=\frac{1}{f_{t}^{2}} \frac{\partial^{2}}{\partial k^{2}} E_{i}(k)
$$

onde $\mathrm{j}=\mathrm{EL}, \mathrm{HH}, \mathrm{LH}, \mathrm{SO}$.

Obtemos, para a masea da banda $\Gamma_{6}$ na direção $[0,0,1]$ (condução), a expręå̃o:

$$
\frac{1}{m_{01}^{*}}=1+2 F+\frac{4}{3} \frac{P^{2}}{E_{g}}\left[1+\frac{1}{2} \frac{E_{g}}{\left(E_{g}+\Delta\right)}\right]
$$

que mostra explicitamente o desvio da parabolicidade devido a contribuçăo das outras bandas. Obtemos também a masea efetiva do buraco-pesado (HH) na direcär [001] como funçăo dos parâmetros $7_{1}$ e $7_{2}$ :

$$
\frac{1}{m_{h h}^{*}}=\pi_{1}-2 \gamma_{2}
$$

e a massa do buraco leve (LH) na direça [001] é dada por: 


$$
\frac{1}{m_{h h}}=7_{1}+27_{2}+\frac{4}{3} \frac{P^{2}}{E_{g}} .
$$

Na direçấo [111] a masse do buraco pesado é :

$$
\frac{1}{m_{h h}^{3}}=r_{i}
$$

e, finalmente, para a massa do ramo $\Gamma_{\eta}$, devido ao spin-órbita. (SO) obtemas:

$$
\frac{1}{m_{s o}^{*}}=\gamma_{1}+\frac{2}{3} \frac{P^{2}}{E_{g}}\left[\frac{E_{g}}{\left(E_{g}+\Delta\right)}\right]
$$

Podemos abservar, nestes casos, que as massas de spin-brbita e do buraco leve sofrem correçóes devido ao seu acoplamento com a banda de condução. Já a massa do buraco pesado é obtida diretamente da derivada segunda do termo da diagonal $D_{h h}$, uma vez que, em $\mathbf{k}=0$, este ramo nä́ se acopla com outras bandas. As massas efetivas, a energia do gap e a separaçäo spin-brbita, uma vez conhecidas para uma dada concentração, podem ser substituidas nas eqs. $3.44-3.48$ que, quando resolvidas, fornecem os parêmetros do Hamiltoniano pars aquela. concentraçáo.

Nas tabelas III.2 e III.3 encontram-6e os valores destes parâmetros para os materiair GaAs, AlAs, GaInAs e Alnas. Para o valor do 'gap' da liga GaAlas como funçá da concentracăo usaremos o valor ${ }^{(15)}$,

$$
E_{g}=1519.2+1247
$$


Tabela III.2 - Conjunto de parâmetros para GaAl e AlAs, a bajxas temperaturas. As massas estão em unidades da massa do elétron livre.

\begin{tabular}{lllllll}
\hline & $\mathrm{m}_{\varepsilon}^{*}$ & $\mathrm{~m}_{\mathrm{h}}^{*}$ & $\mathrm{~m}_{1}$ & $\mathrm{~m}_{\text {so }}^{*}$ & $\mathrm{~m}_{\mathrm{h}}^{*}(111)$ & $\Delta(\mathrm{meV})$ \\
$\mathrm{GaAs}$ & 0.0665 & 0.3800 & 0.0870 & 0.1735 & 0.9524 & 340. \\
$\mathrm{AlAs}$ & 0.1500 & 0.4785 & 0.2079 & 0.3147 & 1.1490 & 280. \\
\hline
\end{tabular}


Tabela III.3 - Conjunto de parâmetros para $\mathrm{Ga}_{0.47} \operatorname{In}_{0 .{ }_{3}} \mathrm{As}, \mathrm{Al}_{0.48} \operatorname{In}_{0 .{ }_{2}{ }_{2} \mathrm{~A}, \mathrm{a}}$ baixas temperaturas, na composicão em que os parâmetros de rede săo compativeis. As massas estão em uridades da massa do elétron livre.

\begin{tabular}{llllllll}
\hline & $m_{c}^{*}$ & $m_{h h}^{*}$ & $m_{h h}^{*}$ & $m_{s 0}^{*}$ & $m_{h}^{*}(111)$ & $E_{g}(m e V)$ & $\Delta(\mathrm{mev})$ \\
GaInAB & 0.0410 & 0.3800 & 0.0520 & 0.1300 & $0.7800^{\circ}$ & 813. & 360 \\
AlInAB & 0.1500 & 0.4785 & 0.2079 & 0.3147 & $1.1490^{\circ}$ & 1508. & 332 \\
\hline
\end{tabular}
a - interpolado da ref. 16
b - ref 17

Apesar de todos os parâmetros sereni determinados de forma consistente, algumas vezes os valores experimentais das maseas, para um dada concentraçăo e para cada material, são dificeis de se encontrar e devemos uaar algum tipo de aproximação ou interpolação. Com este Hamiltoniano e os parâmetros calculados da maneira acima, o movimento dos elétrons e buracos, em qualquer semicondutor Zinc-Blend, heterojunção ou poço quântico, pode ser determinado. 


\section{CAPÍTULO IV}

\section{A APROXIMAĞ̃O DE FUNĢÃO ENVELOPE}

IV.1 - Introdução

A aproximação de função envelope é uma teoria de massa efetiva usada para descrever o movimentr de elétrons e buracos sobre a influência de perturbaçáes do campo periódico de um cristal. Nesta descriçăo encaixam-se grande parte das prablemas da teoria dos sólidos.

As origens do método podem ser traçadas até o trabalho de Wannier (1) sobre estados excitados em semicondutores. Mas, J. C. Slater (2) foi quem realmente percebeu a importância do trabalho de Wannier, eqpecificaraente do hoje conhecido Teorema de Wannier, para o desenvolvimento de uma teoria do movimento dos elétrons e buracos em perturbaçzes do campo periódico. Slater utilizou o trabalho de Wannier para estudar estados de impurezas e estados excitados em semicondutores. Adams ${ }^{(3)}$ generalizou o método para incluir transições entre bandas. Contuda, estes trabalhos trataram apenas casos simples, onde a banda considerada era näo-degenerada e com o extremo no centro da zona de Brillowin. Foj com o trabalho de Luttinger e Kohn ${ }^{(4)}$ que generalizaçzes necessárias, tais como degenerescência das bandas e mínimo fora do centro da zona de Brillouin, foram desenvolvidss para descrever casos importantes como nos dos materiais sj e Ge. A partir daf, o método finalmente foi colocado em bases formais sólidas.

Nós iremos, a seguir, discutir estas generaliagçoses as condiçóes de contorno para a funçăo envelope en poços quânticos $(5,6)$, usadas em nosso trabalho.

\section{V.2 - Banda Năo-Degenerada}

Assumindo un potencial perturbativo $\mathrm{U}(\mathbf{r})$ que age sobre uma partícula, e $\mathrm{H}_{0}$ como o Hamiltoniano do sistems năo-perturbado, peribdico, com autofunçōes ${ }^{\Phi_{k}, n}(\mathbf{r})$ - autovalores $E_{n}(\mathbf{k})$, onde $n$ numera as bandas e $\mathbf{k}$ os estados na primeira zona de 
Brillouin, a equação de Schroedinger para o sistema periódico é escrita como:

$$
\mathrm{H}_{0} \Phi_{n}(\mathbf{r}, \mathbf{k})=\left[-\frac{\hbar^{2}}{2 \mathrm{~m}_{0}} \nabla^{2}+V_{c}(\mathbf{r})\right] \Psi_{n}(\mathbf{r}, \mathbf{k})=\mathrm{E}_{\mathrm{n}}(\mathbf{k}) \mathbf{\Phi}_{\mathrm{n}}(\mathbf{r}, \mathbf{k})
$$

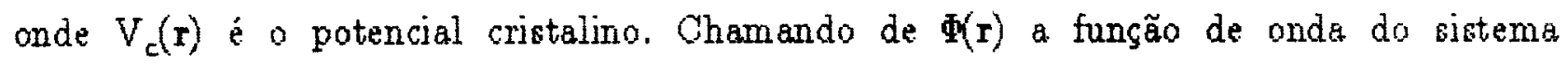
perturbado, a equação que descreve o sistema com a perturbação U(r) é:

$$
\left[H_{0}+U(\mathbf{r}) \Phi(r)\right]=E \Phi(\mathbf{r})
$$

Para resolver esta equação, Slater propỏs a expansão da solução em funções do tipo Wannier. Contudo, nós seguiremos o métado de Luttinger e $\mathrm{Kahr}$, que será facilmente generalizado mais adiante para o caso de bandas degeneradas. Considerando, portanto, o conjunto de funçбes de base:

$$
x_{n}(\mathbf{r}, \mathbf{k})=\mathrm{e}^{-\mathrm{ik} \cdot \mathbf{r}_{\mathrm{o}, \mathrm{n}}}(\mathbf{r})
$$

é necessário, de inicio, mostrar que podemos expandir qualquer funçäo nesta base. Isto pode eer mostrado provando-se que as funçóes $x_{n}(\mathbf{r}, \mathbf{k})$ formam um conjunto completo.

Considere um funçäo $f(\mathbf{r})$ qualquer, expandida em termos des $\Psi_{n}(\mathbf{r}, \mathbf{k})$, que formam uma base completa:

$$
\begin{aligned}
& f(r)=\sum \int d^{3} \varepsilon_{n}(k) \Psi_{n}(r, k)
\end{aligned}
$$

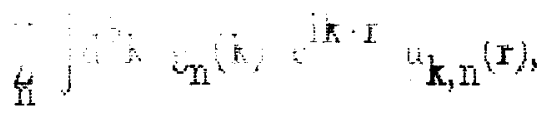

usando-se a expansấ das funçoes de Bloch em un dado $\mathbf{k}$ em temos das funçoes de Bloch em $\mathbf{k}=0$ (seçấo II.2):

$$
u_{k, n}(r)=\sum_{\mathrm{m}} \sigma_{n, m}(k) u_{0, m}(r)
$$


e fazendo a substituição da eq. 4.5 na eq. 4.4, obtém-se:

$$
f(\mathbf{r})=\sum \int d^{3} \mathbf{k} \bar{g}_{n}(\mathbf{k}) x_{n}(\mathbf{r}, \mathbf{k})
$$

e

$$
\mathrm{g}_{\mathrm{n}}(\mathbf{k})=\sum_{\mathrm{n}} \mathrm{C}_{\mathrm{nm}}(\mathbf{k}) \mathrm{g}_{\mathrm{m}}(\mathbf{k})
$$

A ortogonalidade pode ser demonstrada facilmente. Para as $\Psi_{n}(r, k)$ a ortogonalidade é dada por:

$$
\left(\Psi_{n}(k) \mid \Psi_{m}(\mathbf{q})\right)=\int_{v o 1} d^{3} \mathbf{r} \Psi_{n}(\mathbf{r}, \mathbf{k}) \Psi_{m}(\mathbf{r}, \mathbf{q})=\delta_{\mathrm{nm}} \delta(\mathbf{k}-\mathbf{q})
$$

Para as $\chi_{n}(\mathbf{r}, \mathbf{k})$ tem-se:

$$
\left(x_{n}(\mathbf{k}) \mid x_{m}(\mathbf{q})\right)=\int_{v_{01}} d^{3} \mathbf{r} e^{j-(\mathbf{k}-\mathbf{q})-\mathbf{r}} u_{o, n}^{*}(\mathbf{r}) u_{o, m}(\mathbf{r})
$$

Uma vez que o produto $u_{a, n}^{*}(\mathbf{r}) u_{a, m}(\mathbf{r})$ é periódico no cristal, podemos expandi-lo em uma série de Fourier, usando vetores da rede reciproca:

$$
u_{o, n}^{n}(\mathbf{r}) u_{a, m}(\mathbf{r})=\sum_{j} B_{j}^{n m u} e^{j G_{j} \cdot \mathbf{r}}
$$

onde $G_{j}$ săo os vetores da rede reciproca e $B_{j}^{n m}$ os coeficientes de Fourier da expansäo. Substituindo a eq. 4.10 ne eq. 4.9 obtém-se:

$$
\left(x_{\mathrm{n}}(\mathbf{k}) \mid x_{\mathrm{m}}(\mathbf{q})\right)=\sum_{\mathrm{j}}(2 \pi)^{3} \mathrm{~B}_{\mathrm{j}}^{\mathrm{mn}} \delta\left(\mathbf{k}-\mathbf{q}-\mathrm{G}_{\mathrm{j}}\right)
$$

Como $k$ e $\mathbf{q}$ pertencem a primeira zona de Brillouin, $\mathbf{k}-\mathbf{q}=\mathbf{G}_{\mathbf{j}}$ é relevante somente para $\mathrm{G}_{j}=0$, entän: 


$$
\left(x_{n}(\mathbf{k}) \mid x_{m}(q)\right)=(2 \pi)^{3} B_{o}^{n m} \delta(\mathbf{k}-\mathbf{q})
$$

e da expressão para os coeficientes de Fourier:

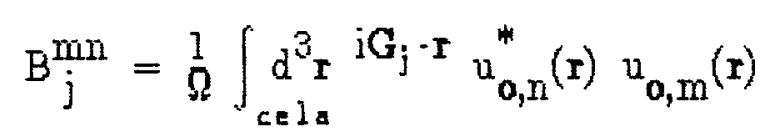

onde $\Omega$ é o volume da cela unitária. Para $G_{j}=0$ tem-6e:

$$
\mathrm{B}_{0}^{\mathrm{mn}}=\frac{1}{(2 \pi)^{3}}{ }_{\mathrm{nm}}
$$

Portanto, substituindo a eq. 4.14 Ia eq. 4.12 , obtemos a expressão para a ortogonalidade das $x_{\mathrm{n}}(\mathbf{r}, \mathbf{k})$ :

$$
\left(x_{\mathrm{n}}(\mathbf{k}) \mid x_{\mathrm{m}}(\mathbf{q})\right)=\delta_{\mathrm{nm}} \delta(\mathbf{k}-\mathbf{q})
$$

Voltando a soluçăo do problema colocado pela eq. 4.2, propôe-se portanto o seguinte 'ansatz':

$$
\Phi(\mathbf{r})=\sum \int d^{3} \mathbf{k} A_{n}(k) x_{n}(\mathbf{r}, \mathbf{k})
$$

que, substituida na eq. 4.2, fornece a equação:

$$
\sum_{\mathrm{n}} \int \mathrm{d}^{3} \mathbf{k}\left(\mathbf{n} \mathbf{k}\left|\mathrm{H}_{\mathrm{o}}+\mathrm{U}(\mathbf{r})\right| \mathrm{mq}\right) \mathrm{A}_{\mathrm{m}}(\mathbf{q})=\mathrm{E} A_{\mathrm{n}}(\mathbf{k})
$$

onde $\left(\mathrm{nk}\left|\mathrm{H}_{0}+\mathrm{U}(\mathbf{r})\right| \mathrm{mq}\right)$ é a notaçäo para o elemento de matriz com respeito a funço $x_{\mathrm{r}}(\mathbf{r}, \mathbf{k})$, on sejs:

$$
\left(\mathrm{n} \mathbf{k}\left|\mathrm{H}_{0}+\mathrm{U}(\mathbf{r})\right| \mathrm{mq}\right)=\int \mathrm{d}^{3} \mathbf{r}{\ddot{x_{\mathrm{n}}}}^{*}(\mathbf{r}, \mathbf{k})\left[\mathrm{H}_{0}+\mathrm{U}(\mathbf{r})\right] x_{\mathrm{n}}(\mathbf{r}, \mathbf{k})
$$


O elemento de matriz para $\mathrm{H}_{0}$ é dado por:

$$
\begin{aligned}
& \left(\mathbf{n} \mathbf{k}\left|\mathrm{H}_{0}\right| \mathrm{mq}\right)=\int \mathrm{d}_{\mathrm{cela}}^{3} \mathbf{r} e^{-\mathrm{ik} \cdot \mathbf{r}} \mathrm{u}_{\mathrm{no}}^{*}(\mathbf{r}) \mathrm{H}_{\mathrm{o}} e^{-\mathrm{iq} \cdot \mathbf{r}} u_{\mathrm{mo}}(\mathbf{r})= \\
& =\int_{c \in l a}^{3} r e^{-i(q-k) \cdot r} u_{n k}^{*}\left[E_{m}+\frac{\hbar}{m_{0}} q \cdot p+\frac{\hbar^{2}}{2 m_{0}} q^{2}\right] u_{m o}
\end{aligned}
$$

onde $\mathrm{E}_{\mathrm{m}}=\mathrm{E}_{\mathrm{m}}(\mathrm{q}=0)$ é a energia no extremo da $\mathrm{n}$-ésima banda e $\mathrm{p}=-\mathrm{j} \hbar \mathrm{p}$ é operador de mamento. Uma vez que o fator que multiplica o termo exponencial do lado direito da eq. 4.19 é perídico na cela unitária, o memo argumento usado para mostrar a ortogonalidade da base nas eqs. 4.9 e 4.10 pode ser usado novamente, dá obtemas que:

$$
\begin{aligned}
& \left(n \mathbf{k}\left|H_{0}\right| m q\right)=\frac{(2 \pi)^{3}}{\Omega} \delta(\mathbf{k}-\mathbf{q}) \int d_{c=l a}^{3} u_{n k}^{*}\left[E_{m}+\frac{\hbar_{0}}{m_{0}} \mathbf{q} \cdot \mathbf{p}+\frac{\hbar^{2}}{2 m_{0}} q^{2}\right] u_{m a} \\
& =\delta(\mathbf{k}-\mathbf{q})\left[\left(\mathrm{E}_{\mathrm{m}}+\frac{\hbar^{2}}{2 \mathrm{~m}_{\mathrm{o}}} \mathrm{q}^{2}\right) \delta_{\mathrm{nm}}+\frac{\hbar_{\mathrm{m}}}{\mathrm{m}_{0}} \sum_{\alpha} k_{\alpha} \mathrm{P}_{\mathrm{nm}}^{\alpha}\right]
\end{aligned}
$$

onde a quantidade $\mathrm{p}_{\mathrm{nm}}^{\alpha}$, definida como:

$$
p_{n m}^{\alpha}=\frac{(2 \pi)^{\beta}}{\Omega} \int_{c=l a}^{\beta} d_{n o}^{*} u_{n}^{*}(\mathbf{r}) \stackrel{\hbar_{b}}{i} u_{m o}(\mathbf{r})
$$

é a elemento de matriz do momento entre as varias bandas do problema. Usaremos, daqui para frente, a convençăo da soma de Einstein no produto escalar da eq. 4.20 acima.

Uaando o memo procedimento para o elemento de matriz do potencial U(r), obtemos: 


$$
\begin{aligned}
& (\mathbf{n}|U| m q)=\int_{c \in l a} d^{3} r e^{-i(q-\mathbf{k}) \cdot \mathbf{r}} u_{n o}^{*}(\mathbf{r}) U(\mathbf{r}) u_{m o}(\mathbf{r}), \\
& \left(n \mathbf{k}\left|H_{0}\right| m q\right)=\sum_{j} \int_{c e l a} d^{3} r e^{-i(q-k) \cdot r} e^{-j G_{j} \cdot r} B_{j}^{m n} U(\mathbf{r}),
\end{aligned}
$$

e, pelos mesmos argumentos que levam à eq. 4.10, pademos escrever:

$$
\left(n \mathbf{k}\left|H_{0}\right| m q\right)=(2 x)^{3} \sum_{j} B_{j}^{m n} U\left(q-k-G_{j}\right),
$$

onde

$$
U(q)=\frac{1}{(2 \pi)^{3}} \int_{c=l a}^{3} \mathbf{r} e^{j q-r} U(\mathbf{r})
$$

Supondo que o potencial $U(\mathbf{r})$ é suave, ou seja, que varia pouco dentro da cela unitário, as componentes de Fourjer do potencial estarão quase todas concentradas dentro da primeira zona de Brillouin e apenas o termo $j=0$ será importante na soma da eq. 4.23. Temos portanto:

$$
\left(n k\left|y_{0}\right| m q\right)=(2-)^{3} B_{0}^{\mathrm{mu}} \mathrm{U}(\mathbf{q} \mathbf{k})=\delta_{\mathrm{nmi}} \mathrm{U}(\mathbf{q - k})
$$

Das eqs. $4.17,4.21$ e 4.25 temos a expressão final para a matriz do Hamiltoniano:

$$
\begin{aligned}
{\left[E_{m}+\frac{\hbar^{2}}{2 m_{0}} k^{2}\right] A_{n}(k) } & +\frac{\hbar}{m_{0}} \sum_{\alpha} k_{\alpha}^{p}{ }_{n m}^{\alpha} A_{m}(k)+\int d^{3} q U(k-q) A_{n}(q)= \\
& =E A_{n}(k)
\end{aligned}
$$

Observando esta equação vemos que ela não está em uma forma prática, já que, para tratarmos o efeito de perturbação sobre uma banda, devemos incluir todas as outras bandas através da soma em $p_{\mathrm{nm}}^{\alpha}$. Podemos portanto utilizar o mesmo métado usado no Cap. II para tratar o termo não-diagonal como perturbação e 
"renormalizar" o efeito destas bandas externas.

Seja $n$ a banda em que estamos interessados, O Hamiltoniano "renormalizado" será portanto do tipo:

$$
H_{n n}=H_{n n}^{o}+\sum_{i} \frac{H_{n i} H_{i n}}{E_{n i}-E_{j}}+\ldots
$$

onde

$$
\mathrm{H}_{\mathrm{ni}}=\frac{\hbar_{4}}{\mathrm{~m}_{0}} \mathrm{k}_{\alpha} \mathrm{p}_{\mathrm{nj}}^{\alpha}
$$

e, apbs a transformaçäo, obtém-se:

$$
\begin{aligned}
& {\left[E_{m}+\frac{\hbar^{2}}{2 m_{0}} k^{2}+\frac{\hbar^{2}}{m_{0}^{2}} k_{\alpha} k_{\beta} \sum_{m} \frac{p_{n m}^{\alpha} p_{m n}^{\beta}}{E_{n}-E_{m}}\right] B_{n}(k)+\int d^{3} q u(k-q) B_{n}(q)} \\
& =E B_{n}(k)
\end{aligned}
$$

Os coeficientes $B_{n}(\mathbf{k})$ săo abtidos pelo memo método, e são dados por:

$$
\mathrm{B}_{\mathrm{n}}(\mathbf{k})=\left[\delta_{\mathrm{mn}}+\frac{\hbar^{2}}{\mathrm{~m}_{\sigma}^{2}} \mathrm{k}_{\alpha} \mathrm{k}_{\phi} \sum_{\mathrm{m}} \frac{\mathrm{F}_{\mathrm{nm}}^{\alpha} \mathrm{E}_{\mathrm{m}}^{\beta}-\mathrm{E}_{\mathrm{m}}}{\mathrm{E}_{\mathrm{m}}}\right] A_{\mathrm{m}}(\mathbf{k})
$$

Comparando a expressä́ entre parênteses, na eq. 4.28, com a expanaăo de $E_{n}(k)$ em série de Taylor até $k^{2}$, em torno do minimo da banda,

$$
\mathrm{E}_{n}(\mathbf{k})=\mathrm{E}_{\mathrm{n}}(0)+\frac{1}{2 !} \frac{\partial^{2}}{\partial \mathrm{k}_{\alpha} \partial \mathrm{K}_{\beta}} \mathrm{E}_{n}(\mathbf{k}) k^{\alpha_{k} \beta}+O\left(\mathrm{k}^{4}\right)
$$

obtemos a regra da soma: 


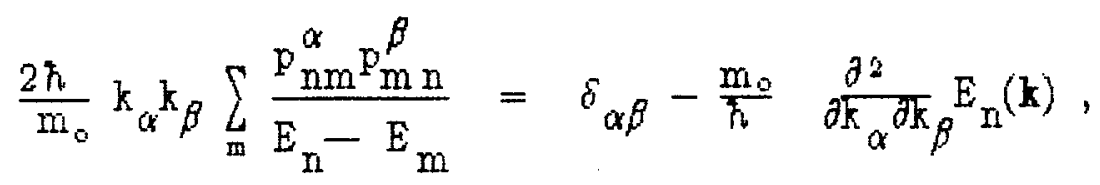

desta forma, apos a substituç̧̃o da eq. 4.31, podemos escrever a eq. 4.29 como:

$$
E_{n}(k) B_{n}(k)+\int d^{3} q U(k-q) B_{n}(q)=E B_{n}(k)
$$

Esta equação pade ser escrita no espaço real usando a definição da transformada de Fourier de $B_{n}(\mathbf{k})$ :

$$
F_{n}(r)=\frac{1}{(2 \pi)^{3}} \int d^{3} q u e^{i q-r} B_{n}(q)
$$

Multiplicando-se a eq. 4.33 por $\mathrm{e}^{-\mathrm{ik} \cdot \mathbf{r}}$ e integrando obtém-ke

$$
E_{n}(-i \hbar \nabla) F_{n}(k)+\int_{v o l}^{3} r \Delta\left(r-r^{\prime}\right) F_{n}(r)=E F_{n}(r)
$$

onde

$$
\Delta(\mathbf{r})=\frac{1}{(2 \pi)^{3}} \int_{\mathrm{d}=1 \mathrm{a}}^{3} \mathbf{q} e^{\mathrm{iq} \cdot \mathbf{r}}
$$

e a expressẵ $E_{n}(-i \hbar \nabla)$ significa que $\mathbf{k}$ deve ser substitudo pelo operador $-\mathrm{i} \boldsymbol{\nabla}$ na expansăo de $E_{n}(k)$. Além disso

$$
\int_{\mathbf{v} 01}^{3} \mathbf{r} \Delta(\mathbf{r})=1
$$

pois $\Delta(\mathbf{r})$ cai com $\mathrm{r}^{3}$ a grandes distancias. Uma vez que o único comprimento em $\Delta(\mathbf{r})$ deve ser o espaçamento da rede a, $\Delta(\mathbf{r})$ deve sex do tipo de una funçăo $\delta(\mathbf{r})$, de extensão - a. Desta forma em qualquer integral como a da eq. 4.35, onde $\Delta(\mathbf{r})$ é multiplicada por uma função que varia euavemente na cela unitária, $\Delta(\mathbf{r})$ se comportaré como uma fungáa delta de Dirac e podemos escrever: 


$$
E_{n}(-i \hbar \nabla) F_{n}(k)+U(r) F_{n}(r)=E F_{n}(r)
$$

que é análogo à equação de Schroedinger para uma particula movendo-ge em um potencial $U(\boldsymbol{r})$ e onde a energia cinética é dada pelo equaça da banda $E_{n}(\mathbf{k})$. Desde que, para $k-0, A_{n}(\mathbf{k})-B_{n}(\mathbf{k})$, o termo principal na função de onda aerá:

$$
\Phi(r)=\int d^{3} k B_{n}(k) e^{i k-r_{u}}(r)=F_{n}(r) u_{o, n}(r) .
$$

A eq. 4.38 não contem termos de acoplamento entre bandas de modo que, se estamos interessados em elétrons da banda de condução, podemos escrever a função de onda como:

$$
\Phi(\mathbf{r})=F(\mathbf{r}) \Phi_{n}^{c}(\mathbf{r}, \mathbf{0})
$$

onde $F(\boldsymbol{r})$ é a funçâa envelope e $\mathbf{I}_{\mathrm{n}}(\mathbf{r}, 0)$ é a função de onda do elétron no fundo da banda de conduçãa. Na fig. 4.1 a funçáo $\Phi(\mathbf{r})$ foi esquematizada para o caso de uma impureza em uma rede unidimensional. 


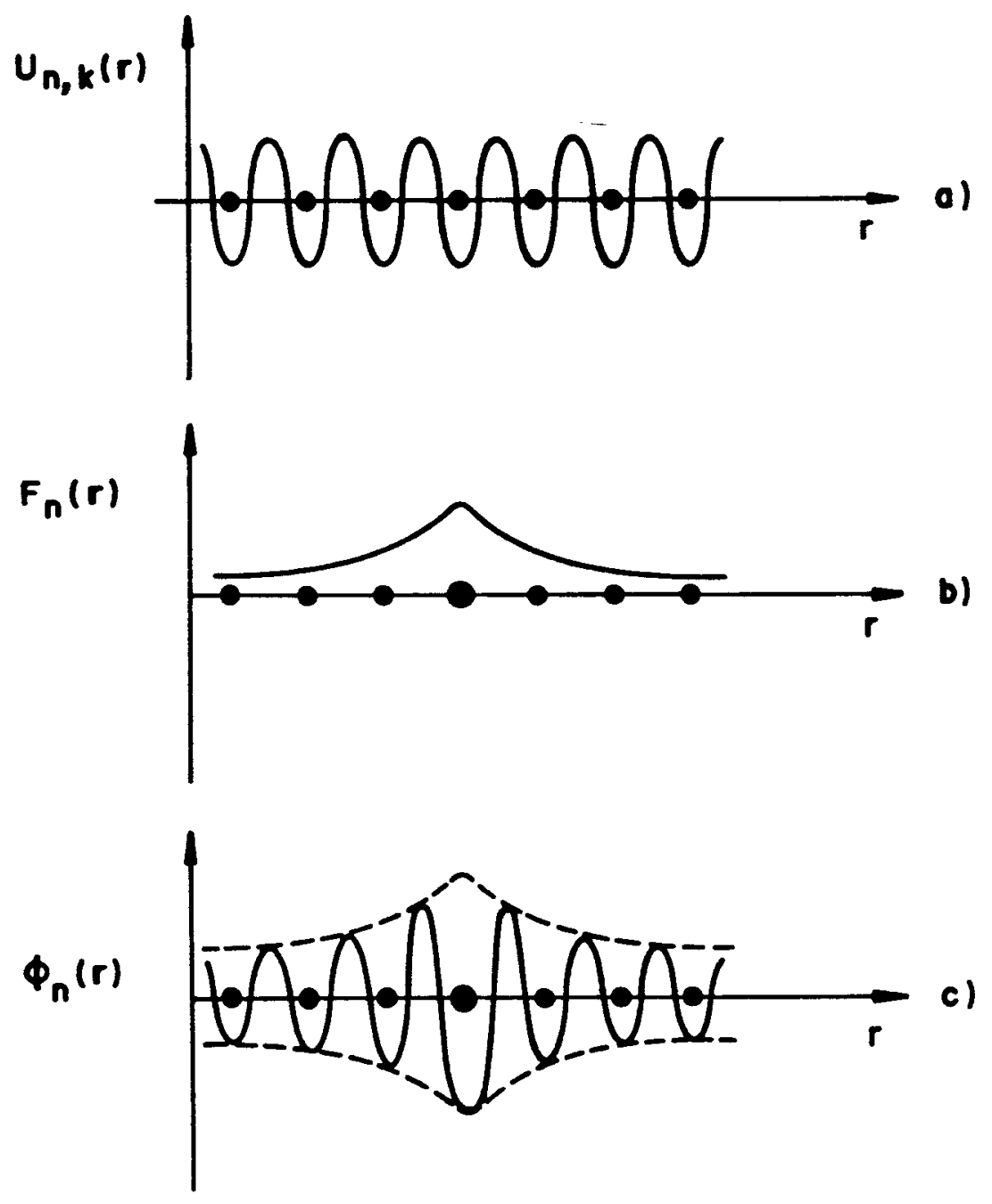

Fig. 4.1 : Função envelope para uma impureza em uma rede linear. Em a) é mastrado uma função típica de Bloch, cam a periodicidade do cristal, em b) a função envelope que é calculada da eq.4.38, e em c) a funçäo de onda total $\phi_{n}(\mathbf{r})=u_{n, 0}(\mathbf{r}) F_{n}(\mathbf{r})$ no cristal com o potencial perturbativo da impureza. 


\section{IV.3 - Banda Degenerada}

Passamos agora para o caso de uma banda degenerada com extremo em $\mathbf{k}=0$. Não levaremos em consideração o acoplamento spin-órbita que possa existir. Considere os estados $\mathbf{\Psi}_{j}(\mathbf{r}, \mathbf{k})$, todos cam a mesma energia em $\mathbf{k}=\mathbf{0}$ :

$$
H_{0} \mathbf{\Phi}_{j}(\mathbf{r}, \mathbf{k})=E_{j}(\mathbf{k}) \mathbf{\Phi}_{j}(\mathbf{r}, \mathbf{k})
$$

Por simplicidade consideraremos as outras funçôes que não são degeneradas também como $\Psi_{j}(\mathbf{r}, \mathbf{k})$ porém com $j>n$, onde $\Phi_{1}, \ldots, \Psi_{n}$ são as autofunç̧̋es degeneradas.

De maneira análoga a seção anterior, temos:

$$
\Phi(\mathbf{r})=\sum_{j} \int d^{3} \mathbf{r} \quad A_{j}(\mathbf{k}) x_{j}(\mathbf{r}, \mathbf{k})
$$

Se a perturbação for ainda $U(\mathbf{r})$ teremas:

$$
\sum_{\mathbf{m}} \int d^{3} \mathbf{q}\left(\mathbf{n k}\left|H_{0}+U(\mathbf{r})\right| \mathbf{m q}\right) A_{m}(\mathbf{q})=E A_{n}(\mathbf{k})
$$

Da mesma análise segue ainda que, para as funçôe degeneradas em consideraçăo:

$$
\begin{gathered}
{\left[E_{m}+\frac{\pi_{b}^{2}}{2 m_{0}} \mathbf{k}^{2}\right] A_{j}(\mathbf{k})+\frac{\hbar}{m_{0}} \sum_{j} k_{\alpha} \mathrm{F}_{j i}^{\alpha} A_{j}(\mathbf{k})+\int d^{3} \mathrm{q} U(\mathbf{k}-\mathbf{q}) A_{j}(\mathbf{q})=} \\
=\mathrm{E} A_{j}(\mathbf{k}) .
\end{gathered}
$$

deterrninado pelas $n$ funços degeneradas, obtemos, até segunda ordem em $\mathbf{k}_{4} 0$ Hamiltoniano:

$$
\sum_{j}\left[E_{0}+\frac{\hbar^{2}}{m_{0}} k^{2}\right] \delta_{j j}+\frac{\hbar_{0}^{2}}{m_{0}^{2}} k_{\alpha} k_{\beta}\left[\frac{E_{i j}^{\alpha} p_{j j}^{\beta}}{E_{0}-E_{j}}\right] B_{j}(k)+\int d^{3} q U(k-q) B_{i}(q)
$$




$$
=E B_{i}(\mathbf{k}) \text {. }
$$

Consideremos, por simplicidade, $E_{0}=0$ no fundo da banda, então podemos escrever:

$$
\sum_{j} D_{i j}^{\alpha \beta} k_{\alpha} k_{\beta} B_{j}(\mathbf{k})+\int d^{3} \mathbf{q} U(\mathbf{k}-\mathbf{q}) B_{i}(\mathbf{q})=E B_{i}(\mathbf{k})
$$

onde

$$
D_{i j}^{\alpha \beta}=\frac{1}{2 m_{0}} \delta_{i j^{\prime} \delta} \delta \beta+\frac{\hbar^{2}}{m_{\sigma}^{2}} \sum_{j} \frac{p_{i j}^{\alpha} p_{j j^{\prime}}^{\beta}}{E_{o}-E_{j}} .
$$

Os números $D_{j j}^{\alpha \beta}$ tomam o lugar da massa na teoria de bandas năo degeneradas. $\mathrm{E}$, uma vez que estes números padem ser determinados experimentalmente através das massas dos portadores, podemos usá-los para determinar o movimento de elétrons e buracos no caso degenerada.

Ueando a transformada de Fourier de $\mathrm{B}_{\mathrm{j}}(\mathbf{k})$, obtemos a equaçăo no espaço real:

$$
\sum_{j} D_{j}^{\alpha \beta}(-i \nabla)_{\alpha}(-i \nabla)_{\beta} B_{j}(k)+\int d^{3} q U(k-q) B_{j}(q)=E B_{i}(k)
$$

onde (iv) $\alpha$ é a componente $\alpha$ do gradiente.

$O$ termo principal da função de onda toma-se:

$$
\Phi(\mathbf{r})=\sum_{i} F_{i}(\mathbf{r}) x_{i}(\mathbf{r}, \mathbf{k})
$$

A quantidade de números $D_{i j}^{\alpha \beta}$ pode ser reduzida pelo uso de simetris. No caso do diamante, por exemplo, a banda de valência é descrita por apenas três paranetros $(7,8)$.

Todo 0 procedimento deste capitulo pode ser utilizado para deteminar o 
Hamiltoniano em qualquer ponto do expaco $\mathbf{k}$ com ou sem campo magnético(4), ou sern perturbação. Neste caso o Hamiltoniano é totalmente equivalente ao obtido da teoria k-p do Cap II. Reciprocamente o Hamiltoniano $4 \times 4$ do capitulo anterior pode ser usado para estudar estados de impurezas, niveis excitados, etc., em qualquer semicondutor do tipo Zinc-Blende.

Em qualquer dos casos um problema de muitos corpos, impossivel de resolver, é subetitufdo por um problema solúvel, mas diffcil, já que se trata de um sistema de equaçzes diferenciais de segundo eron acopladas.

T.4 - Condição de Contorno da Função Envelope

o problema principal no uso da teoria da função envelope para o estudo da estrutura eletrónica de heteroestruturas é o problema da condição de contorno para as furçães envelopes na interface semicondutora. A principio, para resolver este problema, devernos conhecer as funçzes de Bloch em cada semicondutor que compóem a interface. Isto requeriria o uro de algum método para o cálculo da estrutura eletrónica de cada cristal, e tornaria o método da função envelope muito complicado. Pode-se fazer uma aproximaçăo, considerando, por exemplo, que estas funçöes de Bloch săo idênticas em cada material, e entäo calcular os elementos de matriz necessários nesta base. Consideraremos, entretanto, uma abordagem diferente ${ }^{(9)}$. Em cada cela unitária escolhe-se uma base de funçöes ortogonais, a abtêm-se as condiçóe de contorno de forma a satisfazer a conservaçä́ de corrente mediada nas celas. Nos veremos que a únjca exigência, neste caso, será que as funçбes de Bloch em cads cristal estejan em correspondência unívaca.

Consideremos a seguinte hipótese para a funçấo de onda total:

$$
\Phi^{\dot{j}}(\mathbf{r})=\sum_{j} F_{j}^{\dot{j}}(\mathbf{r}) X_{i}^{\dot{i}}(\mathbf{r}, \mathbf{k})
$$

ande $j$ é 0 indice para a cela unitáris, $j$ rotula as bandas e $F_{j}^{j}$ e $\chi_{j}^{i}$ säo análogas as funçêes das seçōes anteriores. $O$ conjunto $\left\{x_{j}\right\}$ de soluçbes em uma cela unitária é equivalente a qualquer cutro conjunto $\left.\left\{x_{j}\right\}^{j}\right\}$ no sentido que, se o potencial cristalino 
$\mathrm{U}\left(\mathbf{r}^{\mathrm{i}}\right)$ (valor do potencial perturbativo no centro da cela unitária) variar continuamente até o valor $U\left(\mathbf{r}^{j}\right)$, na paseagem da cela unitãria $i$ para a cela $j$, estas funçôs transformar-se-ão umas nas outras, $e$ as energias $\left\{\mathrm{E}_{n}^{i_{1}}\right\}$ do fundo de cada banda $n$ também transformar-se-ão nas energias $\left\{\mathrm{E}_{\mathrm{n}}^{\mathrm{j}}\right\}$.

Da definição da função de onda na eq. 4.50 acima, obtemos a corrente coma:

$$
\mathrm{J}(\mathbf{k})=\frac{\hbar}{2 \mathrm{i} \mathrm{m}_{0}}\left[\Phi^{\mathrm{i} *}(\mathrm{r}) \nabla^{\mathrm{i}}(\mathbf{r})-\left(\nabla^{\mathbf{i}^{*}}(\mathbf{r})\right) \Phi^{\mathrm{i}}(\mathrm{r})\right]
$$

Esta nấo é a forma necessária para o caso da funçăo envelope, uma vez que a teoria descreve eventos em regióes de comprimento maior que o parâmetro de rede. No noseo caso, o que precisamos é da média da corrente na cela unitária. Usando a ortogonalidade das funçoes $\chi_{j}^{i}(\mathbf{r})$ como:

$$
\left(x_{m}^{i} \mid x_{n}^{i}\right)=\delta_{n m} \Omega^{i}
$$

onde $g^{i}$ é a volume de cela unitária, obtemos para a média da corrente por cela unitária:

$$
\langle\mathrm{J}(\mathbf{k})\rangle=\frac{\hbar}{2 i \mathrm{mi}_{0}}\left[\sum_{j} \mathrm{~F}_{j}^{\mathrm{j}^{*}}(\mathbf{r}) \nabla \mathrm{F}_{j}^{\mathrm{i}}(\mathbf{r})+\sum_{j j} \mathrm{~F}_{j}^{\mathrm{j}^{*}}(\mathbf{r}) \mathrm{P}_{j j^{\prime}}^{\mathrm{i}} \mathrm{F}_{j}^{\mathrm{i}}(\mathbf{r})\right]+c . c
$$

onde c.c. indica a complexo conjungado da expressão dos dois termos entre chaves, e $P_{j}^{i}$ t tem uma definiçăo modificado, tal que:

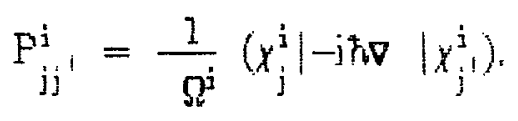

Dentro da aproximaçấo de funçăo enveloge á a eq. 4.53 que deve ser conservada na interface. O memo é verdadeiro para a média da densidade de probabilidade em cada cela unitáris: 


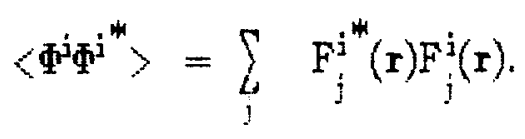

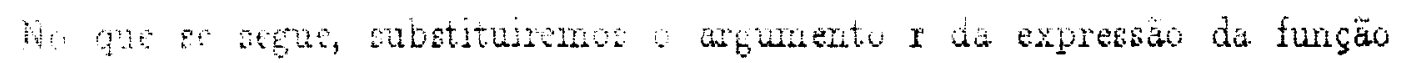
envelope pelo vetor de posição do centro da cela unitária $\mathbf{r}^{\mathfrak{j}}$.

Em cada cela unitária consideramos o Hamiltoniano $\mathrm{H}_{0}$ como sendo apenas o termo cinético e obtemos o sistema acoplado de equações diferencjais para a função envelope:

$$
\left[E_{n}^{i}-E-\frac{\hbar_{k}^{2}}{2 m_{0}} \nabla^{2}\right] F_{j}^{i}\left(r^{i}\right)+\frac{\hbar_{h}}{2 m_{0}} \sum P_{j m}^{i} \nabla F_{m}^{i}\left(r^{i}\right)=0
$$

Esta é a meama equação que já obtivemos anteriormente (eq. 4.26), mas em uma base ligeiramente diferente. $E_{n}^{i}$ é a energia do fundo da banda ascociada com a funçăo $x_{n}^{i}$. Se o indice $i$ variar continuamente através da interface como funçăo da distribuição espacial de dopante, as funçбes de base passam a variar espacialmente e, desta forma, os elementos de matriz passam a depender da posiçä́. Assumindo a variaçăo apenas na direçấo $z$, o indice $j$ pode ser substituido pela variável $z$. Ascim, o termo $P_{j j}^{j}$ ra eq. 4.56 pasea a depender da posição e a equação deixa de ser hermitiana. Nós devemos achar, portanto, um procedimento para "re-quantizar" o Hamiltoniano da eq. 4.56. Este problema ainda é discutido na literatura e vários processos empiricos $(10)$, e semi-empíricos $(11)$, foram inventados. Nós usaremos uma regra criada por $\mathrm{H}$. Weyl ${ }^{(12)}$ que pode ser colocada da seguinte forma: para quantizar um Hamiltoniano que coneiste da soms de vários produtos dos operadores $\hat{x}$ e $\hat{p}$ devemos tornar esta soma a mas simétrica possivel nestes operadores. No nosso caso, obtemos:

$$
\left[E_{n}^{i}-E \frac{n^{2}}{2 m s} \nabla^{2}\right] F_{j}(z)+\frac{\hbar_{4}}{m m_{0}} \sum\left[\frac{d}{d z} P_{j m}(z)+P_{j m}(z) \frac{d}{d z}\right] F_{m}(z)=0
$$

A condiçăo de contorno pode ser, entăo, obtida integrando-se esta equação através da interface, que suporemos em $2=0$. Após a integraçấ, obtemos: 


$$
\lim _{\varepsilon \rightarrow 0}\left[\frac{d}{d z} F_{j}(z)+\frac{\hbar}{i m_{0}} \sum_{m} P_{j m}(z) F_{m}(z)\right]=0
$$

Esta é a condição que obteriamos se impuséssemos a continuidade de corrente:

$$
\langle\mathrm{J}(-\varepsilon)\rangle=\langle\mathrm{J}(\varepsilon)\rangle
$$

onde

$$
\langle\mathrm{J}(\mathrm{z})\rangle=\frac{\hbar_{\mathrm{h}}}{2 \mathrm{~m} \mathrm{~m}_{\mathrm{o}}}\left[\sum_{\mathrm{j}} \mathrm{F}_{\mathrm{j}}(\mathrm{z})\left[\frac{\mathrm{d}}{\mathrm{d} z} \mathrm{~F}_{\mathrm{j}}(\mathrm{z})+\sum_{\mathrm{m}} \mathrm{P}_{\mathrm{jm}}(\mathrm{z}) \mathrm{F}_{\mathrm{m}}(\mathrm{z})\right]+c . c .\right.
$$

Portanto o Hamiltoniano, simetrizado camo acime, satisfaz a condjção de continuidade da corrente de probabilidade. Na caso de uma banda não-degenerada a condiçâo de contorno será dada por:

$$
\left.\frac{1}{m_{A}} \frac{d}{d z} F(z)\right|_{-\varepsilon}=\left.\frac{1}{m_{B}^{*}} \frac{d}{d z} F(z)\right|_{+\varepsilon}
$$

onde $m_{A, B}^{*} \dot{z}$ a massa efetiva da região respectiva e $F(z)$ a funçăo envelope.

Em muitos trabalhos sobre heteroestruturas, que utilizam a aproximação de funç̧o envelope, esta condiçấo de contomo năo é usada e é comum considerar as mases iguais entre as interfaces. Em alguns materiais esta aproximaçấo pode até ser adruitida, mas en materias, como interface $\mathrm{HgCdTe}-\mathrm{HgOdSe}$, pode ocorrer uma inversấo do tipo de portador (elétron + buraco ), causando uma diferença de sinal na eq. 4.61, e a funçấo envelope estaria totalmente errada se năo considerásemos esta equação de contimuidade.. 


\section{CAPFTULO $\mathrm{V}$ \\ METODO AUTOCONSISTENTE PARA $O$ \\ CALCULO DE BANDAS DE ENERGIA}

V.1 - Intradução

Neste capitulo, especificamente na seção V.2, nós resumiremos of resultados dos capitulas anteriores em um métado numérico para o cálculo da estrutora eletrónica em poços quânticos dopados.

$\mathrm{Na}$ seção V.3, nós discutiremos o método no caso de bandas razias para esclarecer pontos relativos a expansão em bases ortogonais, condição de contorno das funçzes de base, limites de validade do métado, etc. Na seção V.4, analisaremos a solução do prablema de poços dopados através de métodos.

V.2 - Expansão em Funçzes Ortogonais

O cálculo da estrutura eletrônica em paços quânticos pode ser colocada da seguinte maneira: assume-se que os materiais que compoem a sistema padem ser descritas pelo Hamiltoniano da eq. 3.41 e, ueando a resultado do Cap. IV, substituímos $\mathrm{k}_{\mathrm{z}}$ por $-\mathrm{i} \frac{\mathrm{d}}{\mathrm{dz}}$, para obtermos o sistema de equaçžes diferenciais para a função envelope em um paço quântico:

$$
\left[\mathbf{H}^{i}\left(\frac{d}{d z}, \mathbf{k}\right)+\delta E_{\nu}(z) I\right] A=E A
$$

onde $\mathrm{i}=$ paço, barreira, $\delta \mathrm{E}_{y}(\mathrm{z})$ é a potencial para os portadores (Apêndice $\mathrm{A}$ ), I é a matriz unitária $4 \times 4$ e $\mathrm{H}^{\mathrm{i}}$ é a matriz dada por: 


$$
H^{i}=\left[\begin{array}{cccc}
D_{21} & P_{1} & P_{2} & P_{3} \\
P_{1} & I_{h h} & L_{1} & L_{2} \\
P_{3} & L_{1}^{*} & D_{1 h} & Q_{1} \\
P_{3} & L_{2}^{*} & Q_{1}^{*} & D_{: 0}
\end{array}\right]
$$

onde

$$
\begin{aligned}
& \mathrm{P}_{1}=-\frac{1}{\sqrt{2}}-\mathrm{Pk} \\
& P_{2}=-\sqrt{\frac{2}{3}} P i \frac{d}{d z}-i-\frac{1}{\sqrt{6}} P k \\
& \mathrm{P}_{3}=\frac{1}{\sqrt{3}}-\mathrm{P} \mathrm{i} \frac{\mathrm{d}}{\mathrm{d} z}-\mathrm{i}-\frac{1}{\sqrt{3}}-\mathrm{Pk} \\
& \mathrm{L}_{1}=-\sqrt{3} 7 \mathrm{k} \mathrm{i} \frac{\mathrm{d}}{\mathrm{dz}}-i \frac{\sqrt{3}}{2} \mathrm{k}^{2} 7(\theta) \\
& \mathrm{L}_{\mathrm{z}}=\sqrt{\frac{3}{2}} \gamma_{\mathrm{a}} \mathrm{k} i \frac{\mathrm{d}}{\mathrm{d} z}-i \sqrt{\frac{3}{2}} k^{2} \gamma(\theta) \\
& Q_{1}=-\sqrt{2} 7_{2}\left(\frac{d^{2}}{d z^{2}}+2 k^{2}\right)+\frac{3}{\sqrt{2}}-7_{3} k \frac{d}{d z} \text {. } \\
& D_{01}=E_{p}+(F+1 / 2)\left(k^{2}-\frac{d^{2}}{d t^{2}}\right) ; k^{2}=k_{z}^{2}+k_{y}^{2} \\
& D+=-\left(\gamma_{1}+\gamma_{2}\right) \mathrm{x}^{2}+\left(\gamma_{1}+2 \gamma_{2}\right) \frac{\mathrm{d}^{2}}{\mathrm{da}} \mathrm{g}^{2}, \\
& \mathrm{D}_{\mathrm{s} o}=-\Delta-\frac{z_{1}}{2}\left(\mathrm{k}^{2}-\frac{\mathrm{d}^{2}}{\mathrm{~d} \mathrm{~g}^{2}}\right)
\end{aligned}
$$

e os parámetros $\mathrm{E}_{\mathrm{g}}, \Delta, 7_{1}, 7_{2}, \gamma_{3}$ e $\mathrm{F}$, são todos dependentes do indice $\mathrm{i}$ referente ao poço ou à barreira.

Existem duas maneiras de se resolver este sistema de equaços. O primeiro consiste em escrever as funçöes envelope, em cada regiăo, como uma combinaçán linear de funçōes do tipo ondas planas e casar as soluçoes nas interfaces, usando a condição de contorno. Com isto, obtém-se um sistema de equaçôes lineares para os coeficientes da expaneão as energias acto obtides através das raiges de equaçäes transcedentais.

outro método consiate na expansăo das funçäes envelape ern alguma base 
ortagonal de funçzes, análogo ao método de combinaçóes lineares de orbitais atômicos (LCAO) da fisica molecular. As energias e autofunçóes săo abtidas da matriz do Hamiltoniano gerada pelo método. Optamos, neste trabalho, por uma abordagem numérica baseada na expansão da colução em uma base apropriada.

Analisemos a função de anda deste Hamiltoniano. Trata-se de um sistema de equaçõe diferenciais cuja solução é escrita como um vetor com quatro componentes:

$$
A(z)=\left[\begin{array}{l}
A_{1}(z) \\
A_{2}(z) \\
A_{3}(z) \\
A_{4}(z)
\end{array}\right]
$$

onde 0 indice 1 indica elétrons, 2 'heavy-hole', 3 'light-hole' e 4 'split-off'. Esta é a forma da solução do sistema de equaçðé diferenciais, mas năo é a função envelope para o sistema que estamos estudando. Como o Hamiltoniano original tem uma degenerescencia de spin, que foi resolvida através da bloco-diagonalização (seção III.6), noseos estados săo 8-dimensionas. Portanto, o vetor da eq. 5.2 nada mais é que um conjunto de componentes nấ-nulas deste vetor de dimensão 8 , que pode ser escrito como:

$$
A(z)=\left[\begin{array}{c}
A_{1}(z) \\
A_{2}(z) \\
A_{3}(z) \\
A_{4}(z) \\
0 \\
0 \\
0 \\
0
\end{array}\right]
$$

onde os $A_{j}(z)$ säo soluçöes do Hamiltoniano do bioco superior. Analogamente, temos para as aluçose do bloco inferior: 


$$
A(z)=\left[\begin{array}{c}
0 \\
0 \\
0 \\
0 \\
A_{5}(z) \\
A_{6}(z) \\
A_{7}(z) \\
A_{8}(z)
\end{array}\right] .
$$

Nós chamaremos estas saluçăes, de maneira informal', coma solução 'spin' para cima (eq. 5.3) e soluçãa 'spin' para baixo (eq. 5.4).

A função de anda do sistema pode ser descrita usando-se a definição de função envelope cama:

$$
\mathbf{u}_{\mathbf{k}, \mathbf{n}}(\mathbf{r}, \mathbf{z})=\sum_{j=1}^{8} A_{\mathbf{k}}^{\mathrm{n}, \mathrm{j}}(\mathbf{z}) \mathrm{e}^{\mathrm{jk} \cdot \mathbf{r}} a_{0, j}(\mathbf{r}, \mathbf{z})
$$

ande $j$ é a indice da banda cuja representaçãa é a funçâa de Blach $u_{a j}(\mathbf{r}$ ) (dadas pelas transformaçzes das eqs. $3.32 \mathrm{a}$ e $3.32 \mathrm{~b}$, para a nova base), $\mathbf{k}$ o momento cristalino da partícula, $\mathbf{r}$ o vetor de posição no plano do poço e a a direção de crescimento do poço. $n$, além de ser a indice da soluçãa da equação diferencial 5.1, também é a indice das sub-bandas criadas pelo canfinamenta. Na eq.5.5, a dependência da solução com a vetar de onda $\mathbf{k}$ está indicada explicitamente.

As soluções de spin para cima e spin para baixo estão relacionadas entre aj pelo operadar de inversão temporal, discutida na seção III.5, tal que

$$
\hat{\mathrm{K}}=-\mathrm{i} \sigma_{\mathbf{y}} \hat{\mathrm{C}} \dot{\mathrm{J}}
$$

de forma que, abtendo-e as saluç̧es para o blaco superior, as do bloco inferior são abtidas pela aplicação deste operador ao vetar da eq. 5.3. Isto é equivalente a dizer que a solução geral da eq.5.3 é invariante sabre inversăo temparal. Aplicando o operador, obtemos a seguinte relação entre as componentes:

1A bloco-diagonalização é obtida de uma combinação de estados de spin $\left|j, m_{j}\right\rangle$, de modo que os estados obtidos não possuem spin definido. 


$$
A_{\mathbf{k}}^{n, j+1}(z)=A_{\mathbf{k}}^{n, j^{*}}(-2) \quad i=1,2 \ldots 1
$$

Nós usaremos esta relação posteriormente.

A solução por ondas ortogonais é feita escollhendo-se quatro conjuntos de funçбes de base, sendo um conjunto de funçốes para expandir a solução de elétron e outros três pará as soluçōes de buracos. Explicitamente, escrevemos as funçžes envelopes como:

$$
\mathrm{A}_{\mathrm{k}}^{\mathrm{n}, \mathrm{j}}(\mathrm{z})=\sum_{\mu, \mathrm{n}} \mathrm{C}_{\mu, \mathrm{k}}^{\mathrm{j}}\left(\mathbf{\varphi}{ }_{\mu}^{\mathrm{j}}(\mathrm{z})\right.
$$

onde $j=1,2,3$ e 4 , corresponde a eletrons e buracos, $\mu=1,2, \ldots, N$, onde $N$ é númera de bases usadas para a expansãoª e $\varphi_{\mu}^{j}(z)$ săo as $N$ funçžes de base para o portador $j$, que devem obedecer a relação de ortagonalidade:

$$
\int \varphi_{\mu}^{j}(z) \varphi_{\nu}^{j}(z) d z=\delta_{\mu, \nu},
$$

e ainda

$$
\int \varphi_{\mu}^{\mathrm{i}}(\mathrm{z}) \varphi_{\mu}^{\mathrm{j}}(\mathrm{z}) \mathrm{d} \mathrm{z} \neq 0
$$

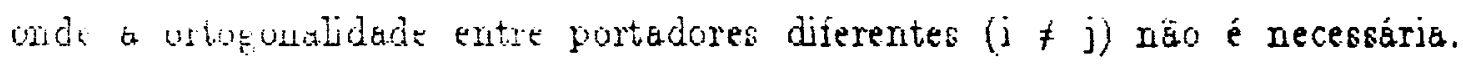

Eliminaremos of Indices $\mathbf{k}$ e $\mathrm{I}$, por um instante, para simplificar a notação. Escrevendo nosso sistema de equaçôes diferenciais original camo:

$$
\sum H_{j j} A^{j}(z)=c A^{i}(z)
$$

onde os $\mathrm{H}_{i j}$ são os elementos de matria, dados pelo Hamiltoniano da eq. 5.1, e

${ }^{2}$ Nos iremos usar, em todo o capitulo, um quantidade grande de indices, par isso adotamos a seguinte notação: para ídices de sub-bandas usaremos as letras $m$ ou $n$, para portadores, as letras j e j, e para indices das funçaes de base, as letras gregas. 
substituindo a expreseão para $\mathrm{A}^{j}(\mathrm{z})$ da eq. 5.8 na eq. 5.10 , obtém-se:

$$
\sum_{j} \mathrm{H}_{\mathrm{jj}} \mathrm{O}_{\mu}^{\mathrm{j}} \varphi_{\mu}^{\mathrm{j}}(\mathrm{z})=\epsilon \sum_{\nu} \mathrm{\sigma}_{\nu}^{\mathrm{i}} \varphi_{\nu}^{\mathrm{j}}(\mathrm{z})
$$

Multiplicando-se em seguida a eq. 5.11 por $\varphi_{\mu}^{j *}(z)$ e integrando:

$$
\sum_{j} \mathrm{H}_{\mathrm{i}}^{\mu}{ }_{\mathrm{j}}^{\nu} \mathrm{O}_{\mu}^{\mathrm{j}}=i \mathrm{C}_{\nu}^{\mathrm{j}}
$$

ande

$$
\mathrm{H}_{\mathrm{i}}^{\mu \nu}=\int \varphi_{\mu}^{\mathrm{j}}(\mathrm{z}) \mathrm{H}_{\mathrm{j} j} \varphi_{\mu}^{\mathrm{j}}(\mathrm{z}) \mathrm{dz}
$$

obtérn-se uma equação de autovalores algébrica em substituição ao sistema diferencial anterior. Da mesma forma que antes, conhecendo-se os autovetores $\sigma_{\mu, n}^{j}(\mathbf{k}) d a$ soluçấo para o Hamiltoniano do bloco superior, podemos obter os autovetores do Hamiltoniano do bloco inferior:

$$
\mathrm{C}_{\mu, \mathrm{n}}^{\mathrm{j}+4}(\mathbf{k})=(-1)^{\mathrm{j}} \mathrm{C}_{\mu, \mathrm{n}}^{\mathrm{j}}(\mathbf{k}) \quad \mathrm{j}=1, \ldots 4 \text { e } \mathbf{k}>0
$$

ou

$$
\mathrm{C}_{\mu, \mathrm{n}}^{\mathrm{j}+4}(0)=\mathrm{C}_{\mu, \mathrm{n}}^{\mathrm{j}}(0) \quad \mathrm{j}=1, \ldots 4
$$

A principio, a escolha das funç̧es de base $\varphi_{\mu h}^{j}(a)$ é arbitrária, Fode-ce, por exemplo, escolher-se gaussianas ou ondas planas. Mas, quanto majs semelhantes à funçấo original forem as funçbes de base, menos termos serão necessários na soma para se atingir uma boa aproximagão, e a calculo numérico será grandemente reduzido. Assim, as $N$ primeiras soluçes da equaçón de Schroedinger para uma particula presa em um pogo finito, isto $\dot{e}$ 


$$
-\frac{\hbar^{2}}{2 \mathrm{~m}_{\mathrm{i}}} \frac{\mathrm{d}^{2}}{\mathrm{dz} \mathrm{z}^{2}} \varphi_{\mu}^{\mathrm{j}}(\mathrm{z})+\mathrm{V}_{\mathrm{j}}(\mathrm{z}) \varphi_{\mu}^{\mathrm{i}}(\mathrm{z})=\epsilon_{\mathrm{i}} \varphi_{\mu}^{\mathrm{j}}(\mathrm{z}) \quad \mathrm{i}=1, \ldots, 4
$$

onde $\mathrm{m}_{\mathrm{i}}^{*}$ é a massa efetiva do j-ésimo portador, foram escolhidas para compor nossa base. Aqui, no entanto, surge um problema. O espectro da eq. 5.15 é formado por uma parte discreta e ums parte continua de modo que, se quisermos ums base com oito funç̧es e se, das soluç̧es da eq. 5.15, apenas três fizerem parte do espectro discreto, nós ficamos com o problema de escolher cinco soluçós do espectro contínuo. Resolvemos este problema confinando o poço finito em uma caixa de potencial infinito, como na fig. 5.1. Esta é uma maneira de simular o espectro contínuo do problema, mas que nos restringirá a consideraçóes sobre os estados ligados do poço $e$ à energias inferiores ao gap do material da barreira, quando analisarmos as bandas de energia ( fig. 5.2 ).

Impomos ainds, sobre as soluçäes da eq. 5.15, a condição de continuidade de corrente, na interface do poço com a barreira:

$$
\left.\frac{1}{\mathrm{~m}_{\mathrm{j}}} \frac{\mathrm{d}}{\mathrm{d} z} \varphi_{\mu}^{\mathrm{j}}\right|_{+}=\left.\frac{1}{\mathrm{~m}_{\mathrm{j}}} \frac{\mathrm{d}}{\mathrm{d} z} \varphi_{\mu}^{\mathrm{j}}\right|_{-}
$$

ańloga à condiçăo de continuidade da funçăo envelope em uma banda nä́ degenerada. Isto é feito, a principio, para se assegurar a conservaça de corrente na estrutura, e tem a vantagem adicional de criar uma descontinuidade na derivada das funçose de base que tambem existe na funçă envelope. Se usásemos uma base continua de funçôes, teriamos que incluir un grande numero de funçōes para cobrir o comportamento da funçăo envelope.

A eq. 5.15 possui soluçáo analítica para o potencial dado na fig. 5.1. Com esta base analitica é possivel calcular os elementos de matriz do Hamiltoniano araliticamente. Observando o Hamiltoniano da eq. 5.1 , vemos que é necessário apenas calcular as seguintes integrais: 


$$
\begin{aligned}
& \mathrm{S}_{\mathrm{j}}^{\mu}{ }_{\mathrm{j}}=\int \varphi_{\mu}^{\mathrm{j} *}(\mathrm{z}) \varphi_{\mu}^{\mathrm{j}}(\mathrm{z}) \mathrm{dz}, \\
& D \varepsilon_{\mathrm{j}}^{\mu \nu}{ }_{\mathrm{j}}^{\nu}=\int \varphi_{\mu}^{\mathrm{j}}(\mathrm{z}) \frac{\mathrm{d}}{\mathrm{d} z} \varphi_{\mu}^{\mathrm{j}}(\mathrm{z}) \mathrm{d} z \text {, } \\
& \mathrm{D} 2 \mathrm{~s}_{\mathrm{i}}^{\mu}{ }_{\mathrm{j}}^{\nu}=\int \varphi_{\mu}^{\mathrm{i} *}(\mathrm{z}) \frac{\mathrm{d}^{2}}{\mathrm{dz}^{2}} \varphi_{\mu}^{\mathrm{j}}(\mathrm{z}) \mathrm{d} \mathrm{z} \text {, }
\end{aligned}
$$

para obtermos o Hamiltoniano para o cálculo da estrutura eletrônica. Se o potencial da fig. 5.1 näo tivesse soluçä́o analítica, terímos que resolver a eq. 5.15 e calcular as integrais das eq. 5.17 numericamente, salvando os resultados em arquivos para usar na montagern do Hamiltoniano. Isto envolveria uma grande quantidade de memória.

\section{V.2 - Cálculo Autoconsistente}

Nesta seção analisaremas o cálculo autoconsistente dentro da aproximaçấo de função envelope. Discutiremos como se escreve a densidade de cargas, urando a função envelope da eq. 5.5 e a expansão em funçóes de base da eq. 5.8, e como se inclui o potencial eletrostático resultante, no Hamiltoniano da eq. 5.12.

Consideremos a funçăo de onda total, dada pela eq. 5.5 , escrita de forma simplificada, como:

$$
\mathbf{\Psi}(\mathbf{r})=\sum_{j} F_{j}(\mathbf{r}) \mathrm{u}_{j}(\mathbf{r})
$$

onde

$$
F_{j}(r)=\frac{1}{\sqrt{5}} e^{i k \cdot \rho} A_{j}(z)
$$

é a funçán envelope, $s$ a área do poço, $\rho=(x, y, 0)$ o vetor de posicán no plano do poso e z a coordenada na direçáa de crescimento do poço. A probabilidade de encontrarmos um elétron ne posiçăo $\mathbf{I}$ é dada por: 


$$
|\mathbf{I}(\mathbf{r})|^{2}=\sum_{i} \sum_{j} F_{i}^{*}(\mathbf{r}) F_{j}(\mathbf{r}) u_{i}^{*}(\mathbf{r}) u_{j}(\mathbf{r})
$$

A integral desta probabilidade sobre o volume do cristal deve ser jgual a um, isto é, a função da eq. 5.18 deve ser normalizada:

$$
\int_{v o l}|\mathbf{I}(\mathbf{r})|^{2} d^{3} \mathbf{r}=\int_{v 01} d^{3} \mathbf{r} \sum_{i} \sum_{j} F_{j}^{*}(\mathbf{r}) F_{j}(\mathbf{r}) u_{j}^{*}(\mathbf{r}) u_{j}(\mathbf{r})=1
$$

Esta integral sobre o volume pode ser dividida em $\mathrm{N}$ integrais sobre a cela unitária e, dentro do espirito da aproximação de função envelope, podemos aproximar o valor de $F_{j}(r)$ na cela pelo seu valor no centro da cela, que chamaremos $F_{j}(r)$, ande $m$ é - Indice da cela. Fazendo uso da ortogonalidade das funçðes de Bloch na cela unitária, podemos escrever a integral da eq. 5.21 como:

$$
\sum_{m} \sum_{i, j} F_{j}^{*}\left(r_{m}\right) F_{j}\left(r_{m}\right) \int_{v o l} d^{3} r u_{j}^{*}(r) u_{j}(r)=\sum_{i, m}\left|F_{j}\left(r_{m}\right)\right|^{2},
$$

usando a eq. 5.21 e aproximando a soma cobre as celas unitárias par uma integral no volume do cristal, abtém-se:

$$
\sum_{i, m}\left|F_{i}\left(r_{m}\right)\right|^{2} \cong \int_{v o l} d^{3} r F_{j}^{m}(r) F_{j}(r)=1
$$

Portanto, a condição necessária para a normalização da função de onda da eq. 5.18 é a normalização da função envelope.

Se existirem $N$ partadores ocupando a paça, da condição que fixa a nivel de Fermi, temos a equação:

$$
\left.\sum_{0 \text { upp }} \int_{v o 1} d^{3} \mathbf{r} \mid \mathbf{r}\right)\left.\right|^{2}=N=\int_{v o l} d^{3} \mathbf{r} n(\mathbf{r}),
$$

onde $\mathrm{n}(\mathbf{r})$ é a densidade volumétrica de partadares, $e$ a soma sobre os estados ocupados inclui of níreis, of estados de momento do portador e o 'spin'. Comparando a eq. 5.24 com a eq. 5.23, podemas escrever a jdentidade: 


$$
\int_{\text {vol }} d^{3} r(r)=\sum_{\operatorname{dup}} \int_{\text {vol }} d^{3} \mathbf{r} \sum\left|F_{i}(r)\right|^{2}
$$

de ande obtemas:

$$
\mathrm{n}(\mathbf{r})=\sum_{\operatorname{atup}} \sum_{j}\left|\mathrm{~F}_{\mathrm{j}}(\mathbf{r})\right|^{2}
$$

Usanda a expressão da eq. 5.19 para a função envelope, encontramos finalmente a densidade de carga $\rho(\mathbf{r})$, criada pelos $\mathrm{N}$ portadores,

$$
p(z)=-\frac{g}{S} \sum_{\text {ocup }} \sum_{i}\left|A_{j}(x)\right|^{2}
$$

Retornando a notação da eção anterior para a função envelope dada pela eq. 5.5, escrevemos a densidade de carga, definitivamente, como:

$$
\rho(\mathbf{r})=\frac{\mathrm{g}}{\mathrm{S}} \sum_{\mathbf{n}, \mathbf{k}} \sum_{\mathrm{i}}\left|\mathrm{A}_{\mathbf{k}}^{\mathrm{n}, \mathrm{i}}(\mathbf{z})\right|^{2}
$$

onde $A_{\mathbf{k}}^{n, j}(z)$ é a função envelope.

De passe desta densidade de carga, resolvemos numericamente a equação de Poisson,

$$
\frac{d^{2}}{d z^{2}} U(z)=-\frac{4 \pi q^{2}}{x} \frac{1}{S} \sum_{n, k}\left\{\left|A_{k}^{n, i}(z)\right|^{2},\right.
$$

usando as condiçōes de contorno dadas no apêndice $A$, e obtemos o patencial criado pelos portadares. O Hamiltaniano da eq. 5.10 tarna-se:

$$
\xi\left[H_{i j}+\delta_{i j} U(z)\right] A_{j}(z)=\epsilon A_{j}(z)
$$

onde acrescentamos o potencial calculado ao Hamiltoniano ariginal. Fazendo a 
expansão em ondas ortogonais, obtemos o Hamiltoniano equivalente à eq. 5.12:

$$
\sum \sum\left[\mathrm{H}_{j}^{\mu \nu}{ }_{j}^{\nu}+\delta_{\mathrm{ij}} \mathrm{U}_{\mathrm{j}}^{\mu k}{ }_{\mathrm{j}}^{y}\right] \mathrm{O}_{\mu}^{\mathrm{j}}=\epsilon \sigma_{y}^{\mathrm{i}}
$$

onde

$$
\mathrm{U}_{\mathrm{i}}^{\mu}{ }_{\mathrm{j}}^{\nu}=\int \varphi_{\mu}^{\mathrm{i} *}(\mathrm{z}) \mathrm{U}(\mathrm{z}) \varphi_{\mu}^{\mathrm{j}}(\mathrm{z}) \mathrm{dz} .
$$

Temas agara todos os ingredientes para a cálculo autoconsistente. O processo de iteraçä́ antoconsistente está esquematizado na fig. 5.3. Para inicializar este processo, os parâmetros do material escolhido já devem ter sido calculados, assim como as funçöes de base e as integrais das eqs. 5.17. Para obtermos uma banda de energia do tipo eqquematizado na fig. $5.2, \mathbf{k}$ deve variar de 0 até o máximo valor desejado, neste caso igusl ao $\mathbf{k}_{\mathrm{form}}$. Para cada um destes $\mathbf{k}$ s, o Hamiltoniano da eq. 5.31 é diagonalizado para se obter as energias e autovetores (bloco (2) na fig. 5.3). As sub-banas săo, portanto, obtidas no ciclo (2)-(3)-...-(6)-(2) da fig. 5.3. No bloco (4) a denaidade parcial $\rho(z, \mathbf{k})$ é obtida e armazenada para a cálculo da densidade total em (7). Este ciclo termina quando $\mathbf{k}$ chega a superficie de Fermi, a que é testado em (5). Em seguida, a dengidade tatal é calculada (7), resolve-se a equaçäo de Poison (8), e calcula-se os novos elementos de matriz do potencial (9). A convergência da iteração é, então, testade (10). Se a convergência não faj obtida, inicia-se uma nava iteraça: (1)-(2)-... (10)-(1). Do contrário, os elementos de matriz sào salvos (11) para uso em outro programa, que poderá calcular a estrutura eletronica para qualquer $\mathbf{k}$ que estejamos interessados.

A implementação do algoritmo de fig. 5.3 encontra um sérjo obstáculo. 0 principal problema é a ciclo de diagonalizaçăo (2)-(3)- .. - (6)-(2). Devemos diagonalizar todo o Hamiltoniano,com as sub-rotinas existentes nas bibliotecas FORTRAN, para obter os vetore desejados para o cáculo da densidade. Se estivermos trabalhando corn 10 funçäes de bare, para cada portador, o Hamiltoniano da eq. 5.31 teré dimensăo 40×40. Mas, ne major parte dos problemas autoconsistentes em poços quânticos, apenas um ou dois estados estão ocupados. Isto 
significa que, a cada diagonalização, 40 vetores de estados são calculados onde apenas dois seriam necescários. Ou seja, 95\% do tempo da sub-rotina é gasto no cálculo de vetores que não são utilizados.

Nós resolvemos este problema usando um método de diagonalização pouco conhecido na literatura, mas muito eficiente, chamado Método de Iteração Inversa $(2,3)$ (apêndice B). Com este método pode-se trabalhar, se necescário, apenas cam os estados ocupados, uma rez que se conheça, aproximadamente, suas energias. Tajs energias podem ser as energias, dester estados ocurados, no passo anterior do autoconsistênciá. O tempo necessário para a sutoconsistência, usando 10 funçzes de base, foi de $\approx 2: 30 \mathrm{~h}$ e de $\approx 10 \mathrm{~min}$, para uma sub-rotina comum de diaganalização (EIGCH-IMSL $\left.{ }^{(14)}\right)$ e para a sub-rotina de iteração inversa, respectivamente. 


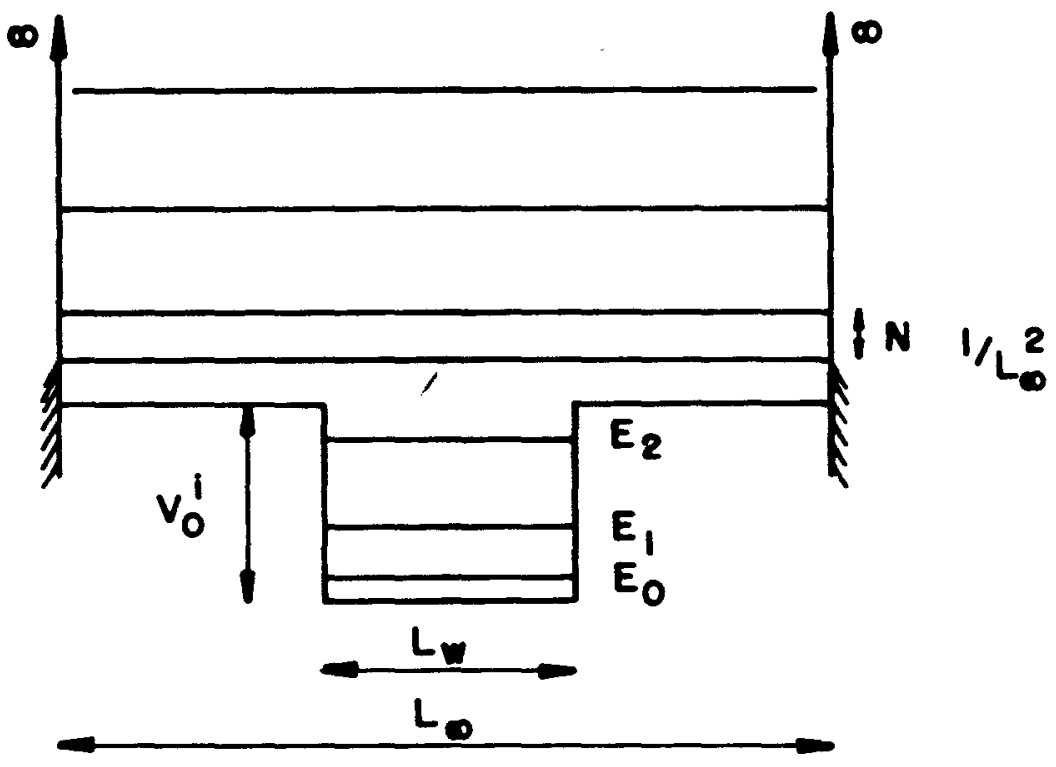

Fig. 5.1 : Potencial usado para o cálculo das funç̧es de base. $V_{0}^{i} \dot{e}$ o potencial calculado do "band-offeet"(apêndice A), onde $i$ é a Indice do portador.

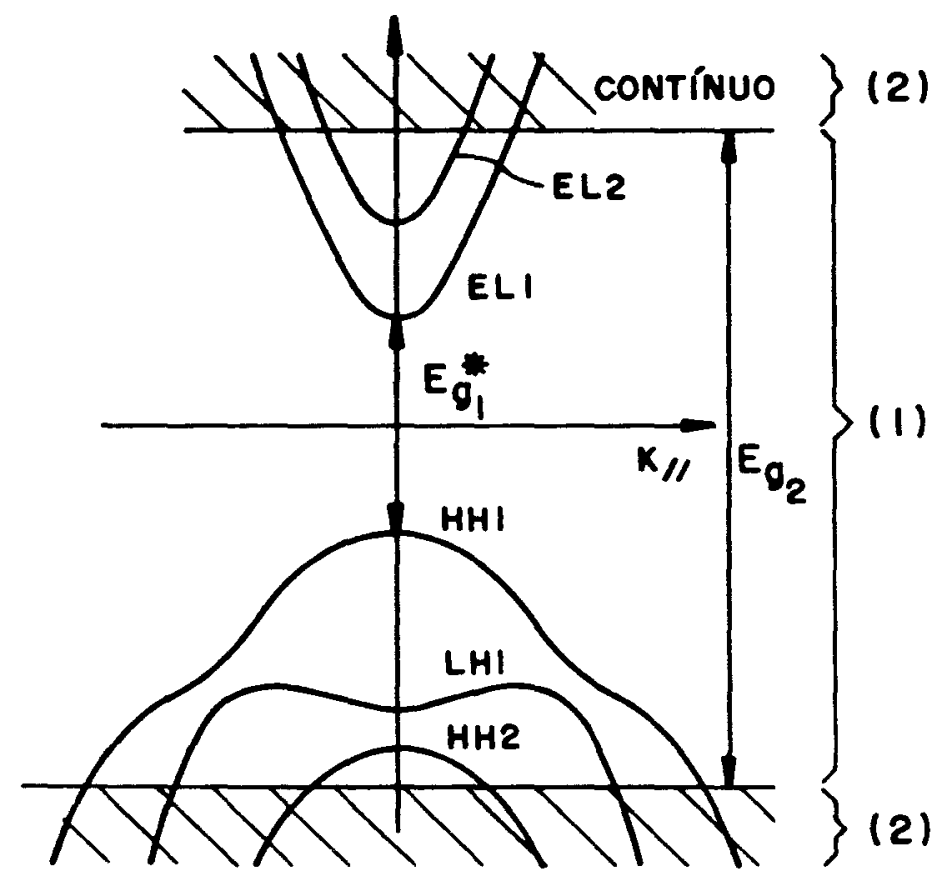

Fig. 5.2 : Espectro típico abtido para o Hamiltoniano da eq. 5.1. $\mathrm{E}_{\mathrm{g}]}^{*}$ é o gap fundamental do poşo, já inclusdo a correção devido ao potercial do pogo (ELI-HH1). $\mathrm{E}_{\mathrm{g}^{2}}$ é o gaf do material da barreira. 


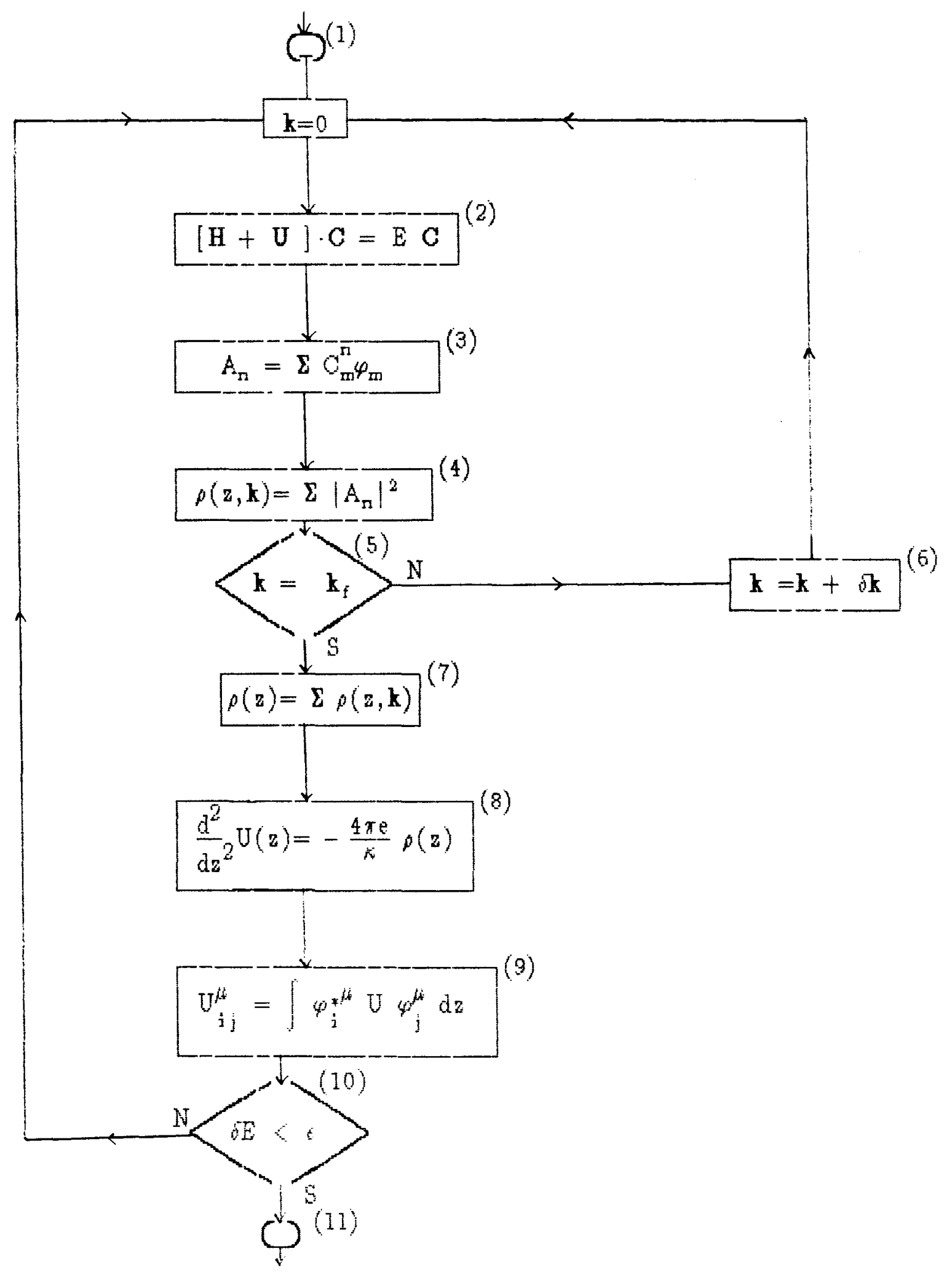

Fig. 5.3: Algoritmo para o cálculo do potencial autoconsistente. As funçбes de base devem aer calculadas antes deste procerso. A saida (11) fornece dados para o cálculo da estrutura de bandas. 


\section{GAPITULO VI \\ RESULTADOS E CONCLUSÖES}

VI.1 - Resultados e Discussóes

Nesta seção analisaremos os resultados abtidos pelo método autoconsistente para poģos quânticos dopados de GaAlAs-GaAs e InAlAs-InGaAs, en várias concentraçōes eletrônicas.

Na fig.6.1, mostramos um resultado típico obtido para as sub-bandas de energia dos elétrons. Os pontos no gráfico são obtidos pelo processo descrito na seção V.3. Para a discuesão do efeito da densidade de carga na estratura eletrónica de poços quânticos, nós optamos por variar o nivel de Fermi e analisar os resultados para as várias densidades assim obtidas. Na fig. 6.1, por exemplo, escolheu-se um nivel de Fermi localizado a $10 \mathrm{meV}$ abaixo do contínuo, que está indicado pela linha tracejada (sem rótulo). Neste caso, obtemos uma densidade superficial de carga igual $\dot{a} 1.26 \times 10^{12} \mathrm{~cm}^{-2}$. Variando o nivel de Fermi, pode-se encontrar densidades täo baixas quanto a apresentada na fig. 6.2 , isto $\dot{e}, \mathrm{~N}_{\mathrm{g}}=8 \times 10^{10} \mathrm{~cm}^{-2}$.

Comparando as figs. 6.1 e 6.2, a primeira diferença importante $\dot{e} a$ diminução da separação entre as bandas EL1 e ELa com o aumento da concentração de elétrons no poģo. Esta aproximação entre os níveis pode ser entendida se considerarmos o efeito do potencial autoconsistente perturbativamente. A energia dos nuveis será dada, entăo, pela teoria de perturbaçáo, até primeira ordem, por:

$$
E_{n}=E_{0}+\left\langle A_{n}^{e}|V(z)| A_{n}^{e}+O\left(N_{g}^{2}\right)\right.
$$

onde $A_{n}^{e}(a)$ é a funçĭ́ de onda, da sub-banda $n$, no poço quântico sem dopagern, $E_{0}$ é a energia da particula cem a pertubação, $V(a)$ é a potencial autoconsistente, que assumimos já calculado.

Fara que a banda EL1 aproxime-re da banda EL2, quando a deneidade de carga aumenta, é necessín que a correçấn eletrostática $\left\langle A|V(z)| A_{1}^{e}\right\rangle$ para ELl 
seja major que a correção $\left\langle A_{2}^{\mathbf{e}}|\mathrm{V}(\mathrm{z})| A_{2}^{\mathbf{e}}\right\rangle$ para a banda EL2. Isto é sempre verdade para poços quânticos com dopagem seletiva, como pode ser observado ra fig. 6.3, onde mostramos a correçăo eletrostática para os dois primeiros niveis EL1 e EL2 em um poşo de largura igual a 300 \&. A explicação para este efeito é simples: o potencial eletrostático atinge seu valor máximo na região central do poço, onde também ocorre o máximo da funçäo de onda do estado fundamental. Nesta regiâa a função de onda do segundo nível é zero de modo que, na integral $\left\langle A_{2}^{e}|V(z)| A_{2}^{e}\right\rangle$, a contribuição máxima do potencial ocorre na região ond a contribuição de $A_{2}^{e}$ é minima. Na integral $\left\langle A_{1}^{e}|V(z)| A_{1}^{e}\right\rangle$ ocorre o contrário, de forma que a correçấo eletrostática maior é na banda EL1. De modo geral, podemos afirmar que esta correçă diminui a medids que consideramos bandas superiores. Na fig. 6.3 podemos ver que a correçăo eletrostática não varia linearmente com a densidade. Como a potencial eletrostático é linear com a densidade (equaçäo de Poisson, Apêndice A), esta não-linearidade é devida aos termos de segunda ordem na perturbaçăo, que não foram considerados na eq. 6.1 .

Na fig. 6.4 mostramos o comportamento dos nívejs eletrónicos com a densidade superficial de elétrons. A origem do comportamento năo-linear é a mema discutida na fig. 6.3. Vemos que (fig. 6.4), para uma dada deneidade crítica, a segunda banda pasáa a ser ocupada. O conhecimento desta densidade critica é importante devido a seus efeitos em várias propriedades fisicas, en especial, na mobilidade eletrônica(1). Notamos que, em razăo da grande separação entre as bandas EL1 e EL2 ( $270 \mathrm{meV}$ ) para a dersidade $\mathrm{N}_{\mathrm{s}}=0$, é necessária una grande densidade de elétrons para preencher todos os niveis entre as duas bendas. Portanto, com o aumento da largura do poşo, e a consequente diminujçăo da separaçấo entre bandas, deve-se esperar uma diminuiçăo na densidade crítica. A dependencia doe niveis eletrônicos com a densidade é mostrada $r_{1}$ fie. 6.5 , para um poço de largura igual a 300 s, onde confirmamos a diminuiçăo da densidade critica.

Na fig. 6.6, mostramos a dependencia dos niveis de buracos com a concentraçá eletrônica. Nesta figura estăo aprecentados somente o primeiro e segundo niveis do buraco pesado ('heavy-hole') HHl e HH2, respectivamente, e o primeiro nivel do buraco leve (light-hole) IH1. Existem outros noveis imediatamente abaixo 
destes, que não foram apresentados aqui, já que seus comportamentos são análogos aos dos três primeiros níveis.

Vemos na fig. 6.6 que a dopagem da banda de condução causa um deslocamento quase uniforme das bandas de valência. Desta forma, pode parecer que - efeito do potencial autoconoistente é despregivel na estrutura eletrónica da banda de valência. Mas não é este o caso. Na fig. 6.7 apresentamas a variação das massas dos três ñveis, estudados na fig. 6.6, em função da concentração eletrónica. 0 comportamento das massas efetivas, com a concentração, pode ser entendido usando-se a eq. 6.1 e a definição de massa efetiva:

$$
\frac{1}{m}=\frac{1}{n^{2}} \frac{\partial^{2}}{\partial k^{2}} E(k)
$$

Tomando a derivada segunda da eq. 6.1, obtemos, então,

$$
\frac{\partial^{2}}{\partial \mathrm{k}^{2}} \mathrm{E}_{\mathrm{n}}^{\mathrm{i}}(\mathrm{k})=\frac{\partial^{2}}{\partial \mathrm{k}^{2}} \mathrm{E}_{0, \mathrm{n}}^{\mathrm{i}}(\mathrm{k})+\frac{\partial^{2}}{\partial \mathrm{k}^{2}}\left\langle\mathrm{~A}_{\mathrm{n}}^{\mathrm{j}}|\mathrm{V}(\mathrm{z})| \mathrm{A}_{\mathrm{n}}^{\mathrm{i}}\right\rangle
$$

onde $\mathrm{i}=\mathrm{EL}, \mathrm{HH}, \mathrm{LH}, \mathrm{SO}$. O primeiro termo do lado direito é proporcional ao inverso da massa efetiva do portador i na subbanda $n$, quando a patencial autoconsistente é aero. No segundo termo acsumimos uma dependencia em $\mathbf{k}$ devida

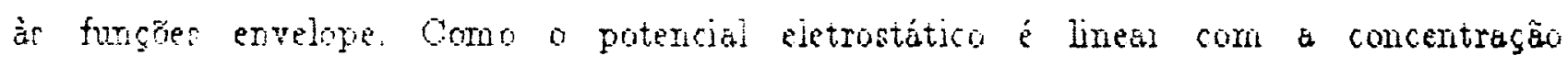
eletrónica, podemos fatorar esta dependência em $\mathrm{N}_{\mathfrak{B}}$ e escrever a eq. 6.2 de forma simplificada como:

$$
\frac{1}{m_{n}^{*}}=\frac{1}{m_{n, 0}^{j}}+\alpha_{n}^{j} N_{s}
$$

ou, invertenda,

$$
m_{n}^{* j}=\frac{m_{n, a}^{m i}}{1+m_{n, 0}^{m i} \alpha_{n}^{i} N_{\varepsilon}}
$$


onde $\alpha_{n}^{j}$ é a derivada segunda do valor médio do patencial autoconsistente nos estado $A_{n}^{i}(z)$, que dependem de $k$. Como o potencial eletrontático não depende do vetor de onda, a dependência de $\alpha_{n}^{j}$ em $\mathbf{k}$ deve vir das funçzes envelopes. Portanto, a constante $\alpha_{n}^{j}$ é uma medida direta desta dependência.

Para reproduzimas o comportamento das massas com a concentração eletrónica da fig. 6.7, usando a eq. 6.4 (válida para baixas concentraçóes), a constante $\alpha_{n}^{i}$ para os buracos leves (LH) deve ser negativa e, para os buracos pesados $(\mathrm{FH})$, positiva.

$\mathrm{Na}$ fig. 6.8 apresentamos o resultado do cálculo da dependência das massas dos buracos com a concentração eletrönica para un paço de InAlAs-InGaAs, com largura igual a 300 \&, na composiçăo em que os parâmetros de rede são compatíveis. Podemos observar, nesta figura, a mesma relação abtida para os sinais da contantes $\alpha_{I L}^{j}$ do poço de GaAlAs-GaAs (fig. 6.7).

Uma vez que a densidade de estados é diretamente proporcional às massas efetivas dos portadores, esaa modificação nas massas deve ser considerada nos cálculos que envolvem a estrutura eletrônica da banda de valência.

Na fig. 6.9 apresentamos a resultado do cálculo da densidade conjunta de estados para um poço de GaAlAs-GaAs com largura de $300 \AA$, para densidades $N_{5}$ $=8 \times 10^{10} \mathrm{~cm}^{-2}$ e $\mathrm{N}_{\varepsilon}=1.3 \times 10^{12} \mathrm{~cm}^{-2}$. Pademas perceber um aumento na densidade de estados provocado pelo aumento das massas efetivas, e uma mudarça ne posiçá de algune picos devida à mudança na estrutura eletrónica.

Na fig. 6.10 mostramos o resultado do cálculo da dencidade de estados para um pogo de InAlAs-InGaAs com largura igual a 300 A. Observamos, nesta figura, o mesmo efeito da mudança de massa sobre a densidade de estados visto na fie. 6.9 . Comparando as fig. 6.9 e 6.10 notamos a existência de um maior numero de patamares na densidade de estados da fig. 6.10. Isto ocorre devido ao fato de que a profundidade do poço de InAIAs-InGaAs é maior que a do poço de GaAlAs-GaAs, e um poso mais profundo contém um numero maior de estados eletrốnicos.

Fara um poço quantico realiata, o nivel de Fermi é dado pelo nivel do dopante utilizado. Com a nivel de Fermi fixo neste valor, podemos caicular a dependência da concentração eletrônica com a largura do poço $\left(L_{w}\right)$ e com a largura 
da região de separação $\left(L_{8}\right)$. Para o silicio em GaAlAs, este nivel depende, de maneira nâo-trivial, da concentraçăo de alumínio. Contudo, a origem de tais níveis näo é bem compreendida.

Fara concentraçôes de alumínio menores que $20 \%$ e temperaturas abaixo de $100 \mathrm{~K}$, o cristal de GaAlAs dopado com Si exibe fotocondutividade persistente (PPC, 'Persistent Photoconductivity', ref 2 ), que é a existencia de fotocondutividade apó a interrup̧ãa da iluminação. Para que se possa entender a PPC é necessário imaginar a existência de dois niveis de energic eletricamerse ativos. Lang, e colaboradores ${ }^{3}$ propôem a existência de um nivel profundo chamado DX, além de um rúvel raso originado pelo silicio substitucional. Alguns modelos supôem que a energia de ativaçáo destes dois njveis varia muito pouco com a concentraçắo de aluminio $x$, mas à medida que aumenta, a concentraçäo de defeitos rasos dimimui e a concentração de defeitos profundos torna-se dominante. Usaremos um modelo proposto por Chand, et $a^{4}$ no qual o nivel raso e o nivel DX coincidem, para concentraçöes de Al com $x \leq 0.22$, com energia de jonização $E_{d}=-10 \mathrm{meV}$. Para valores de $t \geq 0.22$ o nivel raso permanece com este valor, enquanto que o nível DX abaixa, atingindo um valor mínimo igual a $\mathrm{E}_{\mathrm{d}}=-160 \mathrm{meV}$, para a energia de ionizaçăo, perto da concentraçáo de transiçăo de gap direto para indireto, $x=0.45^{0}$, e crescendo novamente apartir daf. Usaremos portanto, a expreseáo:

$$
E_{d}(x)= \begin{cases}10 . \mathrm{meV}, & x \leq 0.22 \\ 707 .-146 . x, x \geq 0.22\end{cases}
$$

para o nivel de impureza e restringiremos a concentraços menores que $t=0.45$.

Na tabela VI.1 apresentamos os resultados do cálculo da deneidade eletronica para vários poços de $\mathrm{GA} A \mathrm{As}$, juntamente com os valores medidos experimentalmente. Devido às incertezas nos pasametros destas amostras, podemos considerar os resultados exin excelente concordancia com os dados experimentais. Para as três primeiras amostras, a varjaça da largura do poço é da ordem de $2 \%$, e cada uma

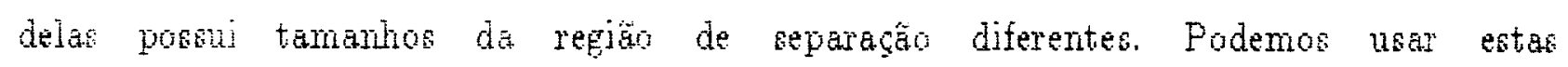


amostras para comparar a variação da densidade eletrónica com este comprimenta. $\mathrm{Na}$ fig. VI.11 vemos que o resultado do métado autoconsistente prevê corretamente a variação da densidade eletrónica com a largura da região de separação $\left(\mathrm{L}_{8}\right)$. Vemos também que, para larguras superiores a $150 \AA$, a densidade no poço é praticamente constante, sendo muito pouco sensível ao comprimento $L_{s}$.

Tabela VI.1 - Valores para as densidades eletrónicas de um poço de GaAlAs-GaAs.

\begin{tabular}{llccc}
\hline & $\begin{array}{c}\mathrm{L}_{\mathrm{W}} \\
(\AA)\end{array}$ & $\begin{array}{c}\mathrm{L}_{\mathrm{g}} \\
(\AA)\end{array}$ & $\begin{array}{c}\mathrm{N}_{\mathrm{s}}(\exp ) \\
\left(10^{11} \mathrm{~cm}-2\right)\end{array}$ & $\begin{array}{c}\mathrm{N}_{8}(\mathrm{calc}) \\
\left(10^{11} \mathrm{~cm}^{-2}\right)\end{array}$ \\
\hline 0.12 & 245 & 51 & 7.6 & 8.2 \\
0.12 & 244 & 99 & 5.6 & 5.8 \\
0.12 & 250 & 151 & 4.0 & 3.8 \\
0.20 & 262 & 163 & 7.0 & 6.9 \\
0.36 & 200 & 240 & 8.0 & 9.1 \\
\hline
\end{tabular}

A espectroscopia de transiç̧es inter-subbandas é muito útil no estudo de gases de elétrons bidimensionais (5). Destes experimentos é possivel conhecer-se as separaçzes dos níveis de energia dos elétrons em paços quânticos dopados, assim como o espectro de excitaç⿸厃s coletivas. Na tabela VI.l encontram-se os valores abtidas para as diferenças de energia, $E_{i j}=E_{j}-E_{j}$, das transiçzes do primeira nivel EL1 aos níveis excitados $\mathrm{EL}(\mathrm{j}+1)$, ( $\mathrm{E}_{01}$ corresponde a transição $\left.E L 1+E L 2\right)$, para um poço de 204 \&. Estes valores sấo comparados com o resultado experimental da ref. (6), e com outros valores té́ricos (7) obtidas por teoria de perturbação. Vemos nesta tabela que a resultado obtida era nosso programa está em boa concordância com o resultado experimental, e mais próxima deste do que a calculado pela ref. 7 . 


\begin{abstract}
Tabele VI.2 - Valores para as transiçbes intersub-banda de um poço de GaAlAe-GaAs com $x=0.12$ e largura igual a $204 \&$.
\end{abstract}

\begin{tabular}{llll}
\hline & Exp. & Cal. & Ref. 7 \\
\hline $\mathrm{E}_{01}$ & 21.7 & 20.6 & 23.7 \\
$\mathrm{E}_{02}$ & 63.7 & 63.5 & 69.8 \\
$\mathrm{E}_{03}$ & 106 & 105. & 128.6 \\
\hline
\end{tabular}

Podemos novamente utilizar as três primeiras amostras da tabela VI.1 para analizarmos a dependência destas energias de transiçós com a deneidade eletrônica. $\mathrm{Na}$ fig. 6.12 mostramos o resultado do cálculo destas energias para varias concentraçăes de elétrons, e fazemos a comparaçăo com as energias obtidas das refa. 6 e 7. Vemos que, mesmo se tratando de amostras diferentes, a concordância entre os resultados do método autoconsistente e os experimentais é muito boa.

\title{
V1.2 - Concluszes
}

A análise dos resultados obtidos pelo método, usando-se as aproximaçós simples de teoria de perturbaça (eqs. 6.1 e 6.4), mostra que a programa desenvolvido neste trabalho não possui nenhuma inconsiatência intema, para baixas densidades. Para densidades eletrónicas altas, a comparaçăo com of resultados experimentais mostrou-se muito boa, e tomamos esta comparaça como garantia neste limite. Tais comparaçoes fazem-se nescessárias uma vez que, devido ao tamanho do código do programa, os erros acidentais tornam-se muto prováveis.

Os limites de aplicagấo do programa desenvolvido ấa totalmente dependentes da máquina dieponvel. Para O VAX 11/780, do IFQSO, podemos trabalhar com um 
limite máximo de 20 funções de base por portador, para o cálculo de propriedades fisicas que näo envolvam o conhecimento de toda a estrutura eletrónica. Em cálculos de absorçăo b́tica e luminescência, por exemplo, o número máximo de funçöes de base é 12. Isto deve-se ao fato de que, nestes cálculos, devemos salvar o vetor de base $\sigma_{\mu, n}^{j}(\mathbf{k})$ para cada ponto $\mathbf{k}$ calculado na banda. Junto com os vetores necessários para o cálculo da estrutura eletrônica, atinge-se o limite de memória do VAX.

O número de bases tem relaçấo direta com a largura do poço finito e infinito usada para o cálculo desta base (fig. 5.9). Quanto mais largo o poço finito, mais largo o poşo infinito e menor a separaçăo energética $\left(\propto 1 / L_{\infty}^{2}\right)$ entre os autovalores das funçoes de base no contínuo. Isto faz com que o espectro das funçges de base privilegie as regiôes de menor energia do espectro contínuo em detrimento das regizes de maior energia ( uma escala para esta análise pode ser a profundidade do poço $\$ 300 \mathrm{meV}$ ). Se isto acontece, um número maior de funçðes deve ser escolhido para preencher uma região maior do espectro contínuo.

Dentro dos limites descritos acima, consideramos que a pragrama funciona de maneira segura e que seus resultados podem ser utilizados para se determinar propriedades físicas do sistema estudado neste trabalho.

Neste trabalho comparamos as resultados de nosso método com resultadoe experimentais para o GaAlAs com dopagem $n$ apenas. Outros materiais podem eer estudados em nenhuma modificaçă no método. A adaptação do programa para o cálculo de poços quânticos com dopagern $p$ é direta e poderá ser conduída em breve.

Trabalhos com esta estrutura eletronica estäo sendo desenvolvidos para estudar efeitos de deformação e tensão em poços dopados. Cálculos de absorçăo b́tica e luminiscencia também estäo em andamento.

Modificaçóes menores podem ser feitas no codigo construido para se estudar outras estruturas como poços quânticos com dopagem lateral ('side doped quantum well'), e/on efeito de campos elétricos fracos neetas estruturas. 


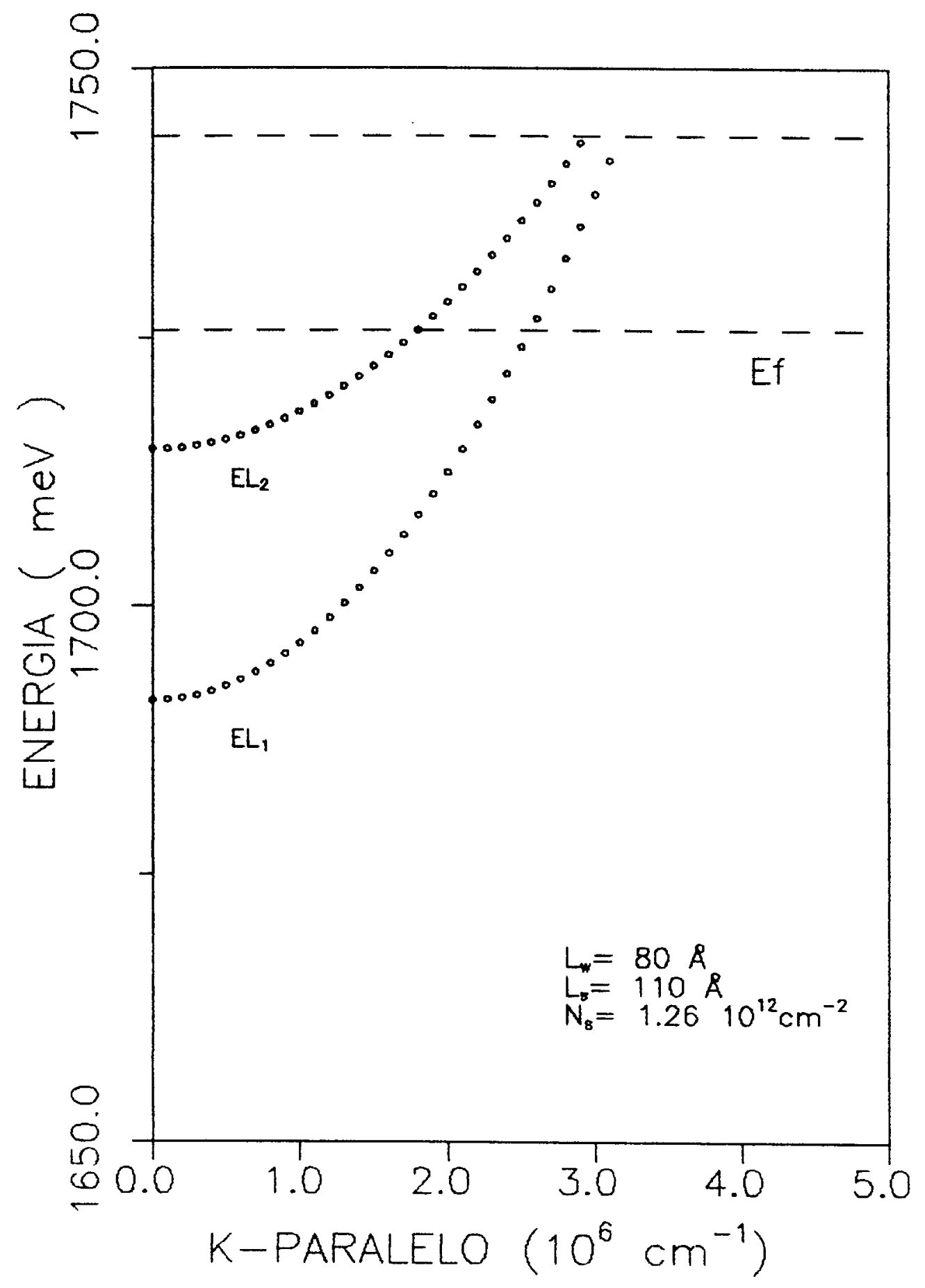

Fig. 6.1 : Sub-banda de energia para um poço quântico de $\mathrm{G}_{0.3} \mathrm{Al}_{0.7} \mathrm{As}-\mathrm{GaAs}$ com largura igual a $80 \mathrm{E}$. 0 inicio do contínuo de energia é marcado pela linha tracejada, sem rótulo. Para a concentração indicada temos duas sub-bandas ocupadas. 


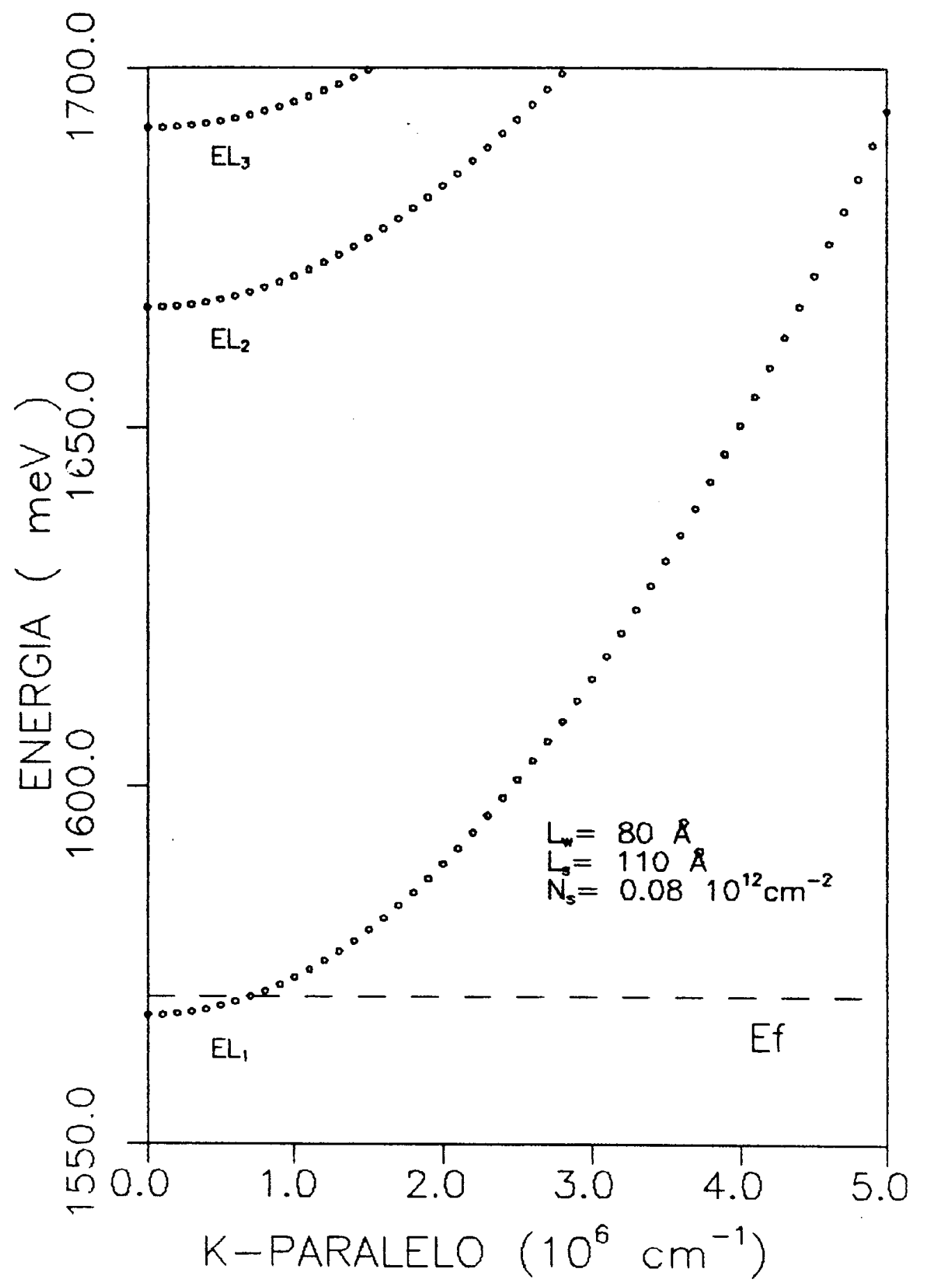

Fig. 6.2 : $O$ mesmo que a fig. 6.1, com uma concentraçấo menor. Para a concentração indicada existe apenas urna sub-bands ocupada. 


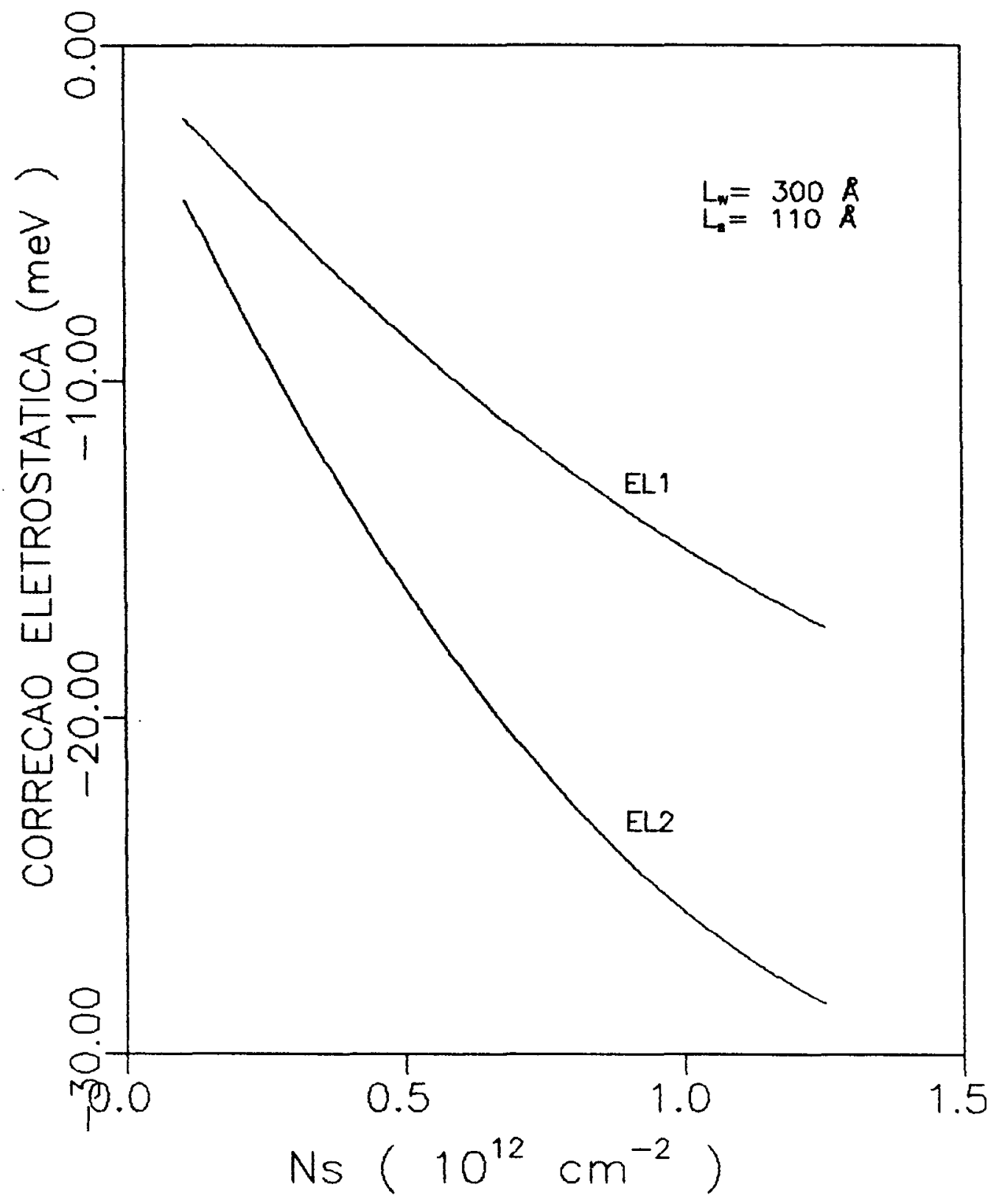

Fig. 6.3 : Correção eletrostática adicionada às sub-bandas

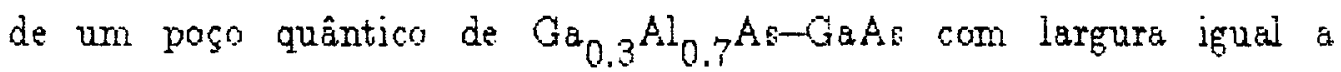
300 A. Para o cálculo deata correção o zero de energia foi tomado na energia do fundo do poço (igual ao gap do material do poco). 


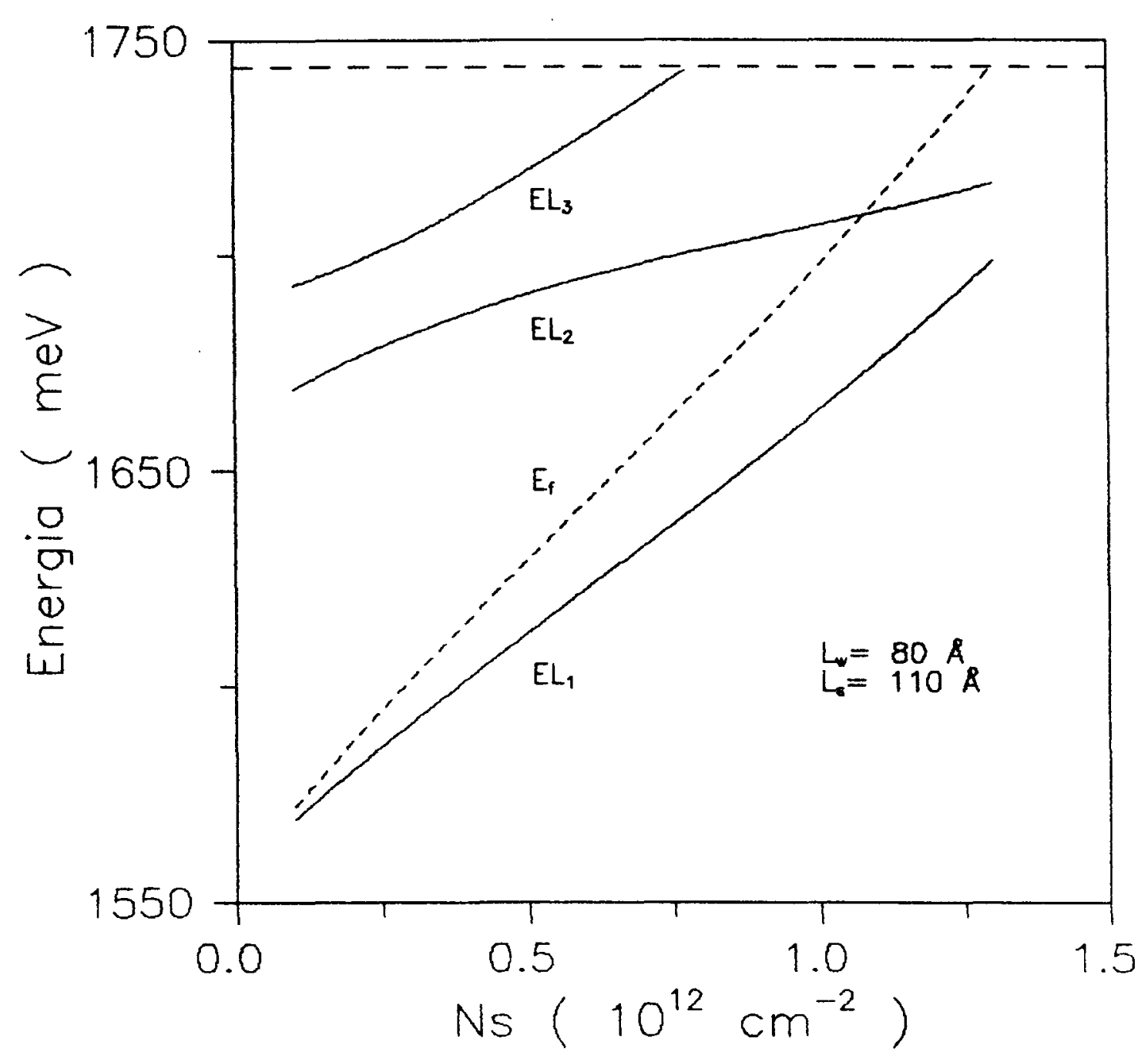

Fig. 6.4 : Variação das energias dos estados ligados, em $\mathbf{k}=0$, e do nivel de Fermi com a concentraçấo eletrónica em um poço de $G_{0.3^{A}} \mathrm{I}_{0.7} \mathrm{As}$ com largura igual a $80 \mathrm{~A}$. $O$ inicio do contínuo de energia é indicado pela linha tracejada. 


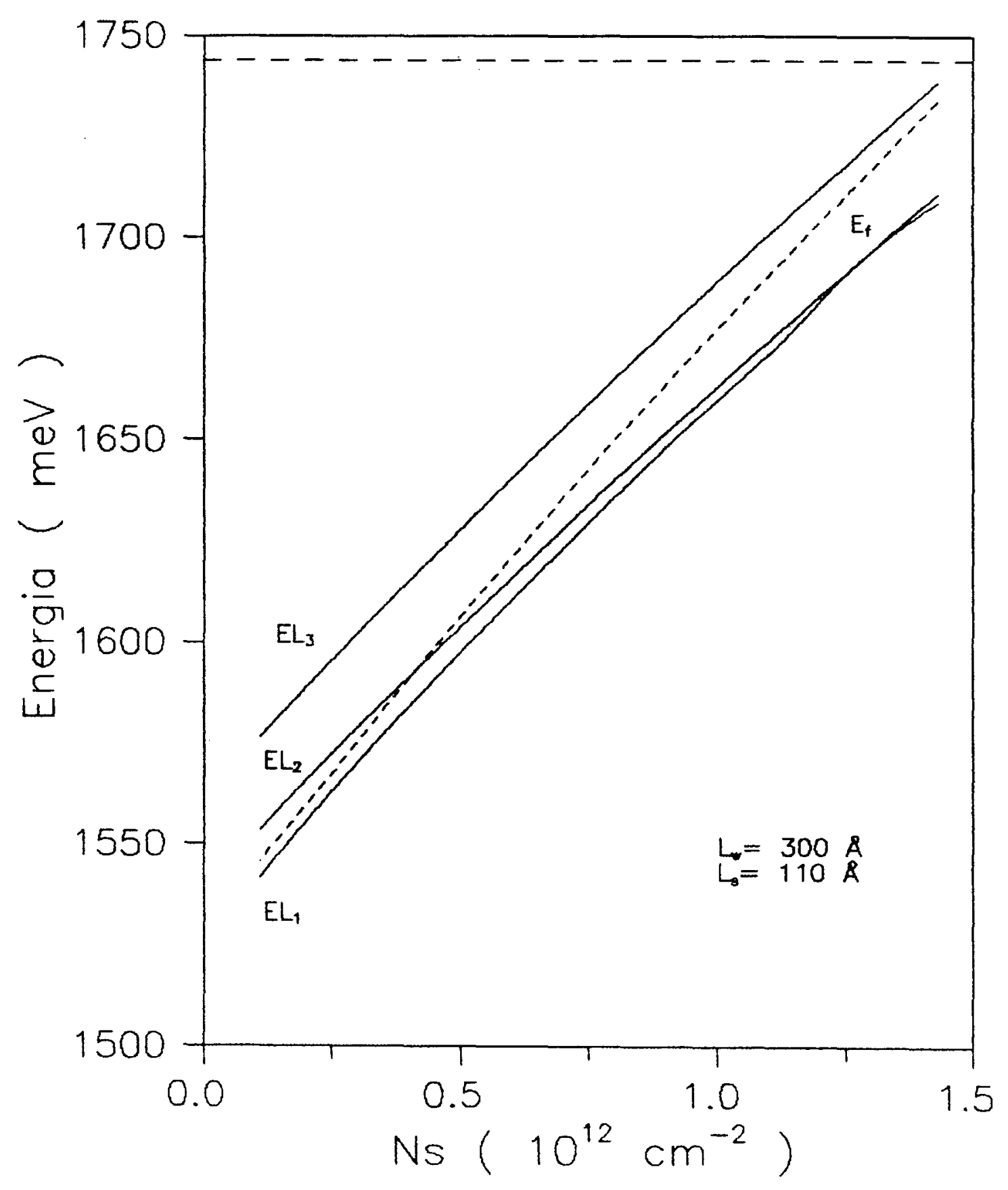

Fig. 6.5 : 0 mesmo que a fig. 6.4, para um poço com $G_{0.3} A_{0.7} A E$ de largura igual a $300 \&$. 


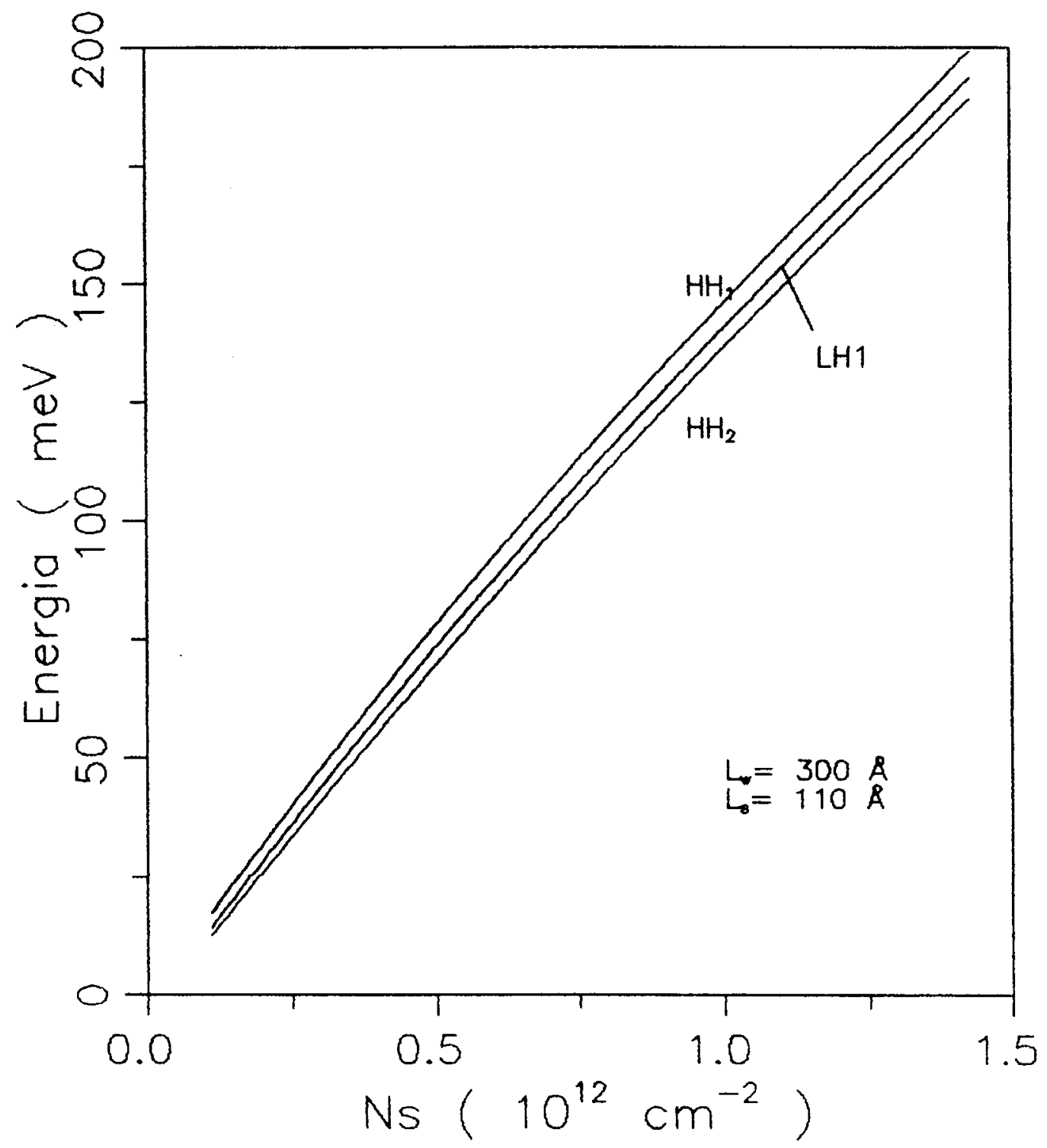

Fig. 6.6 : Variação das energias em $\mathbf{k}=0$, para as sub-bandas de valência em un poço de $\mathrm{Ga}_{0.3} \mathrm{Al}_{0.7} \mathrm{As}$ com largura igual a 300 \&. Somente as três primeira sub-bandas sắ apresentadas. 


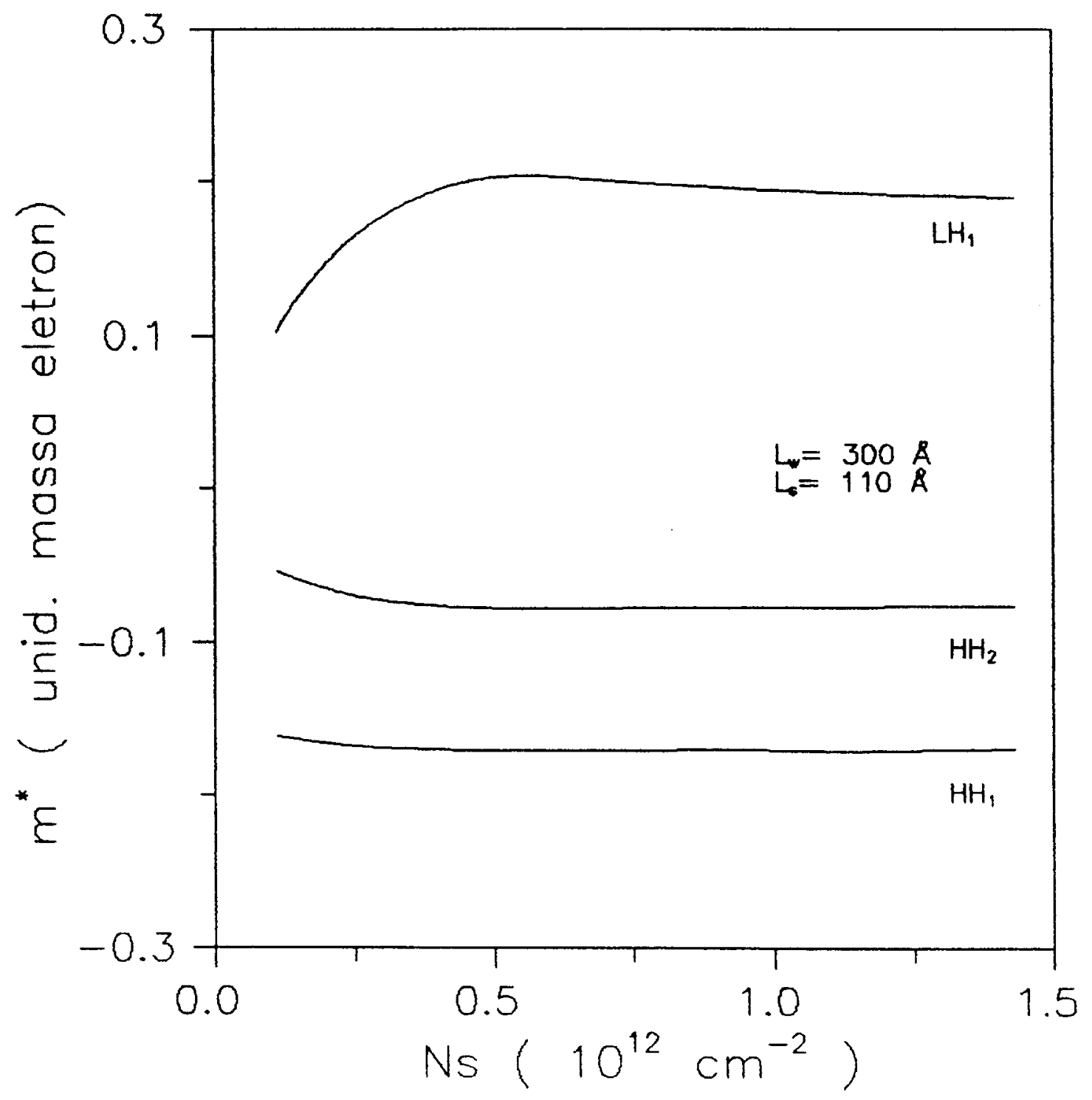

Fig. 6.7 : Dependêncis com a concentraçấo eletrônica das massas efetiva das três primeiras sub-bandas de valencis, em um poco de $\mathrm{Ga}_{0.3} \mathrm{Al}_{0.7} \mathrm{As}$ com largura igual a $300 \mathrm{~A}$. As maseas aấ dadas oxii unidades da massa do elétron. 


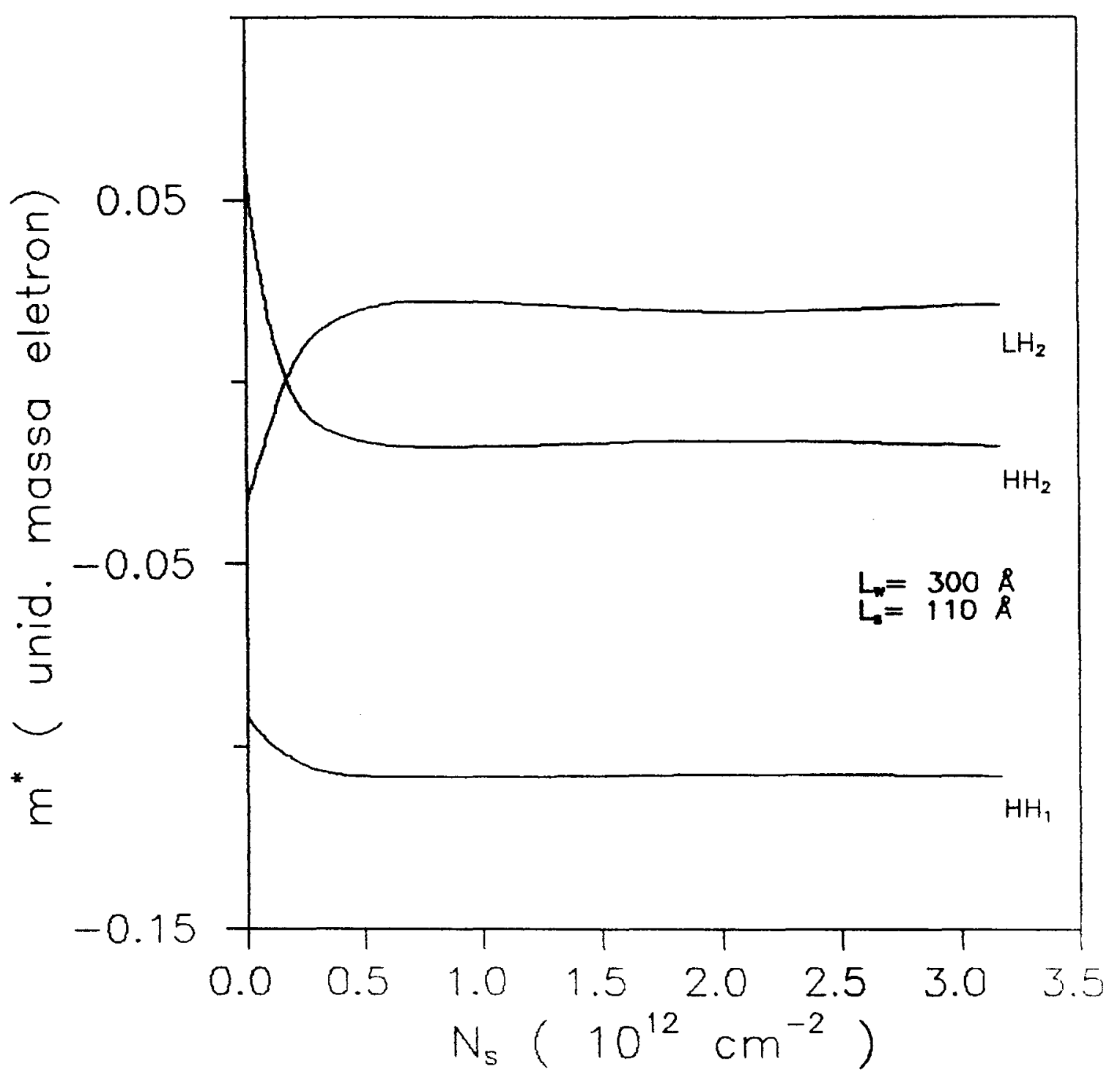

Fig. 6.8: 0 mesmo que a $\overline{i n g}_{\text {g. }}$ 6.7, para um poç quântico

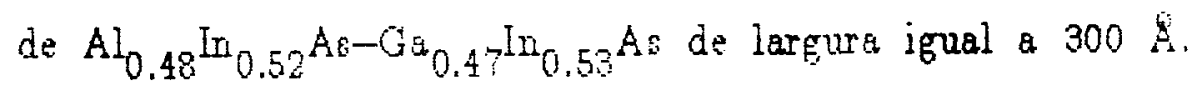




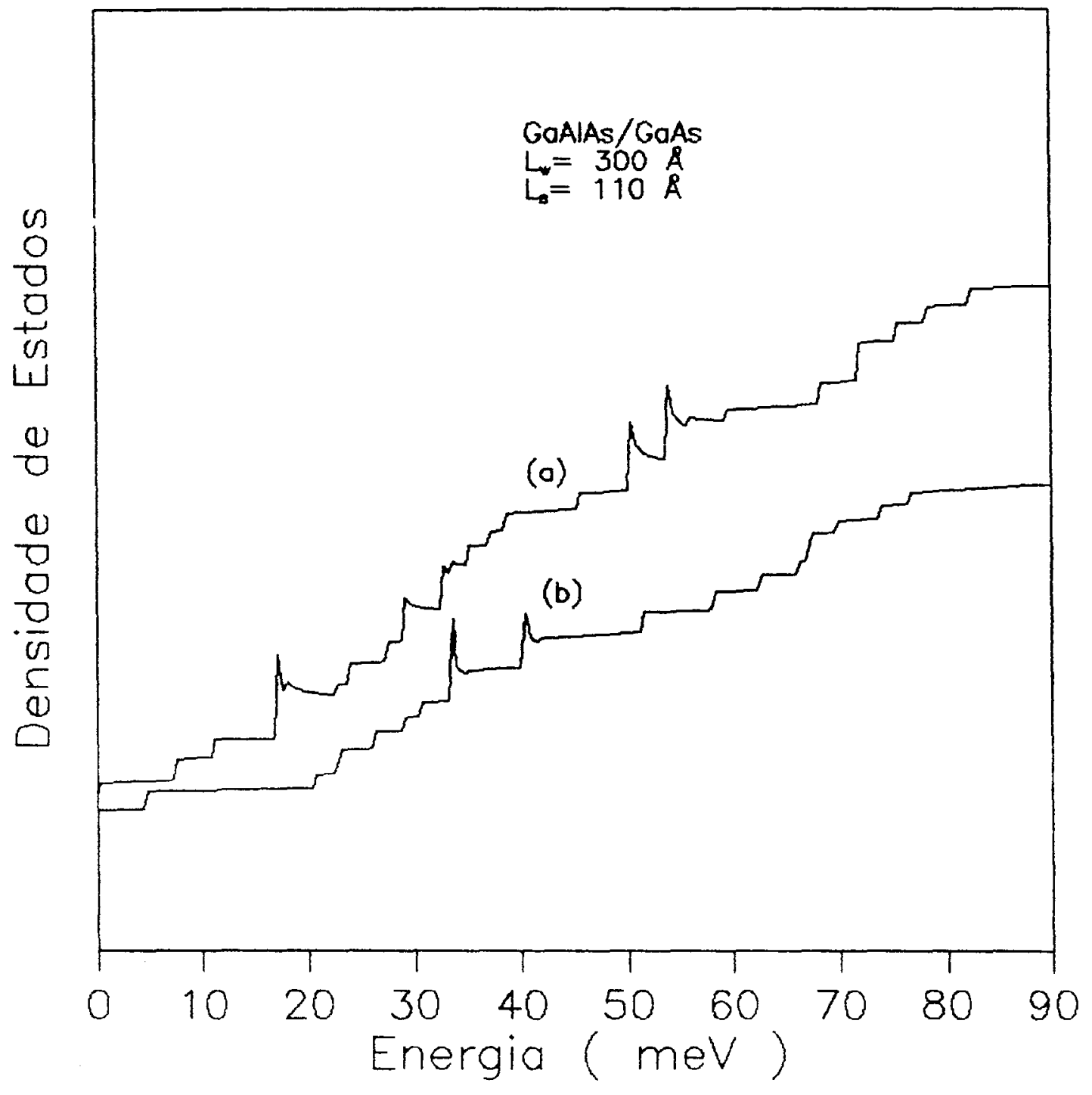

Fig. 6.9: Dersidade de estados para um pogo de GaAlAB-GaAs, com largura jgual a $300 \mathrm{E}$. 


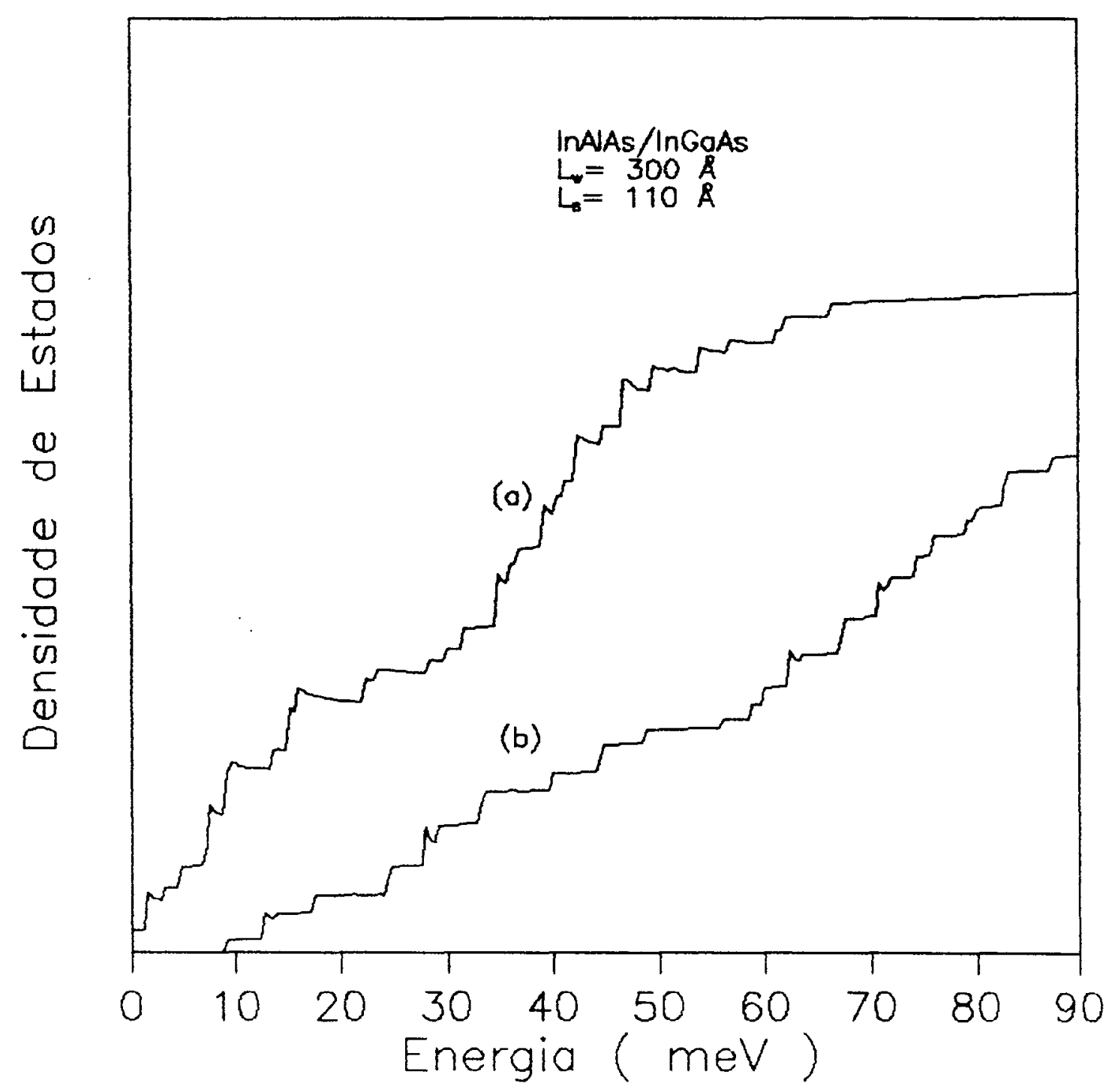

Fig. 6.10: 0 mesmo da fig. 6.9, porém para um poşo de InA $A$ A $-\operatorname{In} G$ ass. 


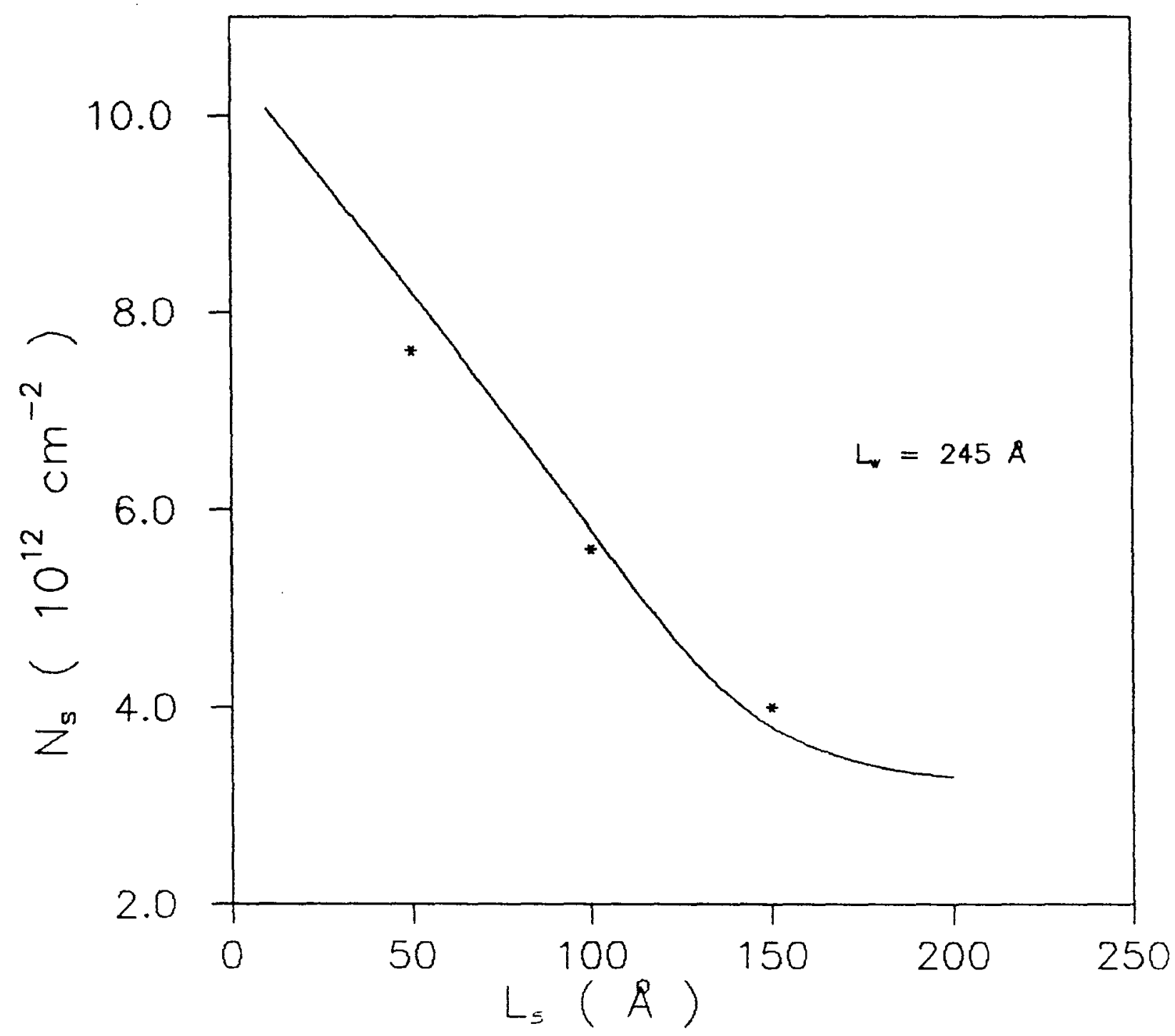

Fig. 6.11: Dependência da concentração eletrônica $\left(\mathrm{N}_{\mathrm{E}}\right)$ com a largura da regiăo de separação $\left(L_{F}\right)$, para um poço de GaAlAs-GaAs, com largura $L_{w}=2458$ e concentraçăo de aluminio $\mathrm{x}=0.12$. 


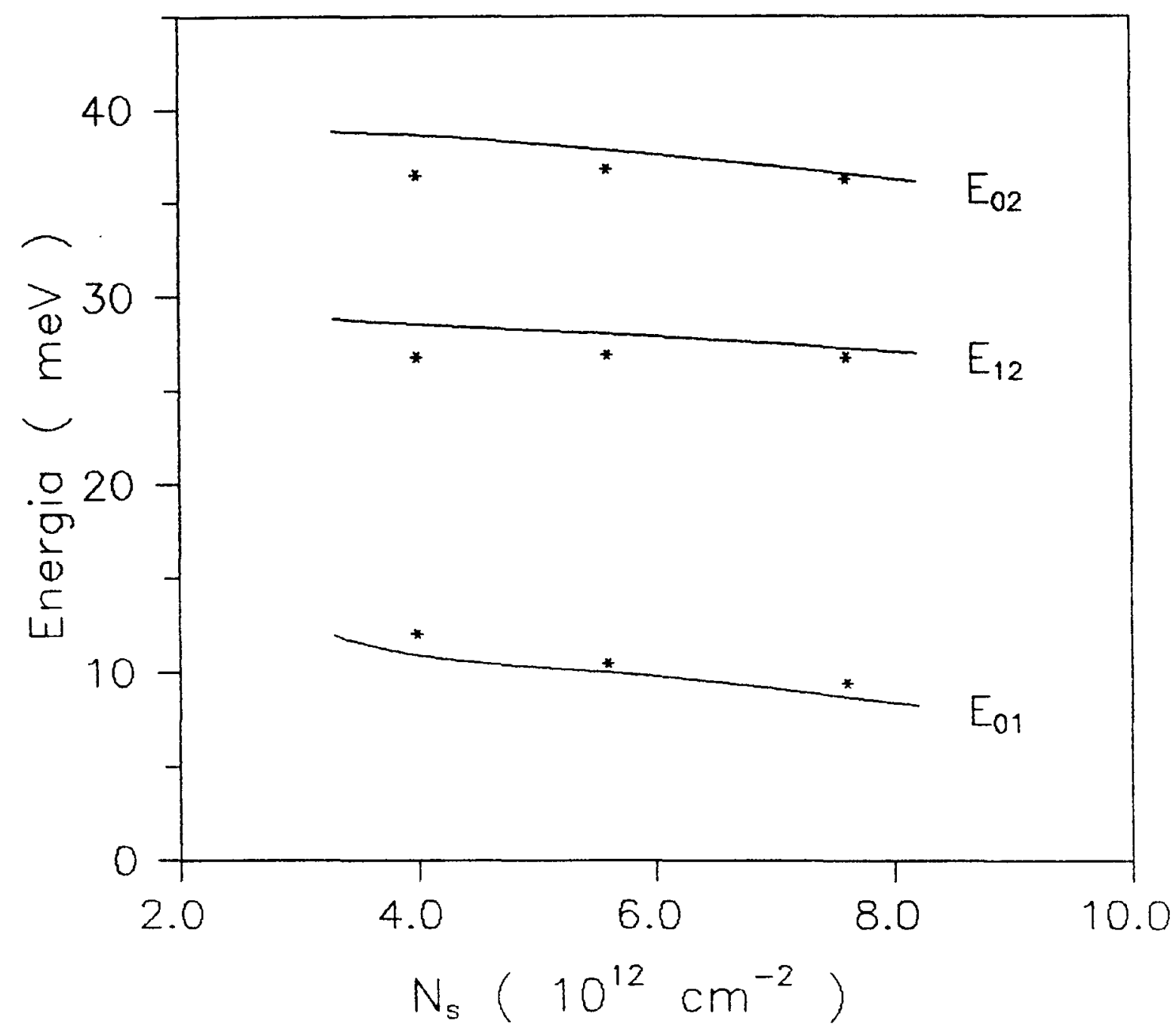

Fig. 6.12: Dependência das energias de transiçăo intersub-banda $E_{i j}$ com a concentração eletrơnica, para um poço com largura $L_{w}=245 \&$ e concentração $x=0.12$. 


\section{APENDICE A - POTENCIAL CONFINANTE E 0 POTENCIAL ELETROSTÁTICO}

O potencial apresentado na figura $1.1 \mathrm{~b}$ pode ser escrito como:

$$
V(z)=V_{p}(z)+U(z)
$$

onde $\mathrm{V}_{\mathrm{p}}(\mathrm{z})$ é o potencial devida a descontinuidade das bandas, $\mathrm{U}(\mathrm{z})$ é a potencial eletrostático criado pelos elétrons ou buracos confinados na região do poço e os dosdores ou aceitadores na regiâo da barreira.

$O$ potencial $V_{p}(a)$ representa a próprio sistema confinante poço-barreira. Para a banda de condução este pode ser escrito como,

$$
V_{c}(z)=E_{g}^{p} \theta\left(L_{w} / 2-|z|\right)+E_{g}^{b} \theta\left(L_{w} / 2-|z|\right)+\delta E_{y}(z)
$$

onde $E_{g}^{p}$ e $E_{g}^{b}$ são os 'gaps' dos materiais do poşo e da barreira, respectivamente, $\theta(z)=0$ se $z<0$ e $\theta(z)=1$ se $z>0$, e os comprimentos e larguras estão definidas ne fig. 1.1b. Definimor $\delta \mathrm{E}_{\nu}(\mathrm{z})$ pela relação,

$$
\delta E_{y}(z)=f\left(E_{g}^{b}-E_{g}^{p}\right) \theta\left(|z|-L_{w} / 2\right)
$$

onde $f$ é a fração da diferença dos 'gape' que dá origem ao potencial dos buracos, e seu valor deve ser obtido experimentalmente. Para a interface GaAlAs/GaAs o valor usado atualmente na literatura é de $40 \%$. Para a interface InAlAs/InGaAs, na composição onde oe parâmetros de rede são compatíveis, seu valor é igual a $15 \%$.

potencial $U(z)$ é obtido da solução da equação de Poisson (unidades C.G.S.):

$$
\frac{d^{2}}{d z^{2}} U(z)=-\frac{4 \pi g}{k} \rho(z),
$$


onde $\kappa$ é a constante dielétrica na região considerada, $q(>0)$ é a carga do elétron, e a densidade de carga $\rho(z)$ é dada por,

$$
\left.p(z)=q \sum_{o \text { cup }}|\mathbf{z}(z)|^{2}\right)-q L_{d} N_{d} \theta\left(|z|-L_{w s}\right) \cdot \theta\left(L_{w d}-|z|\right)
$$

onde $\mathrm{L}_{w s}=\mathrm{I}_{w} / 2+\mathrm{L}_{\mathrm{s}}$ e $\mathrm{L}_{w d}=\mathrm{L}_{w s}+\mathrm{L}_{d}$, e $\mathrm{N}_{d}$ é a concentração de dopantes $\left(1 / \mathrm{cm}^{-3}\right)$ na barreira. 0 primeiro termo da soma representa a dencidade de cargas devido aos elétrons ou buracos confinados, o segundo termo é devido a densidade de carga dos daadores ou aceitadores jonizadas.

A equaçăo acima, junto com a condição de neutralidade de carga:

$$
\int_{-\infty}^{\infty} p(z) d z=0,
$$

determina o patencial eletrostático $\mathrm{U}(\mathbf{z})$,

Assumiremos que, qualquer que seja a função de onda, podemos escrever:

$$
\boldsymbol{\Psi}\left(|\mathrm{z}|=\frac{\mathrm{L}_{\mathrm{w}}}{2}+\mathrm{L}_{\mathrm{b}}+\mathrm{L}_{\mathrm{d}}\right)=0 \text {. }
$$

Isto se justifica uma vez que a largura $\mathrm{L}_{\mathrm{s}}+\mathrm{L}_{\mathrm{d}}$ é maior que 100 \& na majoria das situaçбer de interesse. Como a funçäo de onda decai exponencialmente nesta regiäo, tal aproximaçố é justificada.

Passemos agora às condiçzes de contorno do potencial eletrostático. Do parágrafo anterior sabemos que a densidade de carga eletrönica, dada por $|\Psi(z)|^{2}$, deverá concentrar-se na região do pogo. Temos nesta regiano, portanto, um 'pleno' de cargas regativas. Nas regiges, onde os doadores estäo ionizados, tem-se uma densidade uniforme de cargas positivas. Pode-se imaginar que estas regizes são planos de carga positiva ou negativa. Temos, portanto, dojs planos de carga positiva, correspondendo a cada uma das regioes dopadas, envolvendo um plano de cargas negativas. 
Assumiremos que $U(\mathbf{x})=0$, para $|z| \geq \frac{I_{w}}{2}+L_{s}+L_{d}$, o que é permitido devida a neutralidade de cargas (eq. A.6). Tomando uma superficie Gaussiana em torno da regjǘo $-\mathrm{L}_{w d}<\mathrm{z}<\mathrm{L}_{w d}$, que envolve todas as cargas presentes, e considerando a carga interna à superfície, obtemos para o campo elétrico:

$$
E\left(z=I_{w d}\right)=0
$$

Desta equação tiramas a condição para a derivada em $z_{0}=L_{w d}$ :

$$
\left.\frac{d U}{d z}\right|_{z=z_{0}}=-q E=0
$$

Procedendo de maneira análoga para a para a região oposta, obtemos:

$$
\left.\frac{d U}{d z}\right|_{z=-z_{0}}=0
$$

Devido a diferença entre as constantes dielétricas do poço e da barreira, teremas que impar em qualquer dos casos a condição de continuidade:

$$
\left.\kappa_{\mathrm{p}} \frac{\mathrm{dU}}{\mathrm{dz}}\right|_{\mathrm{z}=\mathrm{z}_{\mathrm{w}}-\epsilon}=\left.\kappa_{\mathrm{b}} \frac{\mathrm{dU}}{\mathrm{dz}}\right|_{\mathrm{z}=\mathrm{z}_{\mathrm{w}}+\epsilon}
$$

onde $\kappa_{p}, \kappa_{\mathrm{b}}$ são as constantes dielétricas do poço a da barreira, respectivamente, e $z_{w}=\frac{L_{w}}{2}$ é a coordenada da interface poço-barreira. Uma condição análoga deve ser imposta na outra interface (em $z=-z_{w}$ ). 


\section{APENDICE B - MÉTODO DA ITERAÇÃO INVERSA}

método da iteração inverga permite a obtençăo de alguns autovalores e autovetors da equação secular,

$$
\mathrm{H} \cdot \mathrm{C}_{\mu}=\mathrm{e}_{\mu} \mathrm{C}_{\mu}
$$

onde $\mathrm{H}$ é uma matriz nxn (real ou complexa), $\mathrm{C}_{\mu}$ é um vetor de dirnersăro $\mathrm{n}$, e $\mu$ é o indice da solução. Para isto é necessário uma aproximação inicial do autovalor ${ }^{e}{ }_{\mu}$ e do autovetor.

Sejam t e A tais aproximaçöes. Sabe-se que a função inicial pode ser encrita como a combinação linear

$$
A=\sum a_{\nu} C_{\nu}
$$

Podemos, então, gerar uma sérje de vetores com o seguinte procedimento: calcula-se um vetor intermediário $\mathrm{B}_{0}$ como

$$
\mathrm{B}_{0}=(\mathrm{H}-\epsilon)^{-1} \mathrm{~A}
$$

Substituindo a eq. B.2 em B.3, eccevemos o segundo vetor da série como

$$
A_{1}=B_{0} / B_{0} \mid=\frac{1}{\left|B_{0}\right|} \sum \frac{a_{y}}{\left(e_{y}-e\right)} C_{y} .
$$

Repetindo este processo abtemos a série de vetores $\mathbf{A}, \mathbf{A}_{1}, \ldots, \mathbf{A}_{n}$, na qual o ultimo vetor calculado $A_{n}$ tenderá ao autovetor $C_{\mu}$ cujo autovalor $e_{\mu}$ for majo próximo da aproximaçăo inicial da energia e. Isto pode ser visto da expressấo para $A_{n}$ :

$$
A_{\mathrm{i}}=\frac{1}{i} \sum_{i}^{a_{j}} \mathrm{C}
$$


onde $b_{n}$ é a constante de normalização. É fácil ver que o major termo da série gerá aquele que tiver a menor diferença $\left(e_{\mu}-e\right)$.

A eq. B.3 pode ser resolvida por qualquer processo numérico de solução de sistemas de equaçóes lineares, já que pode ser escrita como um sistema de equaçóes não homogêneo:

$$
(\mathrm{H}-e) \cdot \mathrm{B}_{\mathrm{n}}=\mathbf{A}_{\mathrm{n}-1}
$$

onde $\mathrm{A}_{\mathrm{n}-1}$ é conhecido, e $\mathrm{B}_{\mathrm{n}}$ é o vetor solução.

Uma aproximação melhor do autovalor $e_{\mu}$ pode ser obtida do valor médio de H no estado $\mathbf{A}_{n}$,

$$
e_{\mu}=A_{n}^{\dagger} \cdot H \cdot A_{n}
$$




\section{Bibliografia}

Capitulo I

(1) G. Bastard, 'Wave Mechanics Applied to Semiconductore Heterostructures'.

(2) T. Arido, J. Phys. Soc. Jpn., 54, (1985), 1528.

(3) U. Ekemberg, Superllat. and Microstruct., 5, (1985), 351.

(4) A. O. Goscard and E. Pinczuk, 'Synthetic Modulated Structures'

L. L. Chang and B. C. Giessen, Ed. New York, Academic Press, 1985.

Gapitulo II

(1) - N. W. Ashcroft and N. D. Mermim, Solid State Physics (Holt, Rinehart and Winston, New-York) 1976.

(2) - C. Kittel, Quantum Theory of Solids (Wiley, New York) 1963.

(3) - J. M. Zimman, Principles of the Theory of Solids (Cambridge University Press).

(4) - Bouckert, Smoluchokky and Wigner, Phys. Rev. 50, 58 (1936).

(5) - J. P. Elliot, P. G. Dawber, Symetry in Physics (Oxford Univereity Prese, New-York) 1986.

(6) - G. Dresselhauss, Phys. Rev. 100, 580 (1955).

(7) - I. I. Schiff, Quantum Mechanics (Mc Graw-Hill, New-York) 1955.

Capitulo III

(1) E. O. Kane, Willardson, R. K. and Beer, A. O. Editors, Academic Press, NY (1966), Vol. 1, p. 75.

(2) G. Dresselhaus, A. F. Kip and O. Kittel, Phys. Rev., 98(2), 368 (1955).

(3) P. O. Lowdin, J. Chem. Phys., 19 (11), 1396 (1951),

(4) E. Feenbere, Phyø. Rev, 74 (2), 206, (1948).

(5) A. M. Gohen, Tere de Doutorado, IFQSC, USF, Dep. Fisica e Ciencia dos Materiais, 1990. 
(6) F. J. Ohkawa and Y. Uemura, J. Phys. Soc. Japan, 37, 1325 (1974).

(7) M. Altarelli, U. Ekenberg and A. Fasolino, Phys. Rev. B, 32, 5138 (1985).

(8) D. A. Broido and I. J. Sham, Phys. Rev. B, 32, 439 (1985).

(9) R. Eppenga, M. F. H. Schuurmans and S. Colack, Phys. Rev. B, 36, 1554 (1987).

(10) M. Cardona, N. E. Christensen and G. Fasol, Phys. Rev. B, 38, 1806 (1988).

(11) Ref. 6, Cap. II.

(12) M. Cardona, N. E. Christensen and G. Fasol, Phys. Rev. Lett., 56, 2831 (1986).

(13) A. M. Gohen and G. E. Marques, Phys. Rev. B, 41, in press.

(14) S. F. White, G. E. Marques, L. J. Sham, J. Vac. Sci. Technol. 21(2), 544, (1982).

(15) H. C. Cacey, Jr. and M. B. Panish, Heterostructures Lasers, edited by Y. H. Pao and P. Kelly (Academic Press, New York, 1978 ).

(16) P. Lawetz, Phys. Rev. B, 4, 3460 (1971).

(17) R. L. Aggarwal, Semiconductors and Semimetals, Vol. 9, ed. by R. K. Williardson and A. O. Beer (Academic Press, N. Y. 1972), pg 151.

Gapitulo IV

(1) G. Wannier, Phys. Rev, 52, 191 (1937).

(2) J. C. Slater, Phys. Rev., 76, 1592 (1949).

(3) E. N. Adams II, Phye. Rev, 85, 41 (1952),

(4) J. M. Luttinger and W. Kohn, Phys. Fev., 97, 869 (1955).

(5) D. J. BenDaniel and đ. B. Duke, Phys. Rev., 152, 683 (1966).

(6) G. Bastard, Phys. Rev. B, 24, 5693 (1981).

(7) J. M. Luttinger, Phys. Rev., 102, 1030 (1956).

(8) Ref. 2 Cap. III.

(9) N. Poeta and D. K. Ferry, Superlattices and Microst, 3, 57 (1987).

(10) O. Von Roos, Phys. Rev. B, 27, 7547 (1983). 
(11) S. R. Aladim, G. E. Marques and S. S. Mirhahi, IV Brasilian School of Semiconductor Physics, Belo Horizonte, MG, 1989.

(12) H. Weyl, Group Theory Applied to Quantum Mechanics.

Capitulo $\mathrm{V}$

(1) J. H. Wilkinson, The Algebric Eigenvalve Problem, (Oxford, Oxford, 1965).

(2) IMSL, Biblioteca Fortran do VAX 11/780, IFQSC-USP.

Capitulo VI

(1) Ref. 1, Cap. I.

(2) H. L. Stormer, A. C. Gossard, W. Wiegmam and K. Baldiwn, Appl. Phys. Lett., 39, 912, (1981).

(3) D. V. Lang, R. A. Logan, M. Jares, Phys. Rev. B. 19, 1015 (1979).

(4) N. Chand, T. Henderson, J. Klem, W. Ted Masselink, R. Fisher,

Y. C. Chang, H. Morkoc, Phys. Rev. B, 30, 4481 (1984).

(5) Gunter Harbeke, Physica Scripta T29, 135, (1989).

(6) A. Pinczuk, J. M. Worlock, Surf, Sci., 113, 69 (1982).

(7) G. Fishman, Phys. Rev. B, 27, 7611 (1983). 